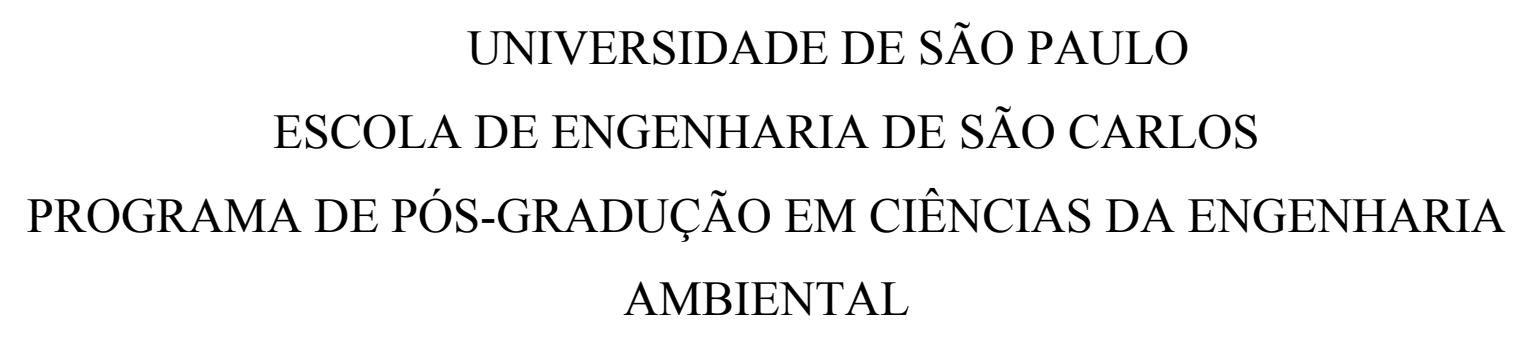

EFIGÊNIA ROSSI

DESENVOLVIMENTO E APLICAÇÃO DE INDICADORES E ÍNDICE DE PRODUTOS E DE MODELOS DE NEGÓCIO PARA A ECONOMIA CIRCULAR

São Carlos

2020 

EFIGÊNIA ROSSI

\section{DESENVOLVIMENTO E APLICAÇÃO DE INDICADORES E ÍNDICE DE PRODUTOS E DE MODELOS DE NEGÓCIO PARA A ECONOMIA CIRCULAR}

\section{Versão corrigida}

Tese apresentada à Escola de Engenharia de São Carlos da Universidade de São Paulo, como requisito para a obtenção do Título de Doutora em Ciências da Engenharia Ambiental.

Orientador: Prof. Dr. Aldo Roberto Ometto

São Carlos

2020 


\section{AUTORIZO A REPRODUÇÃO TOTAL OU PARCIAL DESTE TRABALHO, POR QUALQUER MEIO CONVENCIONAL OU ELETRÔNICO, PARA FINS DE ESTUDO E PESQUISA, DESDE QUE CITADA A FONTE.}

Ficha catalográfica elaborada pela Biblioteca Prof. Dr. Sérgio Rodrigues Fontes da EESC/USP com os dados inseridos pelo(a) autor(a).

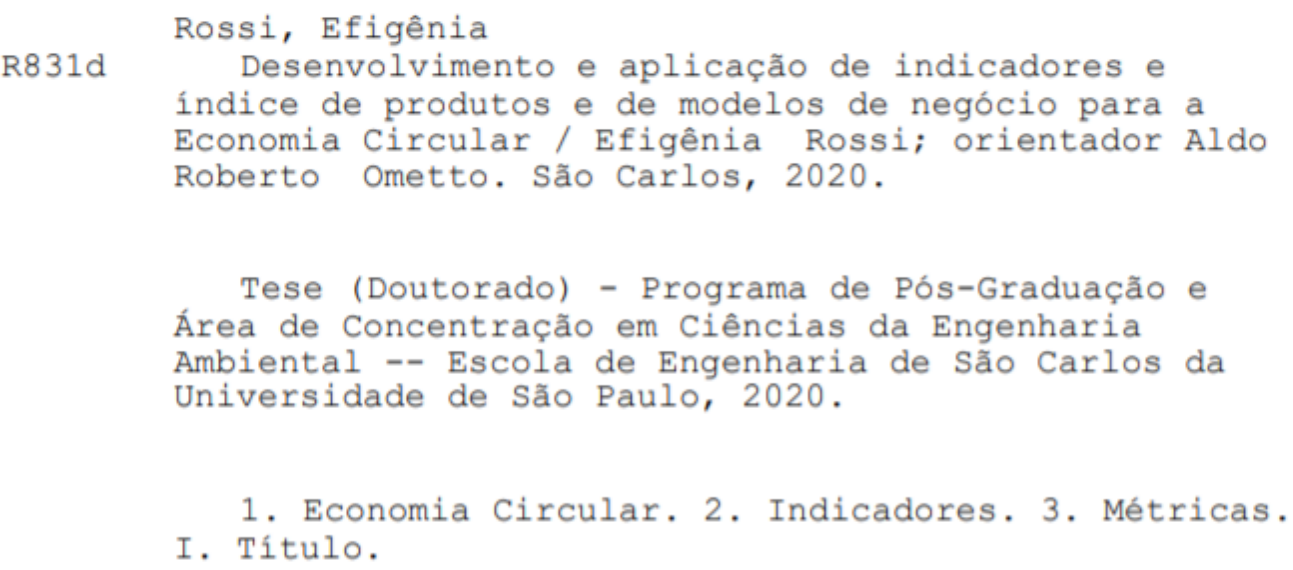

Eduardo Graziosi Silva - CRB - 8/8907 


Ao meu marido Bruno, Pelo amor, paciência e carinho. 



\section{AGRADECIMENTOS}

A Deus, por me dar o dom da vida e permitir toda minha história. Aos meus pais, por me apoiarem e acompanharem meus dias de luta, vitórias e fracassos. À Isadora, minha irmã e melhor amiga, por ser a companheira fiel de meus passos. Ao meu marido Bruno, pela paciência, carinho e amor. À minha comunidade, por ser apoio, compreensão e caridade. Aos meus padrinhos e à toda a minha família. A todos os meus amigos por me ajudarem acadêmica e pessoalmente. Ao meu orientador Prof. Dr. Aldo Roberto Ometto, pelo apoio, oportunidades e todo crescimento profissional com esse trabalho. Aos colegas de laboratório, em especial, Giovana D., Camilinha, Ana Carol, Ana Laura, Lucas Calache, Giovana M.,

Danika, Murilo, Camila Z. e Lucas Zanon, pela amizade, cafés, apoio e risadas. Ao CNPq/CAPES e empresa parceira/FUSP pela concessão da bolsa de doutorado. À Universidade de São Paulo, ao Programa de Pós-Graduação em Ciências da Engenharia Ambiental (PPGSEA) e ao Programa de Pós-Graduação em Engenharia de Produção (PPGEP). À Secretaria do PPGSEA, à Secretaria do PPGEP e todos os funcionários do Departamento de Engenharia de Produção da EESC pelo suporte acadêmico. Aos professores do PPGSEA e PPGEP pelos ensinamentos passados ao longo desses anos, que me acompanharão por toda a vida. Às empresas estudadas, por incentivarem a pesquisa, permitindo a realização de visitas técnicas e a disponibilização dos dados necessários. A todos sem os quais seria impossível a realização dessa tese. 

"Por esse tempo, pôs-se Jesus a dizer: Eu te louvo, ó Pai, Senhor do céu e da terra, porque ocultaste estas coisas dos sábios e doutores e as revelaste aos pequeninos.

Sim, Pai, porque assim foi do teu agrado".

(Mateus 11, 25-26) 


\section{RESUMO}

ROSSI, E. Desenvolvimento e aplicação de indicadores e índice de produtos e de modelos de negócio para a Economia Circular. 2020. 157 p. Tese (Doutorado em Ciências da Engenharia Ambiental) - Escola de Engenharia de São Carlos, Universidade de São Paulo, São Carlos, 2020.

A problemática linear do modelo econômico baseado no extrair-produzir-descartar mostra-se ineficaz tendo em vista que os recursos naturais são limitados. Essa visão linear reflete em impactos ambientais sucessivos, tanto pela utilização excessiva dos recursos naturais, como pela geração de resíduos e emissões. Há uma crescente necessidade da superação desse modelo pelo modelo circular. Nele há a presença de processos regenerativos e restaurativos, visando conservar o valor e a utilidade dos produtos e serviços em todo tempo, além de promover o fechamento de ciclos, minimizando resíduos e externalidades e promovendo a efetividade do sistema. A lacuna da presente pesquisa pauta-se na necessidade de criação de métricas que capturem a Economia Circular em sua totalidade, incluindo seus princípios e estratégias, buscando quantificar a transição para um modo operacional mais circular e sustentável. O objetivo central é, portanto, desenvolver e aplicar um conjunto multidimensional de indicadores e índice no contexto da Economia Circular. A presente pesquisa adotou a abordagem Design Research Methodology (DRM), que incorpora procedimentos iterativos teoria e prática, como a revisão de literatura respaldada por estudos de caso. Após o desenvolvimento de três versões do índice, aplicados em seis estudos de caso, foi possível a obtenção de uma versão final. Eles permitiram identificar pontos de melhoria nas empresas, tanto em relação aos seus produtos como seus modelos de negócio. A principal contribuição foi a criação de métricas para a Economia Circular para empresas de diferentes modelos de negócio, evidenciando sua relação com a sustentabilidade. Trabalhos futuros poderão aplicar em outras empresas e ampliar o escopo do pilar social.

Palavras-chave: Economia Circular, indicadores, métricas. 


\begin{abstract}
ROSSI, E. Development and application of indicators and index of products and business models for the Circular Economy. 2020. 157 p. Tese (Doutorado em Ciências da Engenharia Ambiental) - Escola de Engenharia de São Carlos, Universidade de São Paulo, São Carlos, 2020.
\end{abstract}

The linear problem of the economic model based on extracting-producing-discarding is ineffective in view of the fact that natural resources are limited. This linear view reflects successive environmental impacts, both due to the excessive use of natural resources, as well as the generation of waste and emissions. There is a need to overcome this model by Circular Economy. It has the presence of regenerative and restorative processes, aiming to conserve the value and usefulness of products and services at all times, in addition to promoting the closing of cycles, minimizing waste and externalities and promoting the effectiveness of the system. The gap in this research is based on the need to create metrics that capture the Circular Economy in its entirety, including its principles and strategies, seeking to quantify the transition to a more circular and sustainable operating mode. The central objective is, therefore, to develop and apply a multidimensional set of indicators and index in the context of Circular Economy. This research adopted the Design Research Methodology (DRM) approach, which incorporates iterative procedures theory and practice, such as the literature review supported by case studies. After the development of three versions of the index, applied in six case studies, it was possible to obtain a final version. They made it possible to identify points of improvement in companies, both in relation to their products and their business models. The main contribution was the creation of metrics for the Circular Economy for companies of different business models, highlighting its relationship with sustainability. Future works may be applied in other companies and expand the scope of the social pillar.

Keywords: Circular Economy, indicators, metrics. 


\section{LISTA DE FIGURAS}

Figura 1 - Abordagem DRM $\quad 30$

Figura 2 - Terminologia utilizada no trabalho

Figura 3-Procedimentos técnicos e DRM

Figura 4 - Publicações nas bases de dados ao longo dos anos

Figura 5 - Co-ocorrência das palavras-chave na base Web of Science $\quad 34$

Figura 6-Co-ocorrência das palavras-chave na base Scopus

Figura 7 - Etapas do Estudo de Caso

Figura 8-Ecoefetividade e Ecoeficiência

Figura 9-Business model Canvas

Figura 10 - Framework do sistema de negócio circular $\quad 50$

Figura 11 - Sistema de medição de desempenho

Figura 12 - Relação dos indicadores micro com os componentes do modelo de negócio 71

Figura 13 - Relação dos indicadores meso com os componentes do modelo de negócio $\quad 81$

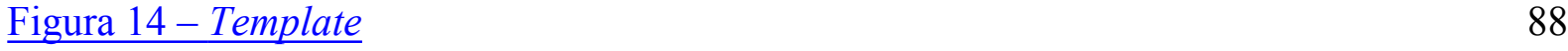

Figura 15 - Gráfico de radar mostrando a pontuação da empresa A quanto à circularidade do produto

Figura 16 - Longevity e Circularity

Figura 17 - Gráfico de radar mostrando a pontuação da empresa B quanto à circularidade do produto

Figura 18 - Indicadores e suas correspondências aos componentes do modelo de negócio CANVAS

Figura 19-Índice do produto circular $\quad 103$

Figura 20 - Índice para modelos de negócio circular $\quad 106$

$\begin{array}{ll}\text { Figura } 21 \text { - Resultado para o vergalhão } & 118\end{array}$

Figura 22 - Pontuação do índice de produto circular $\quad 118$

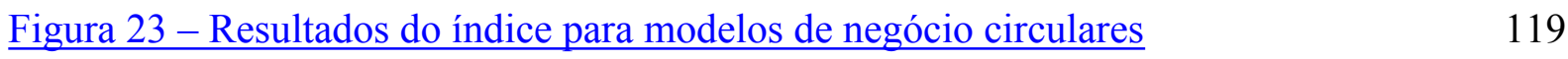




\section{LISTA DE QUADROS}

Quadro 1 - Indicadores de Economia Circular do nível micro

Quadro 2 - Análise dos indicadores de Economia Circular no nível micro

Quadro 3 - Indicadores de Economia Circular do nível meso

Quadro 4 - Análise dos indicadores de Economia Circular no nível meso. $\quad 78$

Quadro 5 - Proposta para elementos chave a serem medidos $\quad 84$

Quadro 6 - Definição das métricas $\quad 100$

Quadro 7-Questionário do índice de produto para Economia Circular $\quad 104$

Quadro 8-Questionário para índice de modelos de negócio circulares $\quad 107$

Quadro 9-Resultado da aplicação dos indicadores

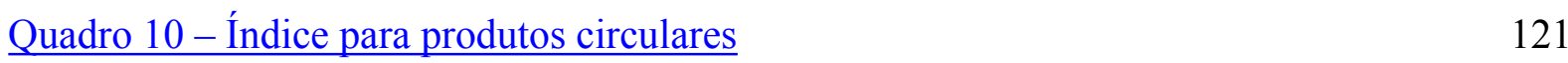

Quadro 11 - Índice para modelos de negócio circulares $\quad 125$ 


\section{LISTA DE SIGLAS}

\begin{tabular}{|c|c|}
\hline ABNT & Associação Brasileira de Normas Técnicas \\
\hline ACT & Assessing Circular Trade-offs \\
\hline $\mathrm{ACV}$ & Avaliação do Ciclo de Vida \\
\hline AFM & Análise de Fluxo de Materiais \\
\hline $\mathrm{AICV}$ & Avaliação do Impacto do Ciclo de Vida \\
\hline ARMC & $\begin{array}{l}\text { Assessing resource productivity for industrial parks using raw material } \\
\text { consumption }\end{array}$ \\
\hline BCI & Building Circularity Indicators \\
\hline BSI & British Standards Institution \\
\hline BWPE & BIM-based Whole-life Performance Estimator \\
\hline $\mathrm{C} 2 \mathrm{C}$ & Cradle to Cradle $\AA$ \\
\hline CA & Circle Assessment \\
\hline CAT & Circularity Assessment Tool \\
\hline CBT & Circular Benefits Tool \\
\hline $\mathrm{CC}$ & Circularity Calculator \\
\hline CECAC & Circular Economy Company Assessment Criteria \\
\hline CEI & Circular Economy Index \\
\hline CEIP & Circular Economy Indicator Prototype \\
\hline CEMS & Circular Economy Measurement Scale \\
\hline CEPI & Circular Economy Performance Indicator \\
\hline CET & Circular Economy Toolkit \\
\hline CETUS & Circular Economy Toolbox US \\
\hline $\mathrm{CEV}$ & Circular Economic Value \\
\hline CI & Circularity Index \\
\hline CIRC & Circularity material indicator \\
\hline CLC & Closed Loop Calculator \\
\hline $\mathrm{CNI}$ & Confederação Nacional da Indústria \\
\hline $\mathrm{CP}$ & Circular Pathfinder \\
\hline CPI & Circularity Potential Indicator \\
\hline CTI & Circular Transition Indicators \\
\hline DRM & Design Research Methodology \\
\hline EAIP & Emergy analysis of an industrial park \\
\hline $\mathrm{EC}$ & Economia Circular \\
\hline EDIM & Ease of Disassembly Metric \\
\hline EEI & Economic-Environmental Indicators \\
\hline EER & Economic-environmental remanufacturing \\
\hline EISCE & Evaluation Indicator System of Circular Economy \\
\hline EOL-RRs & End-of-Life Recycling Rates \\
\hline EVR & Eco-efficient Value Ratio \\
\hline FCIM & Five Category Index Method \\
\hline HLCAM & Hybrid LCA Model \\
\hline ICT & Circularity Indicator Project \\
\hline $\mathrm{ICV}$ & Análise de Inventário do Ciclo de Vida \\
\hline IOBS & Input-Output Balance Sheet \\
\hline IPCEIS & Industrial Park Circular Economy Indicator System \\
\hline ISSEP & Indicator standards for sector-integrated eco-industrial parks \\
\hline ISO & International Organization for Standardization \\
\hline $\mathrm{L} \& \mathrm{C}$ & Longevity and Circularity \\
\hline
\end{tabular}




$\begin{array}{ll}\text { MCI } & \text { Material Circularity Indicator } \\ \text { MI } & \text { Mine site MFA Indicator } \\ \text { MIS } & \text { Multidimensional Indicator Set } \\ \text { PCM } & \text { Product-Level Circularity Metric } \\ \text { PET } & \text { Poli Tereftalato de Etila } \\ \text { PSS } & \text { Product Service System } \\ \text { RDI } & \text { Resource Duration Indicator } \\ \text { RIS } & \text { Recycling Indices } \\ \text { ROA } & \text { Retorno sobre Ativos } \\ \text { ROI } & \text { Retorno Sobre Investimento } \\ \text { RP } & \text { Resource Productivity } \\ \text { RPI } & \text { Reuse Potential Indicator } \\ \text { RRS } & \text { Recycling Rates } \\ \text { SAC } & \text { Serviço de Atendimento ao Consumidor } \\ \text { SCI } & \text { Sustainable Circular Index } \\ \text { SI } & \text { Sustainability Indicators } \\ \text { SIAS } & \text { Set of Indicators to Assess Sustainability } \\ \text { SMD } & \text { Sistema de medição de desempenho } \\ \text { VRE } & \text { Value-based Resource Efficiency }\end{array}$


1 INTRODUÇÃO

$\underline{1.1}$ Contextualização da pesquisa 23

$\underline{1.2}$ Justificativa da pesquisa 25

$\underline{2}$ OBJETIVOS

$\underline{2.1}$ Objetivo geral 27

$\underline{2.2}$ Objetivos específicos $\quad 27$

$\underline{3}$ MÉTODO DE PESQUISA

$\underline{3.1}$ Abordagem metodológica 29

3.2 Procedimentos técnicos 31

3.2.1 Clarificação da Pesquisa 32

$\underline{3.2 .2}$ Estudo descritivo 1 35

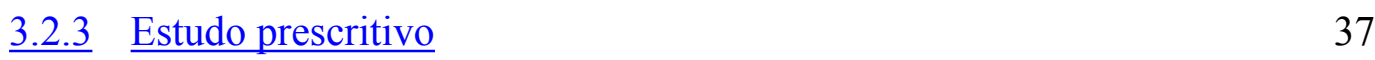

3.2.4 Estudo descritivo 2 38

4 FUNDAMENTAČ̃̃O TEÓRICA

$\underline{4.1}$ Economia Circular $\quad 39$

4.1.1 Da ecoeficiência para a ecoefetividade $\quad 44$

4.1.2 Modelos de negócio circulares $\quad 46$

$\underline{4.2}$ Indicadores para Economia Circular $\quad 50$

$\underline{4.2 .1}$ Indicadores no nível micro $\quad 55$

4.2.2 Indicadores no nível meso $\quad 71$

$\underline{5} \quad \underline{\text { RESULTADOS E DISCUSSÃO }} 83$

5.1 Primeira versão do índice para Economia Circular 83

5.2 Estudos de caso exploratórios

$\underline{5.2 .1}$ Empresa A $\quad 88$

$\underline{5.2 .2}$ Empresa B 93

$\underline{5.3}$ Segunda versão para indicadores de Economia Circular 96

$\underline{5.4}$ Terceira versão de índices para Economia Circular 103

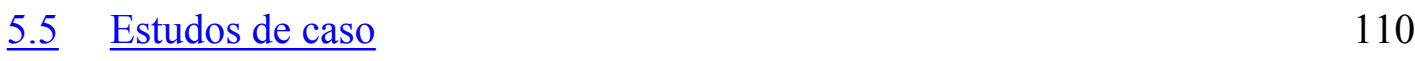

$\underline{\text { 5.5.1 Empresas C, D e E }} \quad 110$

$\begin{array}{ll}\text { 5.5.2 } & 117\end{array}$

$\underline{5.6}$ Proposta final dos índices para Economia Circular $\quad 120$

$\underline{6}$ CONCLUSÕES 129

$\begin{array}{ll}\text { REFERENCIAS } & 131\end{array}$ 
APÊNDICE A

APÊNDICE B 



\section{INTRODUÇÃO}

\subsection{Contextualização da pesquisa}

A problemática linear do modelo econômico baseado no extrair-produzir-descartar mostra-se ineficaz tendo em vista que os recursos naturais são limitados. Essa visão linear reflete em impactos ambientais sucessivos, tanto pela utilização excessiva dos recursos naturais, como pela geração de resíduos e emissões. Há uma crescente necessidade da superação desse modelo pelo modelo econômico circular. Nele há a presença de processos regenerativos e restaurativos, visando conservar o valor e a utilidade dos produtos e serviços em todo tempo, além de promover o fechamento de ciclos, minimizando resíduos e externalidades e promovendo a efetividade do sistema.

Nas últimas quatro décadas, o uso global de materiais triplicou, passando de 26,7 bilhões de toneladas em 1970 a 92,1 bilhões de toneladas em 2017 (IRP, 2019) e para 2050 é previsto cerca de 170 a 184 bilhões de toneladas (HATFIELD-DODDS et al., 2017). A Economia Circular (EC) busca reduzir a pressão pelos recursos naturais e a geração de resíduos por meio do fechamento de ciclos, tanto em termos econômicos como em ambientais (HAAS et al., 2015). Entretanto, em termos globais, nota-se que a economia tem baixos valores de circularidade, em 2005 esse indicador atingiu 6\% (HAAS et al., 2015), em 2019 atingiu 9\% (CIRCLE ECONOMY, 2019), e em 2020 diminuiu para 8,6\% (CIRCLE ECONOMY, 2019).

Sendo assim, mostra-se essencial que a EC traga além de novas estratégias, inovações em modelos de negócio (KIRCHHERR; REIKE; HEKKERT, 2017), com o intuito de repensar o modelo de produção atual. Evidencia-se também a necessidade de mudança de mentalidade, ou mindset, para proporcionar mudanças sistêmicas, transitando da cadeia de suprimento para as redes de valor circulares (CONFEDERAÇÃO NACIONAL DA INDÚSTRIA, 2018). Além disso, proporcionar a ecoefetividade, ou seja, maximizar os benefícios para os sistemas ecológicos e econômicos, ou seja, a geração de impactos positivos (NIERO et al., 2017).

A Economia Circular pode ser aplicada em três níveis: micro, meso e macro (YUAN; BI; MORIGUICHI, 2006). No nível micro (produtos, componentes e empresas), as empresas focam em estratégias e ações voltadas para o ecodesign e a produção mais limpa, buscando tornar público o monitoramento de sua operação. No nível meso (entre empresas) há a busca de encorajar o desenvolvimento de eco parques industriais e redes que beneficiem a economia regional e o meio ambiente. E no nível macro (cidades, regiões e países) há a busca da 
sustentabilidade em produção e atividades de consumo que busquem a criação de uma sociedade orientada ao fechamento de ciclos (GENG et al., 2012). Vale acrescentar que alguns autores necessitam especificar essa terminologia de micro, meso e macro em: produto/serviço, empresa, entre empresas, cidade, região, país e mundo (MORAGA et al., 2019).

Enquanto na Economia Linear busca-se atingir a Ecoeficiência, ou seja, o aumento de valor com a diminuição do uso de recursos e impactos ambientais, a Economia Circular busca a Ecoefetividade, ou seja, maximizar os benefícios para os sistemas ecológicos e econômicos, ou seja, a geração de impactos positivos (NIERO et al., 2017). Essa efetividade mostra a ideia de regeneração ao invés de depleção de recursos, objetivando que os nutrientes técnicos entrem nos ciclos biológicos sem os alterarem (BARBIROLI, 2006).

Um modelo de negócio circular pode ser classificado como aquele com uma companhia focal, que juntamente com parceiros, usa a inovação para criar, capturar e entregar valor para melhorar a eficiência de recursos, por meio da extensão da durabilidade de produtos e partes, além de obter benefícios ambientais, sociais e econômicos (FRISHAMMAR; PARIDA, 2019).

Dada a necessidade de uma padronização normativa empresarial para a Economia Circular, a British Standards Institution lançou a norma BSI 8001:2007 "Framework for implementing the principles of the circular economy in organizations", para auxiliar nos princípios, estratégias, implementação e monitoramento da Economia Circular em empresas (BSI, 2017; PAULIUK, 2018). Entretanto ainda persiste a necessidade de normas específicas e métricas para Economia Circular (TECCHIO et al., 2017).

Vale salientar a diferença entre indicadores e índices. Um indicador é um "parâmetro ou um valor derivado de parâmetros que providencia informação ou descreve o estado de um fenômeno, podendo ser quantitativo ou qualitativo e derivado de um modelo ou ferramenta" (SALA; FARIOLI; ZAMAGNI, 2013, p.1662). Um índice é uma medida sintética que relaciona um conjunto de indicadores (HAWKEN; MUNCK, 2013)

Linder, Sarasini e van Loon (2017) definem circularidade, à nível micro, como a "fração do produto proveniente de produtos usados, ou seja, provenientes de ciclos abertos ou fechados" (p.547). Sendo assim, muitos autores enfatizam a necessidade de criação de métricas de circularidade no nível micro (ELIA; GNONI; TORNESE, 2017; LONCA et al., 2018; NIERO; KALBAR, 2019). Além da criação de indicadores propriamente ditos que dissociem o desenvolvimento econômico dos impactos ambientais (GENG et al., 2013). 
Indicadores de circularidade estão em um estágio inicial de desenvolvimento (GIURCO et al., 2014). Indicadores tradicionais não expressam a Economia Circular em sua totalidade, pois não foram desenhados originalmente para serem sistêmicos, trabalharem com ciclos fechados e terem mecanismos de retroalimentação ou feedback (GENG et al., 2013). Além disso, a complexidade da EC implica a necessidade de um conjunto de indicadores multidimensionais em vez de um único (DI MAIO; REM, 2015; GRIFFITHS; CAYZER, 2016; MORAGA et al., 2019).

Alguns autores trazem propostas para avaliar (LINDER; SARASINI; VAN LOON, 2017; MORAGA et al., 2019; SAIDANI et al., 2019) e aplicar (PAULIUK, 2018) os indicadores. Porém o debate sobre a identificação das métricas mais adequadas para a EC é aberto, ainda não há consenso sobre o que os indicadores do nível micro devem medir (NIERO; KALBAR, 2019). Desde 2019 a ISO se organiza mundialmente para lançar em 2021 uma norma de Economia Circular e indicadores para empresas.

\subsection{Justificativa da pesquisa}

Há a necessidade da criação de um índice de desempenho circular e de uma ferramenta de avaliação na Economia Circular (MENTIK, 2014). Esse índice deve ser simples de ser usado, baseado em uma sinergia de conhecimentos práticos e científicos, transparentes em termos de ponderações e limitações, e os dados utilizados devem estar abertos para verificação (FOLAN; BROWNE, 2005). O índice deve ser criado de tal forma que seja utilizado pela maioria das empresas (KOK; WURPEL; TEN WOLDE, 2013).

Dessa maneira, a lacuna de pesquisa permeia:

- a inexistência de uma abordagem universalmente aceita para medir a efetividade da transição para um modo operacional mais circular e sustentável (BSI, 2017; MORAGA et al., 2019; PARCHOMENKO et al., 2019);

- a falta de guias para o monitoramento da implementação de estratégias da Economia Circular (PAULIUK, 2018);

- a crescente necessidade de pesquisa em indicadores de circularidade no nível micro (ALAMEREW et al., 2020; ELIA; GNONI; TORNESE, 2017; KRISTENSEN; MOSGAARD, 2020);

- a necessidade de uma proposta de indicadores para diferentes modelos de negócio (PIERONI; MCALOONE; PIGOSSO, 2019) que abranjam as dimensões da sustentabilidade (GENG et al., 2012; MESA; ESPARRAGOZA; MAURY, 2018); 
- a falta de uma métrica que capture amplamente a circularidade de uma empresa (BSI, 2017; SASSANELLI et al., 2019);

- a necessidade do desenvolvimento de indicadores para Economia Circular (KAYAL et al., 2019; PIERONI; MCALOONE; PIGOSSO, 2019; VIRTANEN et al., 2019),

- e a necessidade de indicadores que avaliem sua efetividade (MAYER et al., 2019). 


\section{OBJETIVOS}

\subsection{Objetivo geral}

O objetivo geral é desenvolver e aplicar um conjunto multidimensional de indicadores ${ }^{1}$ e propor um índice ${ }^{2}$ para mensurar a Economia Circular em empresas.

\subsection{Objetivos específicos}

- Identificar os principais indicadores da literatura considerando os níveis micro e meso.

- Propor e aplicar um conjunto multidimensional de indicadores para Economia Circular, nos pilares ambiental (dimensão material), econômico e social.

- Desenvolver e aplicar índices para produtos e modelos de negócio circulares.

${ }^{1}$ Indicador: "parâmetro ou um valor derivado de parâmetros que providencia informação ou descreve o estado de um fenômeno, podendo ser quantitativo ou qualitativo e derivado de um modelo ou ferramenta" (SALA; FARIOLI; ZAMAGNI, 2013, p.1662).

2 Índice: medida sintética que relaciona um conjunto de indicadores (HAWKEN; MUNCK, 2013). 


\section{MÉTODO DE PESQUISA}

O fator chave do desenvolvimento da pesquisa é a contribuição científica, portanto seguir algumas etapas para a construção da contribuição facilita o processo de criação de conhecimento. A sequência problema-método-contribuição é uma busca iterativa (KARLSSON, 2009).

O método de pesquisa aplicado neste trabalho pode ser classificado nos seguintes termos (GIL, 1999):

- Natureza: quanto à natureza, a pesquisa pode ser classificada em pura ou aplicada. A presente pesquisa é aplicada pois visa gerar conhecimentos para a aplicação prática, ou seja, busca preencher as lacunas encontradas na literatura aliadas às necessidades reais das organizações, objetos de estudo.

- Abordagem do problema: pode ser qualitativa ou quantitativa. Esse trabalho tem a abordagem qualitativa, pois busca analisar as proposições teóricas dos indicadores em Economia Circular, identificar as lacunas e propor o preenchimento das mesmas, a partir de pesquisa empírica.

- Objetivos: podem ser classificados em pesquisas exploratórias, descritivas ou explicativas. As pesquisas exploratórias têm a finalidade de desenvolver, esclarecer e modificar conceitos e ideias, buscando a formulação de problemas ou hipóteses para estudos posteriores. As pesquisas descritivas têm por objetivo a descrição das características de determinado fenômeno ou o estabelecimento de relações entre variáveis. E as pesquisas explicativas são focadas na identificação de fatores que determinam ou contribuem para a ocorrência de fenômenos. Como a Economia Circular é um tema contemporâneo e aplicado, a presente pesquisa pode ser classificada como exploratória, por identificar as principais lacunas encontradas, e como descritiva, por analisar e aplicar a conceituação teórica em estudos de caso.

\subsection{Abordagem metodológica}

A presente pesquisa adotou a abordagem Design Research Methodology (DRM) proposta por Blessing e Chakrabarti (2009) por proporcionar um conjunto iterativo de testes de teoria e prática aliados a um planejamento sistemático da pesquisa. Dessa maneira, o desenvolvimento dos indicadores foi baseado em um sistema dedutivo-hipotético, em que a teoria aplicada aos estudos de caso, proporcionava elementos para a criação de novos indicadores. 
O DRM possui quatro fases, descritas na Figura 1: Clarificação da Pesquisa, Estudo descritivo 1, Estudo prescritivo e Estudo descritivo 2 (BLESSING; CHAKRABARTI, 2009).

Figura 1 - Abordagem DRM

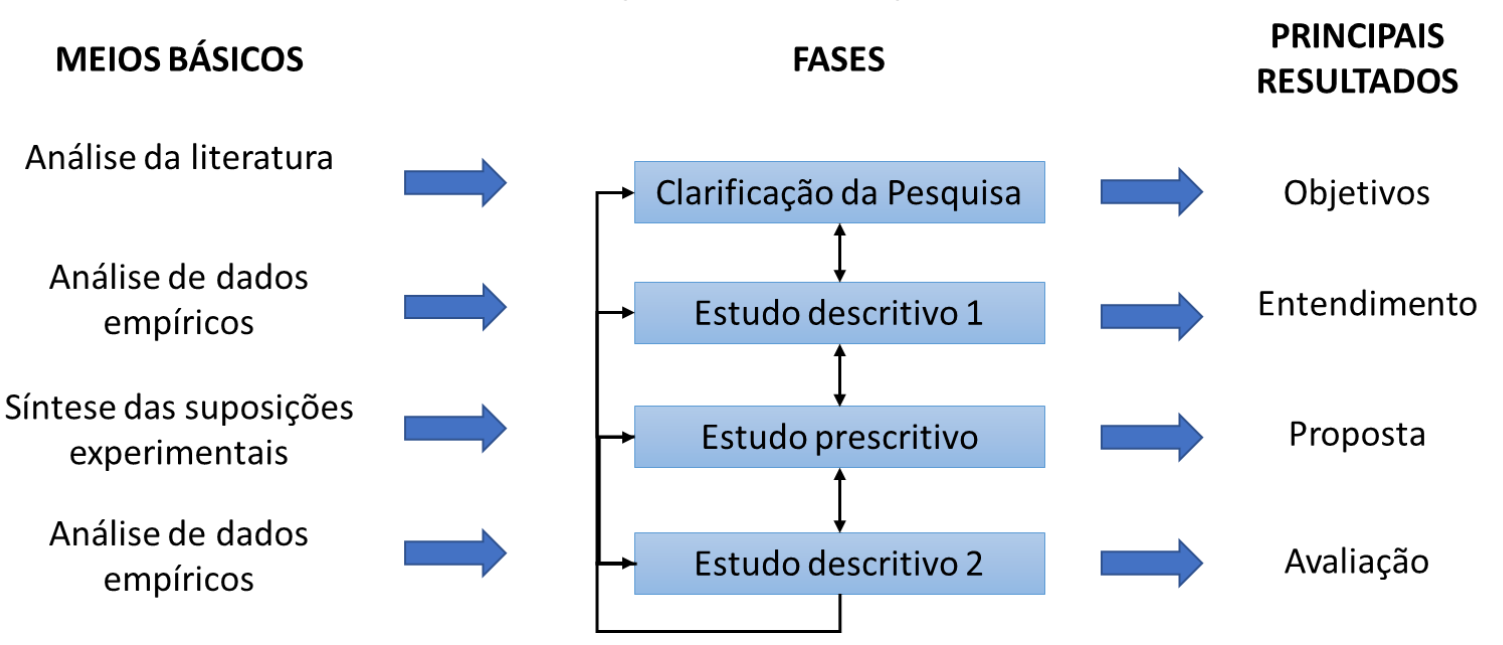

Fonte: Adaptado de Blessing e Chakrabarti (2009)

Na fase de Clarificação da Pesquisa, o pesquisador busca evidências para basear suas hipóteses com o intuito de formular seu objetivo de pesquisa. É realizada, portanto uma busca na literatura. Baseado nessas buscas, uma descrição da situação atual é desenvolvida, bem como uma descrição da situação ideal, no sentido de estabelecer hipóteses que conectem o problema com as finalidades da pesquisa (BLESSING; CHAKRABARTI, 2009).

Na fase do Estudo descritivo 1, o pesquisador, após obter um objetivo claro e definido, revisa a literatura para encontrar mais fatores influenciadores para elaborar a descrição inicial da situação atual. A intenção é fazer uma descrição detalhada o bastante para determinar qual fator pode ser atribuído para melhorar eficaz e eficientemente o problema de pesquisa. A análise de dados empíricos exploratórios pode auxiliar ainda mais nesse detalhamento (BLESSING; CHAKRABARTI, 2009).

$\mathrm{Na}$ fase de Estudo prescritivo, o pesquisador usa seu conhecimento da situação atual para corrigir e elaborar sua descrição inicial da situação desejada. Essa descrição representa sua visão de como superar um ou mais fatores da situação atual que viabilizem a realização da situação desejada. Podem ser desenvolvidos vários cenários com a variação desses fatores, com a finalidade de realizar uma proposta que possa superar os problemas encontrados na situação atual. Assim como nas fases anteriores, pode-se ter iterações para aprimorar sua elaboração (BLESSING; CHAKRABARTI, 2009). 
$\mathrm{Na}$ fase de Estudo descritivo 2, o pesquisador investiga a capacidade da sua proposta ante a situação desejada. Recomenda-se a realização de dois estudos empíricos, o primeiro para verificar a aplicabilidade da proposta e o segundo para verificar a utilidade da proposta. Caso não atinja o resultado esperado deve-se realizar as etapas anteriores novamente (BLESSING; CHAKRABARTI, 2009).

\subsection{Procedimentos técnicos}

A terminologia usada no presente trabalho (Figura 2) segue a sugerida por Sala, Farioli e Zamagni (2013) que distingue framework, metodologia, métodos, modelos, ferramentas e indicadores. Um framework é uma estrutura racional que integra conceitos, metodologias, métodos e ferramentas. Metodologias (por exemplo, a ACV), que são um conjunto de

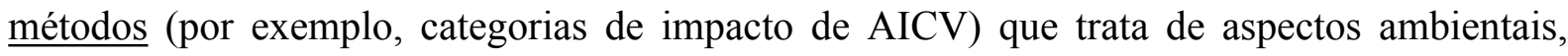

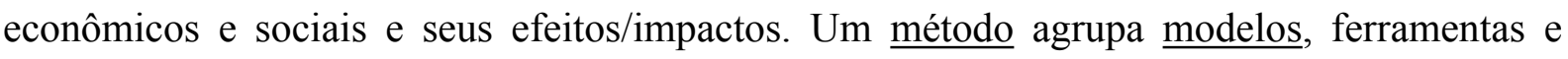
indicadores relevantes para mostrar informações, por exemplo, valores de uma categoria de impacto. Um modelo é uma descrição matemática do cálculo de um indicador, que pode ser obtido através de uma ferramenta ${ }^{3}$ (por exemplo um software). Um indicador é uma variável (parâmetro) ou uma função de variáveis para fornecer informações sobre a circularidade (ciclos tecnológicos) ou os efeitos (modelagem de causa e efeito). Sendo assim, um indicador é a representação operacional de um atributo de um sistema, podendo ser quantitativo ou qualitativo (MORAGA et al., 2019; SALA; FARIOLI; ZAMAGNI, 2013; WAAS et al., 2014).

Figura 2 - Terminologia utilizada no trabalho

${ }^{3}$ Ferramenta é algo "tangível, como um programa de software, usada na realização de uma atividade para produzir um produto ou resultado” (PROJECT MANAGEMENT INSTITUTE, 2004, p.364). 


\section{Framework}

Estrutura para integração de conceitos, metodologias, métodos e ferramentas (por exemplo, frameworks conceituais)

\section{Metodologias}

Uma coleção de métodos de caracterização, que juntos tratam de aspectos ambientais, econômicos e sociais associados aos seus efeitos/impactos (por exemplo ACV)

\section{Métodos}

Um conjunto de modelos, ferramentas e indicadores que permitem calcular valores de indicadores de uma certa categoria de impacto (por exemplo ReCiPe)

\begin{tabular}{|c|c|c|c|}
\hline $\begin{array}{c}\text { Modelos } \\
\text { Modelo matemático } \\
\text { para uma categoria de } \\
\text { impacto ambiental, } \\
\text { econômica ou social } \\
\text { adotado para calcular } \\
\text { um indicador específico }\end{array}$ & $\begin{array}{c}\text { Ferramentas } \\
\text { Softwares, aplicações, } \\
\text { bases de dados, que } \\
\text { suportam a análise } \\
\text { adotando um método } \\
\text { específico (por exemplo } \\
\text { Gabi) }\end{array}$ & $\begin{array}{c}\text { Indicadores } \\
\text { Parâmetro ou valor } \\
\text { derivado de } \\
\text { parâmetros que }\end{array}$ \\
& $\begin{array}{c}\text { providencia informação } \\
\text { ou descreve o estado } \\
\text { de um fenômeno, pode } \\
\text { ser quanti ou } \\
\text { qualitativo }\end{array}$ \\
\hline
\end{tabular}

Fonte: adaptado de Sala, Farioli, Zamagni (2013).

A presente pesquisa pautou-se nos seguintes procedimentos técnicos, de acordo com as fases da DRM, Figura 3.

Figura 3 - Procedimentos técnicos e DRM

ENTRADAS

\author{
Revisão Bibliográfica \\ Estudo de caso \\ exploratório, empresas
}

A e B

Estudo de caso, empresas C, D e E

Estudo de caso, empresa B
FASES
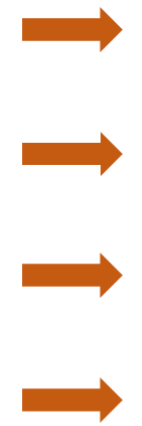

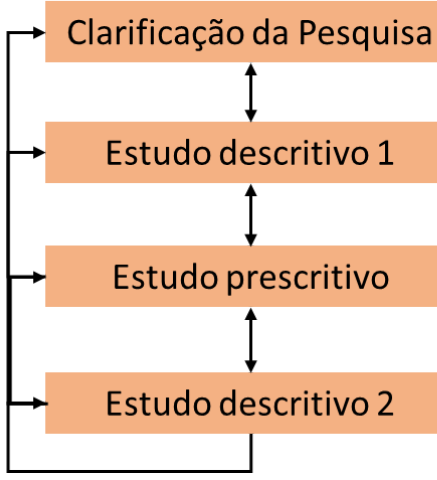

Fonte: elaboração própria
SAÍDAS

Versão 1

Versão 2

Versão 3

Versão final

\subsubsection{Clarificação da Pesquisa}

A pesquisa bibliográfica pautou-se inicialmente em publicações periódicas de revistas científicas obtidas nas bases de dados ISI Web of Science (http://apps.webofknowledge.com) e Sci Verse Scopus (https://www.scopus.com), as palavras-chaves utilizadas foram "circular economy”AND (“indicator\$” OR “metric\$”). Os critérios de inclusão dos artigos permearam: 
- Apresentar e especificar métricas que incluam princípios e práticas da Economia Circular.

- Idioma: inglês.

- Tipo: artigo.

- Preferencialmente mostrar aplicações práticas, como estudos de caso.

- Terem sido publicadas até o ano de 2020 (contagem inicial).

Portanto, pela Figura 4 nota-se um crescimento acentuado das publicações a partir do ano de 2014.

Figura 4 - Publicações nas bases de dados ao longo dos anos

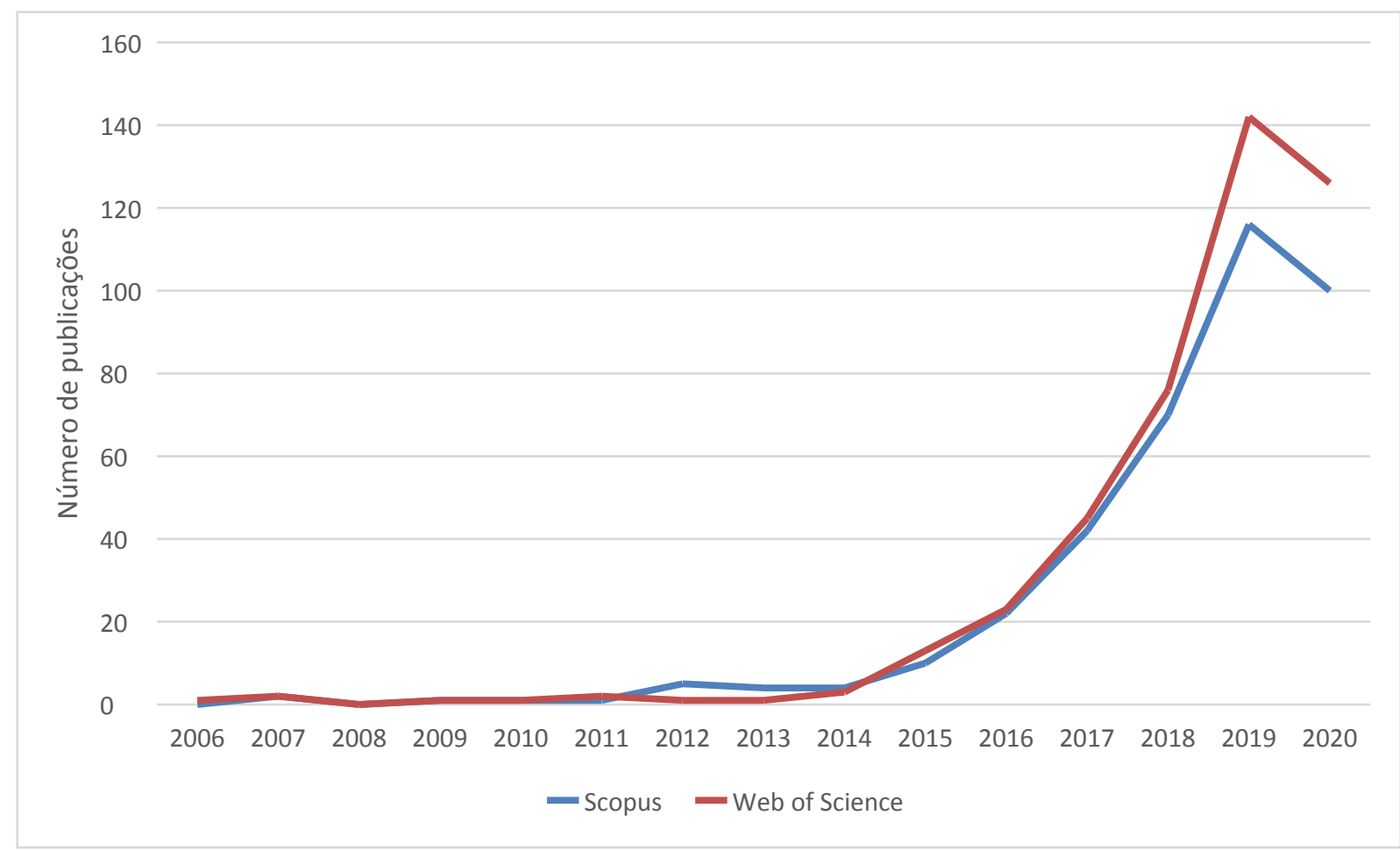

Fonte: elaboração própria.

Por meio do auxílio do software VOSViewer versão 1.6.11(VOSVIEWER, 2019), foi possível elaborar redes que evidenciam a co-ocorrência de palavras-chaves nos documentos das duas bases de dados, Web of Science e Scopus, respectivamente, considerando um critério de corte de no mínimo 3 ocorrências de palavras-chave. Vale salientar que não foi possível fazer uma análise com as duas bases de dados, uma vez que esta é uma limitação do software.

Nas Figuras 5 e 6, quanto maior a circunferência, maior a ocorrência das palavras. Pode-se observar que em ambas as bases, a palavra-chave de maior co-ocorrência foi 
"Circular Economy", demonstrando sua alta difusão no contexto acadêmico. Além disso, mostra-se diretamente relacionada a palavras como "Sustainable Development", "Life Cycle Assessment", "Sustainability", "Recycling” entre outras. A quantidade de palavras-chave é superior na base Scopus pois esta indexa mais palavras do que a Web of Science.

Figura 5 - Co-ocorrência das palavras-chave na base Web of Science

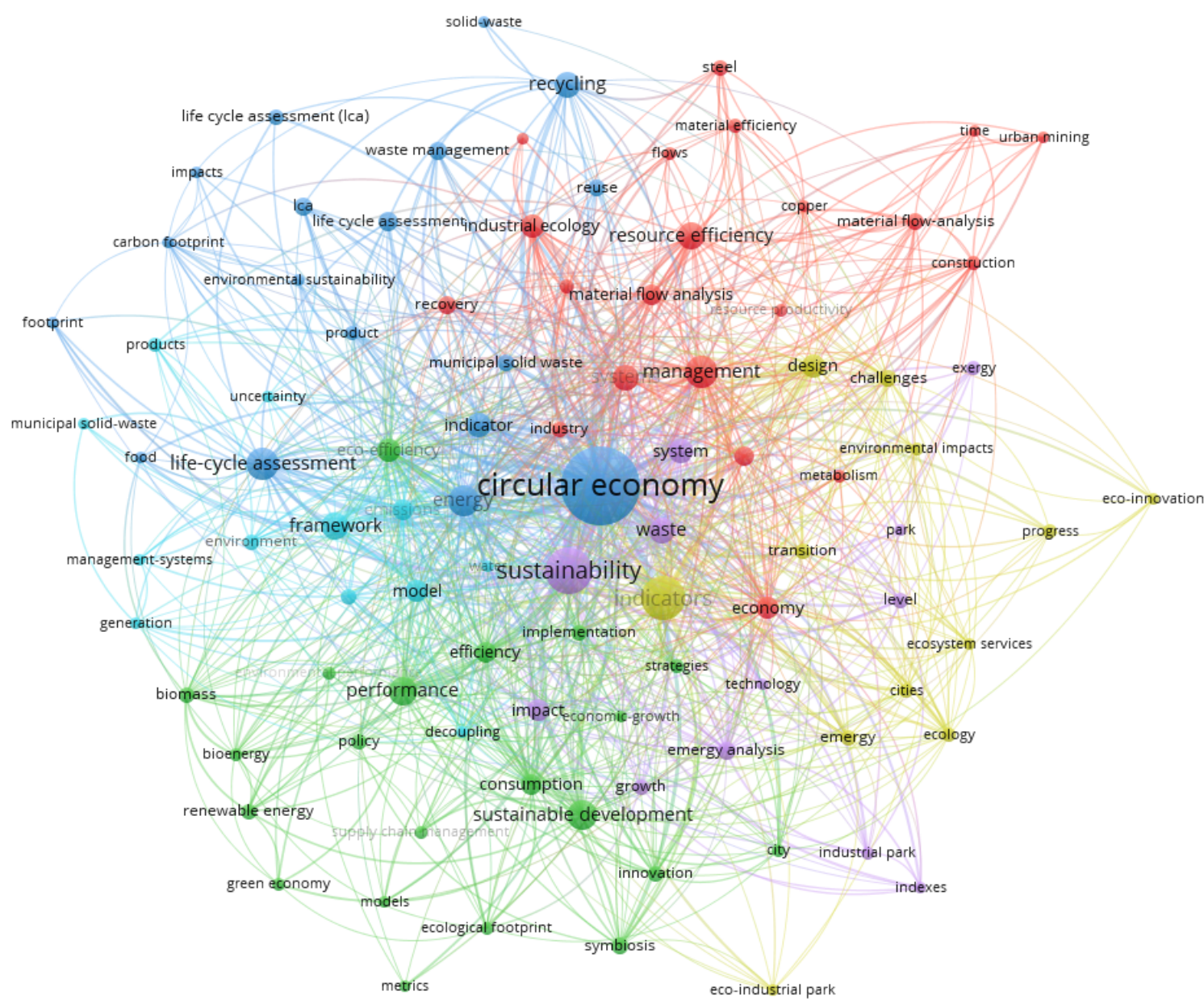

Fonte: elaboração própria.

Figura 6 - Co-ocorrência das palavras-chave na base Scopus 


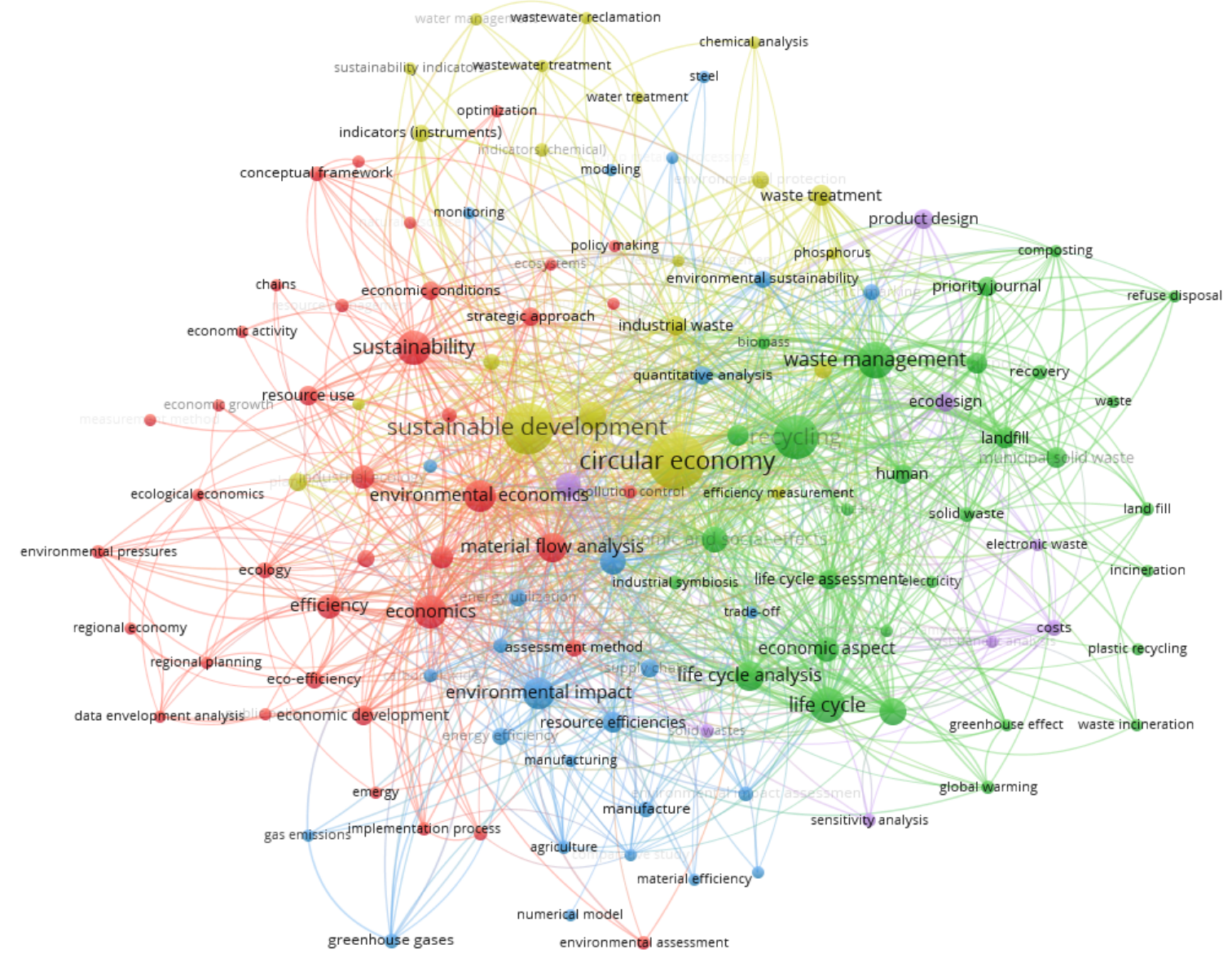

Fonte: elaboração própria.

Entretanto a pesquisa não se restringiu apenas às bases de dados, também foram feitos levantamentos em relatórios de organizações internacionais e consultorias. A pesquisa bibliográfica permitiu identificar a lacuna de pesquisa, e a listagem dos indicadores presentes no item 4.2. Por fim, a clarificação de pesquisa propiciou o desenvolvimento da Versão 1 do índice, vide item 5.1 .

\subsubsection{Estudo descritivo 1}

O Estudo descritivo 1 foi feito por meio de estudo de caso exploratório nas Empresas A e B (item 5.2). Ele propiciou o desenvolvimento da Versão 2 do índice, vide item 5.3.

O estudo de caso pode ser definido como uma investigação empírica acerca de um fenômeno contemporâneo em seu contexto, cujas interações entre eles não são claramente definidas. Ele pode ser único ou múltiplo, sendo que na presente pesquisa foram realizados casos múltiplos. Além disso, o estudo de caso é um método que trata da lógica de planejamento, técnicas de coleta de dados, e análise dos mesmos (YIN, 2005). 
Existem diversos propósitos nas pesquisas que justificam o estudo de caso, à saber: "explorar situações da vida real cujos limites não são claramente definidos" (GIL, 1999, p.73), "descrever a situação do contexto em que está sendo feita determinada investigação" (GIL, 1999, p.73), ou então, “explicar variáveis causais de determinado fenômeno em situações muito complexas que não possibilitam a utilização de levantamentos e experimentos" (GIL, 1999, p.73).

Karlsson (2009) mostra que o estudo de caso pode ser utilizado para diferentes propósitos de pesquisa, como: exploratória, construção de teoria, teste de teoria e refinamento de teoria. A exploratória é utilizada para desenvolver ideias e questões, a construção de teoria é focada na identificação, descrição e interação entre variáveis, o teste de teoria envolve o teste propriamente dito de teorias desenvolvidas previamente e o refinamento de teoria é pautado na estruturação da teoria tendo em vista os resultados obtidos.

A condução do estudo de caso permeou as seguintes etapas descritas na Figura 7.

Figura 7 - Etapas do Estudo de Caso

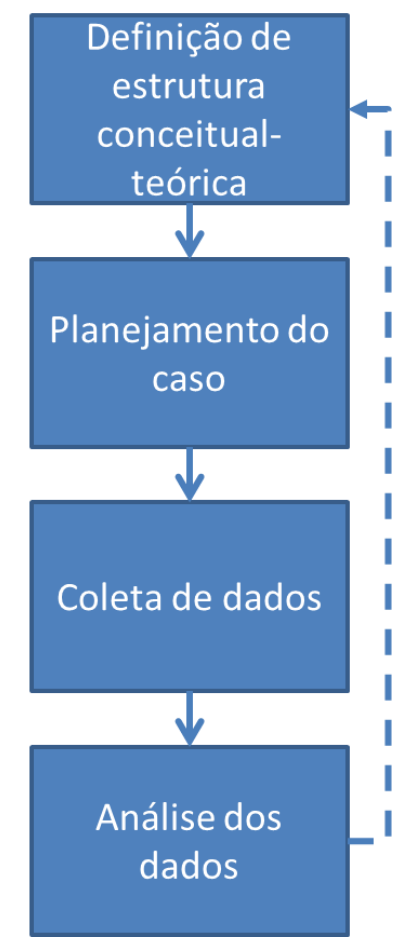

Fonte: adaptado de Miguel (2012).

Para o estudo de caso exploratório (item 5.2), inicialmente houve a definição de estrutura conceitual-teórica por meio da pesquisa bibliográfica cujos resultados estão presentes no item 4. Dessa maneira elencou-se os principais indicadores de Economia Circular encontrados na literatura, item 4.2. A partir dessa definição, os indicadores foram 
analisados a fim de se estabelecer aqueles que seriam aplicados nas empresas selecionadas. $\mathrm{O}$ planejamento do caso pautou-se na realização do protocolo de estudo de caso presente no Apêndice A, em que foram levantados quais dados seriam necessários, além dos contatos com empresas que possuíam modelos de negócio voltados para Economia Circular. A coleta de dados propriamente dita foi realizada conjuntamente duas empresas dos setores de Revestimentos Metálicos e Minero-metalúrgicos (Empresas A e B). A análise dos dados permitiu identificar os principais pontos a serem trabalhados que podem ter sua implicação na construção conceitual-teórica (MIGUEL, 2012).

\subsubsection{Estudo prescritivo}

Por meio de atualizações constantes da pesquisa bibliográfica inicial foi possível classificar os indicadores em uma taxonomia e propor uma versão inicial do índice proposto no presente trabalho (item 5.1). Essa versão foi obtida por meio de variáveis encontradas na literatura, classificadas de acordo com sua fase de aplicação no ciclo de vida do produto, à saber: modelo de negócio (estratégia), planejamento do produto, extração (entrada de matéria prima), manufatura, distribuição, uso e fim de vida. Essa classificação proposta permitiu abranger mais fases do ciclo de vida do produto, tornando uma abordagem mais sistêmica do que a encontrada na literatura (RINCÓN-MORENO et al., 2021).

Após a aplicação dessa primeira versão, foi percebida a necessidade de criação de novas métricas por meio de listas, envolvendo mais componentes do modelo de negócio. Isso foi constatado por meio da pesquisa bibliográfica, já que os indicadores encontrados se enquadravam basicamente apenas em três componentes do modelo de negócio CANVAS, à saber: atividades principais, recursos principais e proposta de valor. Além disso, a análise crítica da pesquisa bibliográfica possibilitou encontrar vantagens e desvantagens desses indicadores segundo sua relação com os princípios da Economia Circular, facilidade de uso e disponibilidade de acesso (vide item 4.2). Feito isso, foi proposta a Versão 2 dos indicadores, correspondendo a 18 métricas que levavam em consideração os modelos de negócio circulares, princípios da EC e facilidade de uso (ROSSI et al., 2019). Esses indicadores foram aplicados em três empresas de setores distintos, item 5.5.1.

Após a aplicação dessa segunda versão, notou-se que as empresas não conseguiam obter prontamente todos os dados e ainda necessitavam de um índice, que reunisse todos os indicadores e mostrasse um número total de circularidade. Sendo assim, a primeira versão do índice foi revisitada, incluindo novos indicadores que foram obtidos na segunda versão e foram criados dois índices: um para produtos circulares e outro para modelos de negócio 
circulares (item 5.4), caracterizando a Versão 3, ela foi aplicada em um estudo de caso final na Empresa B (a mesma que participou do estudo de caso exploratório), item 5.5.2.

Por fim, tendo em vista o feedback da empresa, optou-se por unir os dois índices, evitando superposição de perguntas, sendo assim, foi definida a proposta final (item 5.6).

\subsubsection{Estudo descritivo 2}

Para o Estudo descritivo 2 foram feitos quatro estudos de caso, presentes no item 5.5. Os indicadores desenvolvidos no estudo prescritivo por meio da abordagem hipotéticodedutiva (GILL; JOHNSON, 2002) indicando ciclos de teste de teoria e prática (BLESSING; CHAKRABARTI, 2009), foram aplicados em três empresas, C, D e E. Por meio da interação com três empresas (Empresas C, D e E) atuantes no Brasil de diferentes setores (eletroeletrônico, têxtil e plástico), foi possível obter os dados dos indicadores. Inicialmente averiguou-se indicadores presentes na literatura e por meio de reuniões internas propôs-se um conjunto multidimensional de indicadores que permearam os componentes do modelo de negócio. Após isso, por meio de workshops e entrevistas com as empresas dos estudos de caso, esses indicadores foram refinados e organizados. Por fim, os dados foram obtidos, analisados e organizados.

A aplicação dos índices também obtidos no Estudo prescritivo foi realizada por meio de um estudo de caso final, na Empresa B. Por fim, a Versão final dos índices pode ser vista no item 5.6. 


\section{FUNDAMENTAÇÃO TEÓRICA}

\subsection{Economia Circular}

A Economia Circular (EC) foi introduzida no livro "Economics of natural resources and the environment" pelos economistas ambientais David Pearce e Kerry Turner em 1990. Nele os autores relacionam conceitos econômicos com primeira lei da termodinâmica ou o princípio de conservação da energia, ou seja, não é possível criar ou destruir energia. Esses conceitos já estavam indicados no livro "The economics of the coming spaceship Earth" em 1966 por Kenneth Boulding mostrando que a economia e o meio ambiente não podem ter conexões lineares, mas circulares, pois, na natureza, saídas tornam-se novas entradas. Entretanto, a totalidade dos resíduos não podem ser transformados em recursos devido a segunda lei da termodinâmica, a qual prevê que a entropia é positiva (PEARCE; TURNER, 1990).

A EC foi formalmente aceita em 2002 pelo governo central da China, mostrando-se como uma nova estratégia de desenvolvimento que buscava conciliar as contradições existentes entre o rápido crescimento econômico e a baixa disponibilidade de matérias primas e energia. A EC implica em uma nova forma de pensar as atividades humanas, superando o modelo linear de extrair-produzir-descartar (YUAN; BI; MORIGUICHI, 2006).

No mundo dos negócios, a Economia Circular popularizou-se em 2014 com a publicação de "Towards the Circular Economy: accelerating the scale-up across global supply chain" publicado pelo World Economic Forum (ELLEN MACARTHUR FOUNDATION; MCKINSEY \& COMPANY, 2014). De acordo com o relatório, a Economia Linear está atingindo seus limites e a Economia Circular proporciona oportunidades de ganhos estimados em um trilhão de dólares em economia de materiais.

Ainda existem divergências ante a definição do conceito de Economia Circular, entretanto alguns autores que publicam sobre o tema incluem conceitos de fim de vida, ou seja, simplificam a Economia Circular a hierarquização da gestão de resíduos como os 4Rs reduzir, reutilizar, reciclar e recuperar energeticamente (KIRCHHERR; REIKE; HEKKERT, 2017).

Algumas definições mais abrangentes sobre EC descrevem-na como um sistema econômico que representa uma mudança de paradigma no modo como a sociedade se relaciona com a natureza e busca facilitar o desenvolvimento sustentável por meio de sua implementação no nível micro (empresas), meso (entre empresas) e macro (cidades, regiões e governos), sendo que o modelo circular requer inovações ambientais cíclicas e regenerativas 
na forma como a sociedade legisla, produz e consome (PRIETO-SANDOVAL; JACA; ORMAZABAL, 2018). Outros autores definem a EC como um modelo econômico em que planejamento, recursos, obtenção, produção e reprocesso são projetados e geridos, tanto como processos e saídas para maximizar o funcionamento do ecossistema e o bem estar humano (MURRAY; SKENE; HAYNES, 2017).

A EC pode ser vista também como um "modelo econômico em que planejamento, recursos, aquisição, produção e reprocesso são projetados e geridos como processos e saídas para maximizar o funcionamento do sistema e do bem-estar humano", focando na sustentabilidade e nos efeitos das estratégias da EC na economia, no meio ambiente e na sociedade (MORAGA et al., 2019, p.453).

$\mathrm{Na}$ realidade, a Economia Circular surgiu da prática (AGRAWAL; ATASU; VAN WASSENHOVEC, 2019), é um conceito contemporâneo, dinâmico (NUNEZ-CACHO et al., 2018) e em construção, "entendendo-se que as atividades econômicas geram e recuperam valores de produtos e serviços, mantidos por longo prazo e para todas as partes envolvidas do sistema econômico" (CONFEDERAÇÃO NACIONAL DA INDÚSTRIA, 2018, p.21). Além disso, ela pode também ser vista como um umbrella concept que por definição propõe relacionar temas que não estavam sendo anteriormente relacionados de maneira a concentrar atenção em uma qualidade particular ou característica compartilhada pelos mesmos (BLOMSMA; BRENNAN, 2017).

A Economia Circular visa "manter produtos, componentes e materiais em sua alta utilidade e valor em todo o tempo" (BOCKEN et al. 2017, p.476). A sua premissa básica é fechar ciclos, utilizando a reciclagem e demais estratégias de reintrodução de materiais, e retardá-los, mantendo, reutilizando, reparando, e remanufaturando produtos para estender sua vida útil, minimizando impactos ambientais (BOCKEN; RITALA; HUOTARI, 2017). Sendo assim, essas estratégias permitem reter o valor do produto por mais tempo (REIKE; VERMEULEN; WITJES, 2018).

O desenvolvimento da EC possibilitou uma mudança de foco da necessidade de fechar os ciclos para mudanças na estrutura industrial (YUAN; BI; MORIGUICHI, 2006), mostrando o desenvolvimento de novos mercados com a recuperação, o compartilhamento, novas tecnologias e novas regulamentações, como também a criação de empregos (ESPOSITO; TSE; SOUFANI, 2017).

$\mathrm{Na}$ natureza não existem resíduos, tudo se comporta com ciclos. Esses ciclos transformam as saídas em entradas de novos ciclos, em um contínuo processo de regeneração, esse é o fundamento da EC (STAHEL, 2016). Nesse sentido, destacam-se dois ciclos: o ciclo 
biológico e o ciclo técnico (BOCKEN et al., 2017). O ciclo biológico é composto por materiais ou produtos que são literalmente consumidos pelos microorganismos do solo ou por animais. O ciclo técnico é composto por materiais ou produtos designados a retornarem ao ciclo técnico pelo metabolismo industrial (MCDONOUGH; BRAUNGART, 2002).

As escolas de pensamento que fundamentam a EC são: Cradle to Cradle ${ }^{\circledR}$, Economia do Desempenho, Biomimética, Capitalismo Natural, Economia Azul, Design Regenerativo e Ecologia Industrial (ELLEN MACARTHUR FOUNDATION, 2013a).

O Design Regenerativo criado em 1970 pelo professor americano John T. Lyle desenvolveu um conceito em que como ocorre na natureza, os sistemas devem ser regenerativos e os processos podem ser renovados ou gerarem fontes de energia e materiais que por sua vez podem ser consumidos (ELLEN MACARTHUR FOUNDATION, 2013a).

A Economia do Desempenho cujo principal autor é Walter Stahel, foi esboçada em 1976 com o relatório "The potential for substituing Manpower for energy", que mostrou a visão da economia em ciclos e seus impactos na criação de empregos, competitividade, economia de recursos e prevenção à poluição (ELLEN MACARTHUR FOUNDATION, 2017). Essa escola representa a mudança para a servitização, em que a venda de produtos é substituída pela venda de serviços. Os principais elementos da Economia do Desempenho são a reutilização e a remanufatura, para manter a qualidade do estoque e ampliar sua vida útil reduzindo a necessidade de recursos (STAHEL; CLIFT, 2015).

O Capitalismo Natural cunhado por Paul Hawken, Amory and Hunter Lovins em 1999 intitulado "Natural capitalismo: creating the next industrial revolution" refere-se a uma economia global em que os interesses econômicos e ambientais se sobrepõem, estreitando as relações entre a produção, uso de capital humano e fluxos de capital natural (ELLEN MACARTHUR FOUNDATION, 2017). Os autores identificam: (i) ganhos substanciais de produtividade, (ii) sucesso no fechamento de ciclos e (iii) perspectiva produtiva a longo prazo (DESROCHERS, 2002).

A escola Cradle to Cradle ${ }^{\circledR}$ foi desenvolvida pelo químico Michael Braungart e o arquiteto Bill McDonough em que os materiais devem ser considerados como nutrientes técnicos ou biológicos, focando na efetividade ao invés da eficiência. Além disso, cria impactos positivos ao invés de se reduzir impactos negativos (BRAUNGART; MCDONOUGH; BOLLINGER, 2007a; ELLEN MACARTHUR FOUNDATION, 2013a).

A Biomimética definida por Janine Benyus em "Biomimicry: Innovation Inspired by Nature" busca estudar as melhores ideias da natureza e imitá-las para resolver problemas 
humanos. Para isso há três princípios básicos: natureza como modelo, como medida e como mentora (ELLEN MACARTHUR FOUNDATION, 2017).

A Economia Azul iniciada por Gunter Pauli busca utilizar “os recursos disponíveis em sistemas de cascatas, sendo que o resíduos de um produto torna-se uma entrada para a criação de um novo fluxo" (ELLEN MACARTHUR FOUNDATION, 2017). Dessa forma, imita a natureza nos negócios, convertendo resíduos em nutrientes (BARGH, 2014).

A Economia Circular (EC), aplica os princípios da Ecologia Industrial, quais sejam: fechar o ciclo produtivo reinserindo materiais e aumentando a durabilidade de produtos, fomentar alternativas ante a exploração de recursos naturais e reduzir a geração de resíduos (JURGILEVICH et al., 2016). Entretanto, a EC não pode ser confundida com a aplicação de uma gestão de resíduos, pois ela mostra-se como um "novo tipo de economia" e de "modelo de desenvolvimento" (JUN; XIANG, 2011).

São três os princípios da EC, segundo a Ellen Macarthur Foundation:

1) Preservar e aprimorar o capital natural controlando estoques finitos e equilibrando os fluxos de recursos renováveis (ELLEN MACARTHUR FOUNDATION, 2014).

2) Otimizar o rendimento de recursos fazendo circular produtos, componentes e materiais no mais alto nível de utilidade o tempo todo, tanto no ciclo técnico quanto no biológico (ELLEN MACARTHUR FOUNDATION, 2014).

3) Estimular a efetividade do sistema revelando e excluindo as externalidades negativas desde o princípio (ELLEN MACARTHUR FOUNDATION, 2014).

Esses princípios podem ser divididos em: eliminar resíduos e poluição por princípio, manter produtos e materiais em ciclos de uso e regenerar sistemas naturais (ELLEN MACARTHUR FOUNDATION, 2018). Nesse sentido mostra-se uma integração entre ciclos técnicos e biológicos, denotados como características chaves.

Embora alguns autores classifiquem os princípios da EC em apenas fluxos de materiais (EEA, 2016; ROMERO HERNÁNDEZ; ROMERO, 2018), fechamento de ciclos (GEISENDORF; PIETRULLA, 2018; GHISELLINI; CIALANI; ULGIATI, 2016; SKENE, 2018) e sustentabilidade (GEISENDORF; PIETRULLA, 2018), a literatura sustenta a maximização do valor de recursos, otimização de estoques, ecoeficiência ${ }^{4}$ e ecoefetividade ${ }^{5}$ (KALMYKOVA; SADAGOPAN; ROSADO, 2018).

\footnotetext{
${ }^{4}$ Ecoeficiência: buscar o aumento de valor com a diminuição do uso de recursos e impactos ambientais (NIERO et al., 2017).

${ }^{5}$ Ecoefetividade: maximizar os benefícios para os sistemas ecológicos e econômicos, ou seja, a geração de impactos positivos (NIERO et al., 2017).
} 
Vale salientar que por ser um conceito contemporâneo, a EC ainda não dispõe de elementos ou características chaves padronizadas e amplamente aceitas na literatura (PARCHOMENKO et al., 2019). O artigo de Parchomenko et al. (2019) propõe vinte e quatro elementos da EC, de acordo com o levantamento de sessenta e três indicadores.

A literatura ainda mostra alguns princípios operacionais e suas estratégias (SUÁREZEIROA et al., 2019), que englobam ajustar entradas para o sistema a fim de criar taxas regenerativas, ajustar saídas do sistema para taxas de absorção, fechamento do sistema, manter o valor do recurso no sistema, reduzir o tamanho do sistema, Design e Educação. Moraga et al. (2019) agrupam as estratégias da EC voltadas para a preservação da função do produto, a preservação do produto em si, seus componentes e seus materiais, além de preservar a energia incorporada e medir a economia linear como um cenário de referência.

Diante do exposto, os princípios da EC apresentam-se além de fluxos materiais e fechamentos de ciclo, mas por levarem em consideração também o valor, os negócios, o gerenciamento de impactos ambientais, a inovação e transparência. Nesse sentido, os princípios adotados no presente trabalho estão descritos na norma BSI 8001 (2017), por se tratar da única norma existente até o presente momento:

1) Pensamento sistêmico: as organizações devem assumir uma abordagem holística para compreender como as decisões individuais e atividades interagem e são partes de sistemas mais amplos. Ou seja, o pensamento sistêmico permeia compreender os complexos, não lineares e interconectados sistemas em que se situa a organização (BSI, 2017).

2) Inovação: as organizações devem inovar continuamente para criar valor possibilitando uma gestão sustentável dos recursos por meio do design de processos, produtos/serviços e modelos de negócio. A circularidade requer uma nova perspectiva de consumo e produção que desafia continuamente as tradicionais práticas de negócio e métodos (BSI, 2017).

3) Gerenciamento: as organizações devem gerir os impactos diretos e indiretos de suas decisões e atividades através do sistema mais amplo em que estão inseridas. Dessa forma, elas devem levar em consideração impactos ambientais e sociais de todo o ciclo de vida $^{6}$ do produto, incluindo a origem da matéria prima e a destinação final. O gerenciamento implica se a responsabilidade da gestão das

\footnotetext{
${ }^{6}$ Ciclo de vida: "estágios consecutivos e encadeados de um sistema de produto, desde a aquisição de matéria prima ou de sua geração a partir de recursos naturais até a disposição final” (ABNT, 2009), p.1.
} 
decisões e atividades da organização será compartilhada ou individualizada levando em consideração a cadeia de valor (BSI, 2017).

4) Colaboração: as organizações devem colaborar interna e externamente através de acordos formais ou não formais para criar valores mútuos. A Economia Circular implica em colaborações progressivas entre negócios, governos, academia, sociedade civil e consumidores. Superando as barreiras encontradas nas divergentes motivações, culturas e requerimentos, a colaboração deve desenvolver a confiança, a comunicação efetiva e a visão compartilhada (BSI, 2017).

5) Otimização de valor: as organizações devem manter todos os produtos, componentes e materiais no seu mais alto valor e utilidade em todo o tempo. $\mathrm{Ou}$ seja, reconsiderar aquilo que poderia ser visto como resíduo ou perdas no sistema e identificar oportunidades para novos potenciais a partir deles. Além disso, aumentar a durabilidade dos produtos, utilizando-os em múltiplos ciclos, utilizar modelos de negócio como o serviço e compartilhamento (BSI, 2017).

6) Transparência: as organizações devem estar aptas a comunicarem suas decisões e atividades de uma maneira clara, acurada, oportuna, honesta e completa. Em geral, a transparência deve ser favorecida para que a informação seja acessível proativamente ou se requerida (BSI, 2017).

\subsubsection{Da ecoeficiência para a ecoefetividade}

A ecoeficiência busca criar mais bens e serviços usando menos recursos e criando menos impactos, enquanto que a ecoefetividade encoraja um remodelamento na forma de pensar a produção, ou seja, desenhá-la para ser restaurativa, incluindo os efeitos ambientais e econômicos na construção e operação da tomada de decisão, não apenas em um processo, mas em todo o sistema (WANG; CÔTÉ, 2011).

Existem diversas abordagens tradicionais que buscam mensurar a ecoeficiência, almejando reduzir o impacto ambiental de processos industriais (ABUKHADER, 2008). Nesse sentido, a Análise de Fluxo de Materiais (AFM) e Avaliação do Ciclo de Vida (ACV) (MERLI; PREZIOSI; ACAMPORA, 2018; PAULIUK, 2018) são importantes para medir, tradicionalmente e respectivamente, balanço de massa e impactos ambientais. Entretanto vale salientar que por trazer novos modelos de negócio e práticas inovadoras, a Economia Circular implica na necessidade de criação de novas métricas. 
Moraga et al. (2019) demonstra que embora alguns autores recomendem a aplicação da ACV na EC (ELIA; GNONI; TORNESE, 2017; LONCA et al., 2018; NIERO et al., 2017; SCHEEPENS; VOGTLÄNDER; BREZET, 2016), algumas estratégias da EC (reciclagem, reuso, reproposição, multifuncionalidade, coprodução) estão no escopo de problemas não resolvidos na ACV (BOBBA et al., 2018; REAP et al., 2008a, 2008b). Outro aspecto é que a avaliação da função é desafiadora pois induz no comportamento de consumo, por exemplo, plataformas de compartilhamento podem motivar a um uso menos cauteloso quando comparadas à posse (TUKKER, 2015). Além disso, a abordagem da ACV tradicional não é adequada para avaliar produtos e processos eco efetivos pois sua natureza linear não permite a otimização no contexto cradle-to-cradle (BRAUNGART; MCDONOUGH; BOLLINGER, 2007).

A EC busca a ecoefetividade focando no desenvolvimento de produtos e sistemas industriais que mantenham ou melhorem a qualidade e produtividade dos materiais em seus subsequentes ciclos de vida, incorporando benefícios sociais, econômicos e ambientais ao sistema (BRAUNGART; MCDONOUGH; BOLLINGER, 2007).

Braungart, McDonough e Bollinger (2007) fazem uma analogia de "metabolismo" para descrever os processos cradle-to-cradle, inspirando-se no modo como por exemplo os organismos de um ecossistema podem circular continuamente os nutrientes (NUNES et al., 2018). Por fim, a principal diferença é que a ecoeficiência busca minimizar impactos negativos e a ecoefetividade busca otimizar impactos positivos (KOEIJER; WEVER; HENSELER, 2016), como pode ser visto na Figura 8.

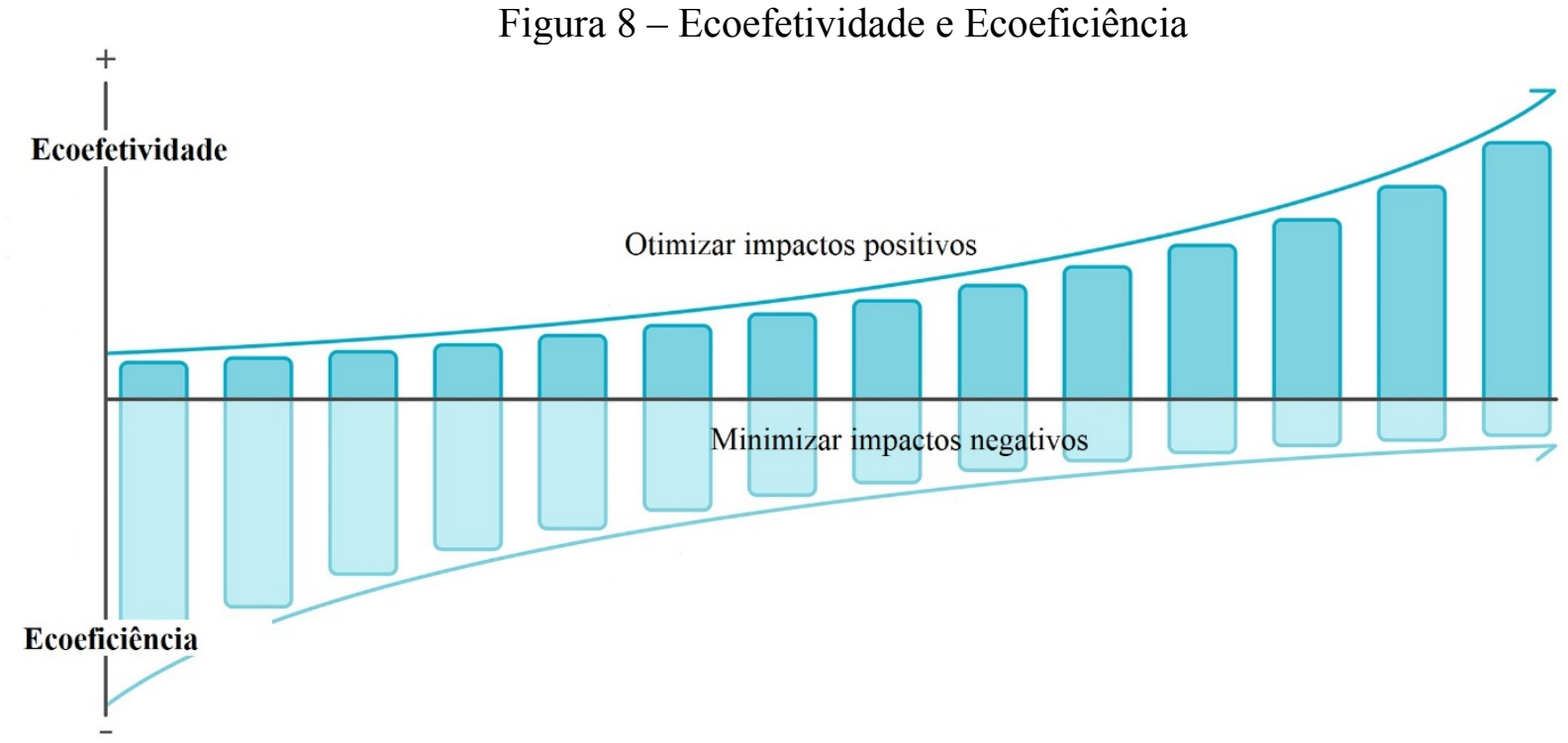

Fonte: adaptado de Koeijer, Wever e Henseler (20016). 
A ecoefetividade é modelada na interdependência bem-sucedida e na produtividade regenerativa dos sistemas naturais. Na natureza, todas as saídas de um processo se tornam entradas para outro. $\mathrm{O}$ conceito de desperdício não existe. As flores de uma cerejeira geram uma nova geração de cerejeiras, ao mesmo tempo em que fornecem alimentos para microorganismos, que por sua vez nutrem o solo e sustentam o crescimento da vida vegetal futura. O crescimento e a liberação de milhares de flores de cerejeira, das quais apenas algumas podem se tornar novas cerejeiras, pode parecer altamente ineficiente. Entretanto, quando a cerejeira deixa de ser vista individualmente e é vista dentro da interdependência do sistema natural, a efetividade do sistema torna-se clara (BRAUNGART; MCDONOUGH; BOLLINGER, 2007).

\subsubsection{Modelos de negócio circulares}

"Um modelo de negócio descreve a lógica de criação entrega e captura de valor por parte de uma organização"(OSTERWALDER; PIGNEUR, 2011, p.14). O Business Model Canvas ou apenas Canvas é uma ferramenta de planejamento estratégico que possibilita desenvolver e esboçar modelos de negócio novos ou existentes. Ele foi escolhido por ser uma ferramenta robusta e tem potencial de se aplicar em diferentes modelos de negócio. Ele está dividido em nove segmentos, Figura 9 (OSTERWALDER; PIGNEUR, 2011).

1) Segmento de Clientes: esse componente é um dos mais importantes do modelo de negócio, ele "define os diferentes grupos de pessoas ou organizações que a empresa busca alcançar e servir" (OSTERWALDER; PIGNEUR, 2011, p.20). Existem diferentes tipos de segmentos, como por exemplo: mercado de massa, nicho de mercado, segmentado, diversificado, plataforma multilateral, etc. A organização determinará quais segmentos deve atender e quais não.

2) Proposta de valor: é determinada pelo benefício que a empresa fornece ao cliente. Ele pode resolver um problema ou satisfazer uma necessidade, além de oferecer um conjunto específico de exigências do consumidor. As características dos valores podem ser quanti ou qualitativos, como por exemplo: novidade, desempenho, personalização, preço, entre outros (OSTERWALDER; PIGNEUR, 2011). 
3) Canais: "descreve como uma empresa se comunica e alcança seus segmentos de clientes para entregar uma proposta de valor" (OSTERWALDER; PIGNEUR, 2011, p.26). Esse componente permeia a interface entre a organização e os clientes, sendo compostos pela comunicação, distribuição, venda e suporte pós compra.

4) Relacionamento com os clientes: "descreve os tipos de relação que uma empresa estabelece com segmentos de clientes específicos" (OSTERWALDER; PIGNEUR, 2011, p.28). Essas relações podem ser pessoais até automáticas, sendo que as principais motivações são: conquista do cliente, retenção do cliente e ampliação de vendas.

5) Fontes de receita: "representa o dinheiro que uma empresa gera a partir de cada segmento de clientes" (OSTERWALDER; PIGNEUR, 2011, p.30). Nesse componente uma das perguntas chaves é que valor cada segmento de clientes está disposto a pagar. Pode-se ter diferentes maneiras de se gerar fontes de receita, como: venda de recursos, taxa de uso, taxa de assinatura, aluguéis, etc.

6) Recursos principais: “descreve os recursos mais importantes exigidos para fazer um modelo de negócio funcionar" (OSTERWALDER; PIGNEUR, 2011, p.34). Os recursos fornecem todo o suporte para a organização criar e oferecer sua proposta de valor, podendo ser físicos, financeiros, intelectuais ou humanos.

7) Atividades chave/principais: "descreve as ações mais importantes que uma empresa deve realizar para fazer seu modelo de negócio funcionar" (OSTERWALDER; PIGNEUR, 2011, p.36).

8) Parcerias principais: "descreve a rede de fornecedores e os parceiros que põem o modelo de negócio para funcionar" (OSTERWALDER; PIGNEUR, 2011, p.38). As organizações necessitam de alianças para otimizar seus modelos, reduzir riscos ou adquirir recursos.

9) Estrutura de custo: "descreve todos os custos envolvidos na operação de um modelo de negócio" (OSTERWALDER; PIGNEUR, 2011, p.40). 


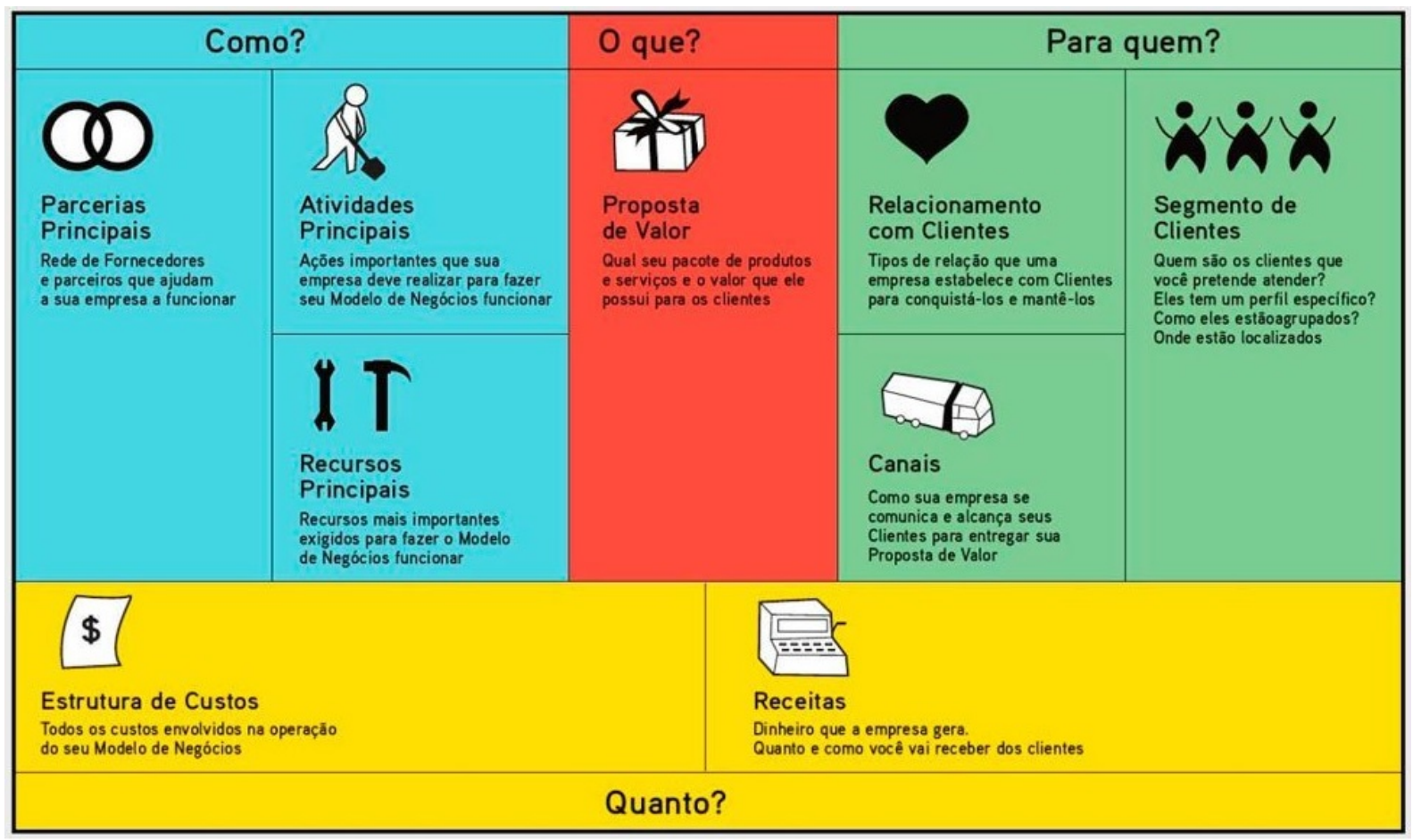

Fonte: Osterwalder e Pigneur (2011).

Um modelo de negócio circular pode ser classificado como aquele com uma companhia focal, que juntamente com parceiros, usa a inovação para criar, capturar e entregar valor para melhorar a eficiência de recursos, por meio da extensão da durabilidade de produtos e partes, além de obter benefícios ambientais, sociais e econômicos (FRISHAMMAR; PARIDA, 2019). Além disso, eles incorporam elementos que desaceleram, estreitam e fecham ciclos de recursos, podendo até desmaterializá-los (GEISSDOERFER et al., 2018).

A norma BSI 8001:2007 "Framework for implementing the principles of the circular economy in organizations" descreve os seis modelos de negócio que tem potencial para se incorporarem à Economia Circular (BSI, 2017):

1) Sob demanda: "produzir um produto ou fornecer um serviço apenas quando a demanda do consumidor é quantificada e confirmada" (BSI, 2017, p.47).

2) Desmaterialização: "substituir estrutura física e ativos por serviços digitais/virtuais" (BSI, 2017, p.47).

3) Extensão da vida do produto/reuso: "novos produtos são desenhados para serem duráveis. Melhorias nos desenhos devem facilitar o reparo/manutenção por terceiros" (BSI, 2017, p.47). 
4) Recuperação de matérias primas secundárias/subprodutos: “otimização de valor pela criação de produtos a partir de matérias primas secundárias/subprodutos e recicladas, sendo em ciclos abertos ou fechados" (BSI, 2017, p.48).

5) Produto como serviço/servitização (PSS): “a organização fornece o desempenho de um produto ou resultados definidos ao invés do próprio produto ou serviço" (BSI, 2017, p.48).

6) Economia compartilhada e consumo colaborativo: "Empréstimo ou consumo colaborativo entre usuários, indivíduos ou organizações" podendo ter acordo financeiro ou não (BSI, 2017, p.50).

A EC busca incorporar a dimensão de modelos de negócio (KIRCHHERR; REIKE; HEKKERT, 2017), de tal modo que traga inovação nos modelos de negócio, ou seja, processos pelos quais permitam as empresas implementar estratégias circulares (HENRY et al., 2020). Esse processo busca reconfigurar um modelo de negócio linear existente para incluir componentes do modelo de negócio circular na forma de recriação de valor, reenvio e recaptura, além de uma proposta de valor estendida, ou o processo de reconfigurar um modelo de negócio circular existente para incluir mais ou melhores versões desses componentes (GULDMANN; HUULGAARD, 2020).

A interação entre modelos de negócio e demais facilitadores no sistema de negócio circular pode ser vista na Figura 10. Evidencia-se a necessidade de mudança de mindset para proporcionar mudanças entre os demais elos da cadeia, desde os modelos de negócio às cadeias de valor circulares (CONFEDERAÇÃO NACIONAL DA INDÚSTRIA, 2018).

Figura 10 - Framework do sistema de negócio circular 


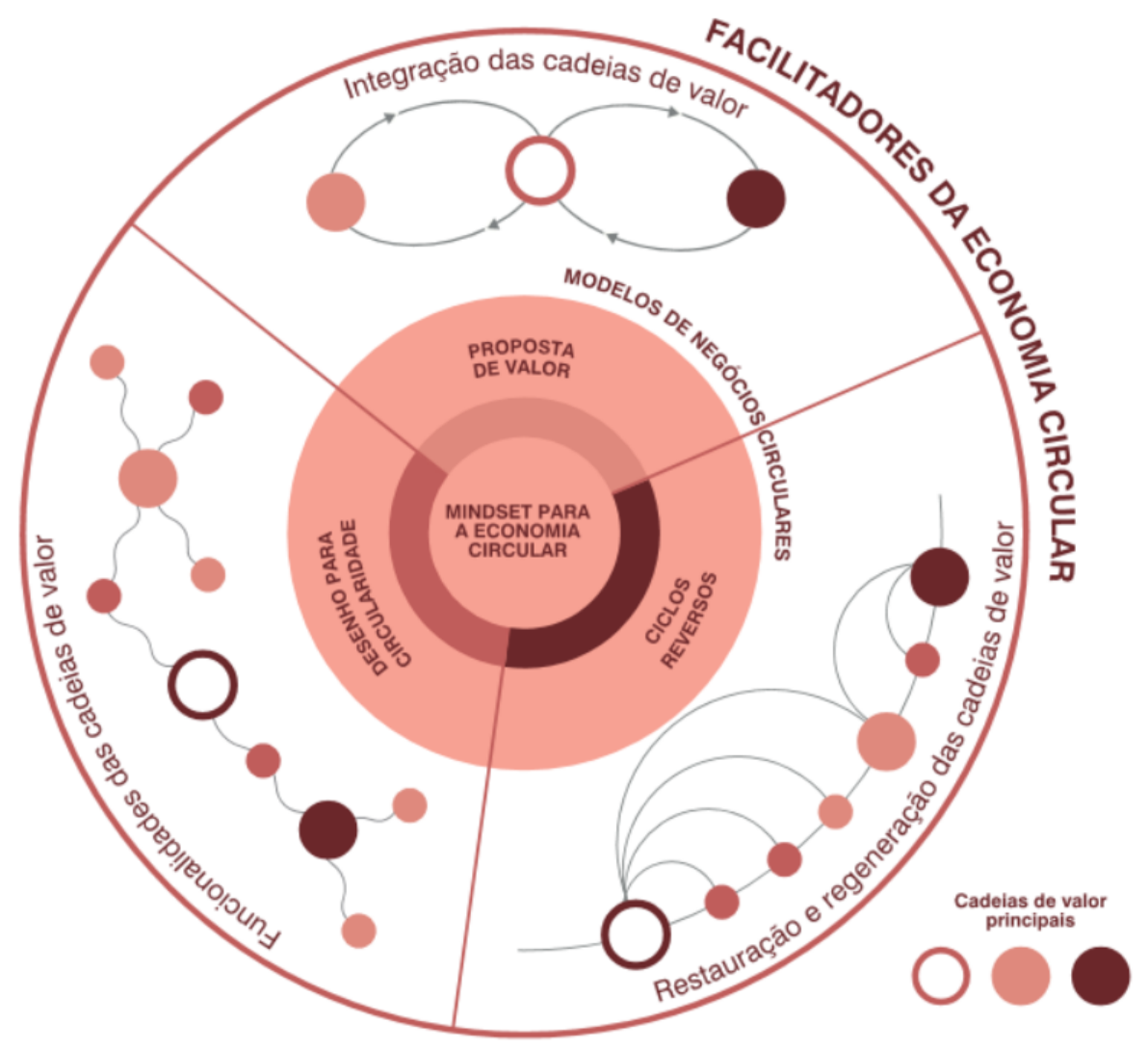

Fonte: Confederação Nacional da Indústria (2018)

Dessa forma, a transição para um modelo de negócio circular não influencia apenas o modelo de negócio de uma companhia, mas afeta a organização do sistema como um todo (PARIDA et al., 2019). Tendo em vista a abordagem sistêmica da EC, é importante definir o conceito de Ecossistema de negócios. Eles são formados por redes de entidades conectadas, sendo que, como acontece com espécies em ecossistemas biológicos, as empresas interagem umas com as outras de formas complexas. O desempenho de cada empresa é dependente do desempenho do todo. Empresas e espécies são, portanto, influenciadas simultaneamente por suas capacidades complexas internas e pelas complexas interações com o resto do ecossistema (IANSITI; LEVIEN, 2004; TATE et al., 2019).

\subsection{Indicadores para Economia Circular}

Uma das principais razões para a medição de desempenho em organizações é o estabelecimento de posição, "Você não pode gerir o que você não pode medir" (NEELY, 1998, p. 71). Podem ser elencadas quatro categorias para as razões da medição: checar posição, comunicar posição, confirmar prioridades e compelir progresso (NEELY, 1998).

Deve-se elencar definições importantes, segundo com Neely, Gregory e Platts (2005): 
- Medição de desempenho: "processo de quantificar a eficiência e eficácia de uma ação" (p.80);

- Indicador de desempenho: "métrica usada para quantificar a eficiência e a eficácia de uma ação" (p.80); e

- Sistema de medição de desempenho (SMD): “conjunto de métricas usadas para quantificar tanto a eficiência como a eficácia de ações" (p.81).

A eficácia refere-se à satisfação dos clientes quanto ao cumprimento de seus requisitos enquanto que a eficiência indica como economicamente os recursos da empresa são utilizados para providenciar um nível de satisfação dos clientes (NEELY; GREGORY; PLATTS, 2005).

Neely, Gregory e Platts (2005) afirmam que um sistema de medição de desempenho pode ser examinado em três níveis: os indicadores de desempenho individuais, o conjunto de indicadores individuais, constituindo o sistema, e a relação entre o sistema de medição de desempenho e o meio em que está inserido, vide Figura 10.

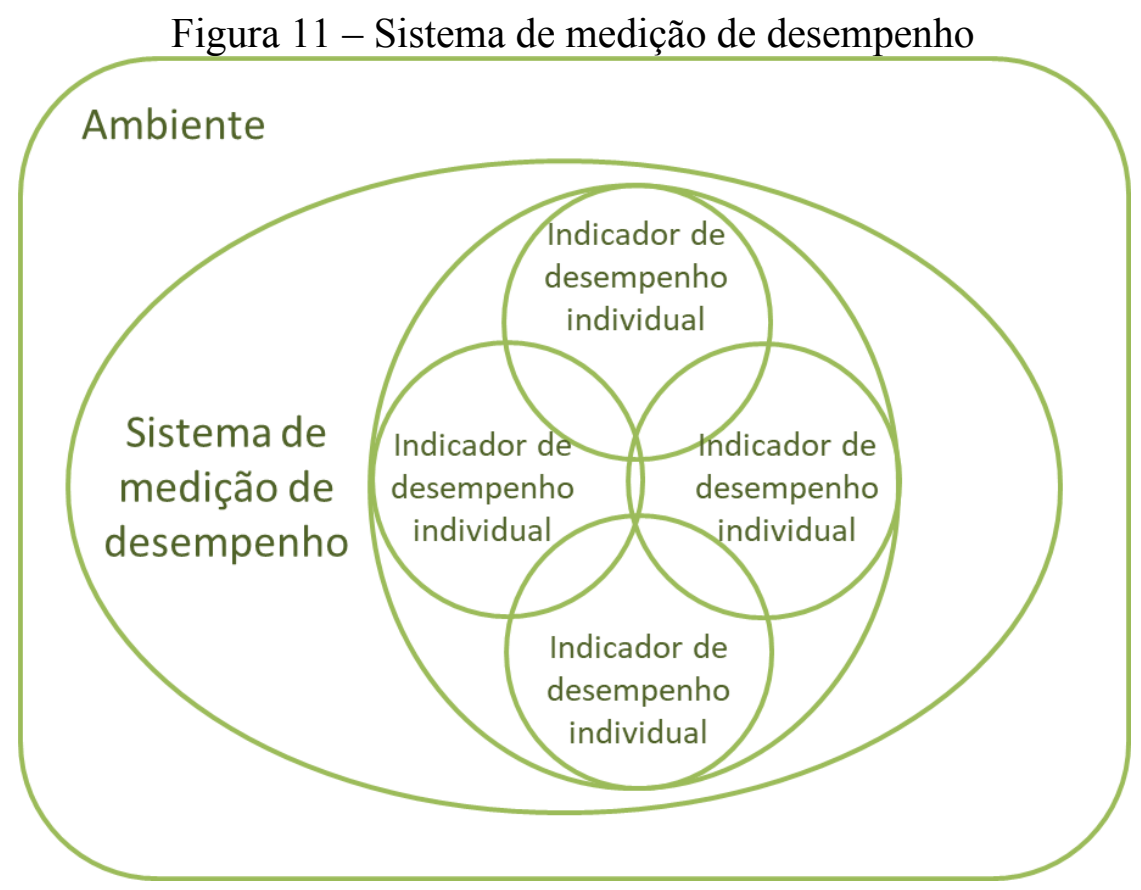

Fonte: Neely, Gregory e Platts (2005)

Existem algumas perguntas chaves que podem ser aplicadas em cada nível do SMD. No nível de indicadores de desempenho individual destacam-se (NEELY; GREGORY; PLATTS, 2005):

- Quais indicadores de desempenho são utilizados?

- Para que eles são utilizados?

- Quanto eles custam? 
- Quais benefícios eles proporcionam?

No nível do SMD, destacam-se (NEELY; GREGORY; PLATTS, 2005):

- Todos os elementos (internos, externos, financeiros e não financeiros) apropriados são cobertos?

- Foram introduzidos indicadores que medem a melhoria?

- Foram introduzidos indicadores a curto e longo prazo dos objetivos do negócio?

- Os indicadores foram integrados vertical e horizontalmente?

- Algum indicador conflita com outro?

No nível de relação do SMD com o ambiente, destacam-se (NEELY; GREGORY; PLATTS, 2005):

- Os indicadores reforçam a estratégia da empresa?

- Os indicadores estão condizentes com a cultura da empresa?

- Os indicadores são consistentes com a estrutura de reconhecimento e a gratificação da empresa?

- Os indicadores focam na satisfação dos clientes?

- Os indicadores focam na competitividade?

Os SMDs são constituídos por três componentes: elementos, funções e processos. Os elementos são propriedades do sistema, as funções são os seus propósitos e os processos são séries de ações combinadas que juntas constituem o sistema. Dentre os elementos estão: os indicadores de desempenho individuais, e a infraestrutura de suporte, que corresponde à aquisição, coleta, classificação, análise, interpretação e disseminação da informação. Dentre as funções está: a medição de desempenho, para monitorar o progresso das organizações. Dentre os processos, estão: gestão da informação, selecionar e desenvolver indicadores, e coletar e tratar dados (FRANCO-SANTOS et al., 2007).

Além disso, há dois modelos para o SMD: estrutural e procedimental. O estrutural exprime a tipologia para a gestão da medição de desempenho, como por exemplo, o Balanced Scorecard, o Performance Prism, e o Performance Pyramid. O procedimental é um passo-apasso para desenvolver a medição de desempenho a partir da estratégia (FOLAN; BROWNE, 2005). 
Um aspecto importante da medição de desempenho é que no nível micro está relacionada às operações da organização e no nível macro, está relacionada à missão, estratégia e objetivos, além da cultura e stakeholders (PUTTERILL; ROUSE, 2003).

Algumas recomendações para o desenvolvimento de frameworks e sistemas de medição de desempenho são que eles devem ser baseados nas estratégias da empresa, devem ser revisados continuamente e abordar informações com medidas simples (FOLAN; BROWNE, 2005).

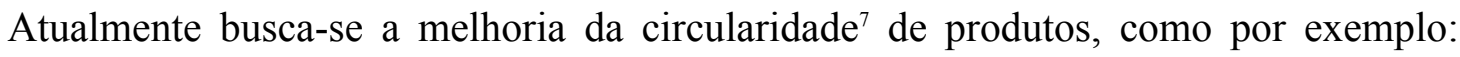
aumentar a vida útil de produtos, modular e remanufaturar, reutilizar componentes, e desenhar produtos com menos material. Esses materiais devem ser livres de substâncias tóxicas e desenhados para ser facilmente desmontáveis e capazes de serem reciclados ou compostados (CAYZER; GRIFFITHS; BEGHETTO, 2017).

O World Business Council for Sustainable Development (WBCSD) publicou um relatório baseado em 39 entrevistas em empresas do mundo todo e concluiu que $74 \%$ dos entrevistados utilizam seu próprio modelo de medição de circularidade. Além disso, 76\% das métricas envolvem o nível micro. Por fim, 48\% das métricas circulares se relacionam às operações internas e processos de negócio, $22 \%$ e $20 \%$ se relacionam à matéria prima e fím de vida, respectivamente. Sendo que raramente as empresas possuem indicadores de design distribuição ou uso (WBCSD, 2018).

Moraga et al. (2019) propuseram um framework para classificar os indicadores quantitativos de Economia Circular encontrados na literatura. Ele é baseado em uma matriz de seis estratégia de EC versus três escopos.

As estratégias são:

1) Preservar a função de produtos e serviços provenientes de modelos de negócio circulares, como plataformas de compartilhamento, PSS e esquemas que promovam a redundância de produtos e multifuncionalidade.

2) Preservar o produto em si, por meio de incremento de sua vida útil, com estratégias como durabilidade, reuso, restauração, remodelamento e remanufatura.

3) Preservar os componentes do produto pelo reuso, recuperação e reproposição de suas partes.

4) Preservar os materiais através de reciclagem e downcycling 8 .

\footnotetext{
${ }^{7}$ Circularidade referindo-se basicamente ao fechamento de ciclos técnicos.
} 
5) Preservar a energia incorporada através da recuperação energética por meio de incineração e aterros.

6) Medir a Economia Linear como um cenário de referência ou ausência de preservação para aferir o estado, progresso ou regresso através da Economia Circular.

Os escopos são:

1) Medir propriedades físicas dos ciclos técnicos sem a abordagem do ciclo de vida, por exemplo taxas de reciclagem.

2) Medir propriedades físicas dos ciclos técnicos com a abordagem do ciclo de vida, por exemplo indicador de reusabilidade/reciclabilidade/recuperabilidade em termos de massa incluindo o potencial de reuso de produtos, reciclagem, e recuperação energética.

3) Medir os efeitos ambientais, econômicos ou sociais em modelagens do tipo causa e efeito, por exemplo indicador de reusabilidade/reciclabilidade/recuperabilidade em termos de impactos ambientais.

Os autores concluíram que os indicadores analisados em sua maioria focam na preservação de materiais (estratégia 4), como a reciclagem, porém a EC abrange muitas outras estratégias. Além disso, nenhum indicador avaliou a preservação da função do produto (estratégia 1), como plataformas de compartilhamento, esquemas de redundância de produtos, desmaterialização, PSS (orientação uso/resultado), e multifuncionalidade, presentes na EC (MORAGA et al., 2019). Outro trabalho encontrou que a maioria dos indicadores da literatura focam em reciclagem, fim de vida ou remanufatura, sendo que poucos consideram a desmontagem, extensão de vida útil, gestão de resíduos, eficiência de recursos ou reuso (KRISTENSEN; MOSGAARD, 2020).

Há uma taxonomia proposta para classificar os indicadores (SAIDANI et al., 2019). Segundo essa taxonomia os indicadores podem ser classificados em:

1) Nível: micro (organizações, produtos e componentes), meso (simbiose industrial e parques industriais) e macro (cidade, província, região ou país).

2) Loops: manter/prolongar, reutilizar/remanufaturar e reciclar.

${ }^{8}$ Downcycling é a perda da qualidade do material que passa por processos de reciclagem (RISSE; WEBER-BLASCHKE; RICHTER, 2019). 
3) Desempenho: intrínsecos (relativos à circularidade inerente, ou seja, taxas de recirculação de recursos) ou impactos (consequências ou efeitos dos loops de Economia Circular, por exemplo a sustentabilidade).

4) Perspectiva: real ou potencial.

5) Usos: melhorias, benchmarking ou comunicação.

6) Transversalidade: genérico ou específico.

7) Dimensão: único ou múltiplo.

8) Unidade: quantitativo ou qualitativo.

9) Formato: ferramenta baseada em website (internet), Excel, fórmulas.

10) Fontes: academia, empresas, agências, etc.

Devido ao escopo do presente trabalho, os indicadores selecionados por meio da taxonomia descrita acima foram os pertencentes ao nível micro e meso (produtos e empresas), descartando o nível macro. Foram selecionadas as seguintes classificações para a análise: desempenho, transversalidade, dimensão, unidade e formato. Além de indicar em quais pilares da sustentabilidade se inserem, sendo econômico, ambiental e/ou social. Após isso, foi feita uma análise crítica dos mesmos e suas vantagens e desvantagens foram atribuídas segundo os critérios: relação com os princípios da Economia Circular, facilidade de uso e disponibilidade.

\subsubsection{Indicadores no nível micro}

Os indicadores do nível micro descritos a seguir foram levantados por meio de pesquisa bibliográfica, vide Quadro 1 (PARCHOMENKO et al., 2019; SAIDANI et al., 2019). 
Quadro 1 - Indicadores de Economia Circular do nível micro

\begin{tabular}{|c|c|c|c|c|c|c|c|c|}
\hline & Indicador & Desempenho & Transversalidade & Dimensão & Unidade & Formato & Sustentabilidade & Referência \\
\hline 1 & $\begin{array}{l}\text { BIM-based Whole- } \\
\text { life Performance } \\
\text { Estimator (BWPE) }\end{array}$ & Intrínseco & $\begin{array}{c}\text { Específico } \\
\text { (Construção Civil) }\end{array}$ & Múltiplo & Quantitativo & $\begin{array}{l}\text { Fórmulas para } \\
\text { calcular }\end{array}$ & Ambiental & $\begin{array}{l}\text { (AKANBI et al., } \\
\text { 2018) }\end{array}$ \\
\hline 2 & $\begin{array}{c}\text { Building } \\
\text { Circularity } \\
\text { Indicators (BCI) }\end{array}$ & Intrínseco & $\begin{array}{c}\text { Específico } \\
\text { (Construção Civil) }\end{array}$ & $\begin{array}{c}\text { Múltiplo } \\
(4 \\
\text { indicadore } \\
\text { s } \\
\text { construído } \\
\text { s um após } \\
\text { o outro) }\end{array}$ & $\begin{array}{l}\text { Quantitativo } \\
\text { (\% de } \\
\text { circularidade) }\end{array}$ & $\begin{array}{c}\text { Planilha } \\
\text { dinâmica do } \\
\text { Excel (Contatar } \\
\text { o autor) }\end{array}$ & Ambiental & $\begin{array}{l}\text { (VERBERNE, } \\
\text { 2016) }\end{array}$ \\
\hline 3 & $\begin{array}{l}\text { Circular Economy } \\
\text { Index (CEI) }\end{array}$ & Intrínseco & $\begin{array}{l}\text { Específico } \\
\text { (recicladores) }\end{array}$ & Único & $\begin{array}{l}\text { Quantitativo } \\
\text { (\%, razão de } \\
\text { valor } \\
\text { econômico) }\end{array}$ & $\begin{array}{l}\text { Fórmulas para } \\
\text { calcular }\end{array}$ & Econômico & $\begin{array}{c}\text { (DI MAIO; REM, } \\
\text { 2015) }\end{array}$ \\
\hline 4 & $\begin{array}{c}\text { Circular Economy } \\
\text { Indicator Prototype } \\
\text { (CEIP) }\end{array}$ & Intrínseco & $\begin{array}{l}\text { Genérico (porém } \\
\text { desenvolvido } \\
\text { inicialmente para } \\
\text { organizações de } \\
\text { bens tangíveis) }\end{array}$ & $\begin{array}{c}\text { Único } \\
\text { (agregação } \\
\text { de } 5 \\
\text { pontuações } \\
\text { de } 5 \text { etapas } \\
\text { do ciclo de } \\
\text { vida do } \\
\text { produto) }\end{array}$ & $\begin{array}{l}\text { Quantitativo } \\
\text { (\% ou } \\
\text { pontuação de } \\
\text { circularidade } \\
\text { de } 0 \text { a 152) }\end{array}$ & $\begin{array}{c}\text { Planilha } \\
\text { dinâmica do } \\
\text { Excel (Contatar } \\
\text { o autor) }\end{array}$ & Ambiental & $\begin{array}{c}\text { (CAYZER; } \\
\text { GRIFFITHS; } \\
\text { BEGHETTO, } \\
\text { 2017) }\end{array}$ \\
\hline 5 & $\begin{array}{c}\text { Circular Economy } \\
\text { Measurement Scale } \\
\text { (CEMS) }\end{array}$ & $\begin{array}{l}\text { Intrínseco e } \\
\text { Impactos } \\
\text { Ambientais }\end{array}$ & $\begin{array}{c}\text { Específico } \\
\text { (Construção Civil) }\end{array}$ & Múltiplo & Quantitativo & $\begin{array}{l}\text { Fórmulas para } \\
\text { calcular }\end{array}$ & Ambiental & $\begin{array}{l}\text { (NUNEZ- } \\
\text { CACHO et al., } \\
2018)\end{array}$ \\
\hline 6 & $\begin{array}{l}\text { Circular Economy } \\
\text { Performance } \\
\text { Indicator (CEPI) }\end{array}$ & $\begin{array}{l}\text { Intrínseco e } \\
\text { impactos } \\
\text { ambientais }\end{array}$ & $\begin{array}{l}\text { Genérico (porém } \\
\text { aplicado ao } \\
\text { plástico) }\end{array}$ & Único & $\begin{array}{c}\text { Quantitativo } \\
(\%)\end{array}$ & $\begin{array}{l}\text { Fórmulas para } \\
\text { calcular }\end{array}$ & Econômico & $\begin{array}{l}\text { (HUYSMAN et } \\
\text { al., 2017) }\end{array}$ \\
\hline 7 & $\begin{array}{l}\text { Circular Economy } \\
\text { Toolkit (CET) }\end{array}$ & Intrínseco & Genérico & $\begin{array}{l}\text { Múltiplo } \\
\text { (relativo } \\
\text { ao ciclo de } \\
\text { vida) }\end{array}$ & $\begin{array}{c}\text { Semi- } \\
\text { quantitativo } \\
\text { (alto, médio } \\
\text { ou baixo } \\
\text { potencial) }\end{array}$ & Website & Ambiental & $\begin{array}{c}\text { (EVANS; } \\
\text { BOCKEN, 2013) }\end{array}$ \\
\hline 8 & $\begin{array}{l}\text { Circular Pathfinder } \\
\text { (CP) }\end{array}$ & Intrínseco & Genérico & $\begin{array}{c}\text { Não } \\
\text { aplicável }\end{array}$ & Qualitativo & Website & Ambiental & $\begin{array}{c}\text { (RESCOM, } \\
2017 \mathrm{a})\end{array}$ \\
\hline
\end{tabular}




\begin{tabular}{|c|c|c|c|c|c|c|c|c|}
\hline Cont & Indicador & Desempenho & Transversalidade & Dimensão & Unidade & Formato & Sustentabilidade & Referência \\
\hline 9 & $\begin{array}{c}\text { Circularity } \\
\text { Calculator (CC) }\end{array}$ & $\begin{array}{l}\text { Intrínseco e } \\
\text { impactos } \\
\text { (valor } \\
\text { capturado) }\end{array}$ & Genérico & $\begin{array}{c}\text { Múltiplo } \\
\text { (circularid } \\
\text { ade, valor } \\
\text { potencial } \\
\text { capturado, } \\
\text { conteúdo } \\
\text { reciclado e } \\
\text { índice de } \\
\text { reuso) } \\
\end{array}$ & $\begin{array}{l}\text { Quantitativo } \\
\text { (\%) }\end{array}$ & Website & $\begin{array}{l}\text { Ambiental e } \\
\text { Econômico }\end{array}$ & $\begin{array}{c}\text { (RESCOM, } \\
\text { 2017b) }\end{array}$ \\
\hline 10 & $\begin{array}{l}\text { Circularity Index } \\
\text { (CI) }\end{array}$ & Intrínseco & Genérico & Único & $\begin{array}{c}\text { Quantitativo } \\
(\%)\end{array}$ & $\begin{array}{c}\text { Fórmulas para } \\
\text { calcular }\end{array}$ & Ambiental & (CULLEN, 2017) \\
\hline 11 & $\begin{array}{c}\text { Circularity } \\
\text { Potential Indicator } \\
\text { (CPI) }\end{array}$ & $\begin{array}{l}\text { Intrínseco e } \\
\text { Impactos } \\
\text { econômicos }\end{array}$ & Genérico & Único & $\begin{array}{l}\text { Quantitativo } \\
\text { (\%) }\end{array}$ & $\begin{array}{c}\text { Planilha } \\
\text { dinâmica do } \\
\text { Excel (Contatar } \\
\text { o autor) } \\
\end{array}$ & $\begin{array}{l}\text { Ambiental e } \\
\text { Econômico }\end{array}$ & $\begin{array}{c}\text { (SAIDANI et al., } \\
\text { 2017) }\end{array}$ \\
\hline 12 & $\begin{array}{c}\text { Closed Loop } \\
\text { Calculator (CLC) }\end{array}$ & Intrínseco & Específico & Único & Quantitativo & $\begin{array}{c}\text { Ferramenta } \\
\text { computacional } \\
\text { (Contatar o } \\
\text { autor) }\end{array}$ & Ambiental & $\begin{array}{c}\text { (KINGFISHER, } \\
\text { 2014) }\end{array}$ \\
\hline 13 & $\begin{array}{c}\text { Ease of } \\
\text { Disassembly } \\
\text { Metric (eDiM) }\end{array}$ & Intrínseco & Genérico & Único & $\begin{array}{l}\text { Quantitativo } \\
\text { (tempo) }\end{array}$ & $\begin{array}{c}\text { Planilha } \\
\text { dinâmica do } \\
\text { Excel (Contatar } \\
\text { o autor) } \\
\end{array}$ & Ambiental & $\begin{array}{l}\text { (VANEGAS et } \\
\text { al., 2018) }\end{array}$ \\
\hline 14 & $\begin{array}{l}\text { Eco-efficient Value } \\
\text { Ratio (EVR) }\end{array}$ & $\begin{array}{c}\text { Impactos } \\
\text { (custos, valor } \\
\text { de mercado e } \\
\text { "eco-costs" ou } \\
\text { externalidades } \\
\text { ) }\end{array}$ & Genérico & Único & $\begin{array}{l}\text { Quantitativo } \\
\text { (saídas } \\
\text { gráficas) }\end{array}$ & $\begin{array}{l}\text { Fórmulas para } \\
\text { calcular }\end{array}$ & $\begin{array}{l}\text { Ambiental e } \\
\text { Econômico }\end{array}$ & $\begin{array}{l}\text { (SCHEEPENS; } \\
\text { VOGTLÄNDER; } \\
\text { BREZET, 2016) }\end{array}$ \\
\hline 15 & $\begin{array}{c}\text { Economic- } \\
\text { Environmental } \\
\text { Indicators (EEI) }\end{array}$ & $\begin{array}{l}\text { Intrínseco e } \\
\text { Impactos } \\
\text { (Ambiental e } \\
\text { Econômico) }\end{array}$ & Específico & Múltiplo & Quantitativo & $\begin{array}{l}\text { Fórmulas para } \\
\text { calcular }\end{array}$ & $\begin{array}{l}\text { Ambiental e } \\
\text { Econômico }\end{array}$ & $\begin{array}{l}\text { (FREGONARA } \\
\text { et al., 2017) }\end{array}$ \\
\hline
\end{tabular}




\begin{tabular}{|c|c|c|c|c|c|c|c|c|}
\hline Cont & Indicador & Desempenho & Transversalidade & Dimensão & Unidade & Formato & Sustentabilidade & Referência \\
\hline 16 & $\begin{array}{c}\text { Economic- } \\
\text { environmental } \\
\text { remanufacturing } \\
(\text { EER) }\end{array}$ & $\begin{array}{l}\text { Intrínseco e } \\
\text { Impactos } \\
\text { (Ambiental e } \\
\text { Econômico) }\end{array}$ & Específico & Múltiplo & Quantitativo & $\begin{array}{l}\text { Fórmulas para } \\
\text { calcular }\end{array}$ & $\begin{array}{l}\text { Ambiental e } \\
\text { Econômico }\end{array}$ & $\begin{array}{c}\text { (VAN LOON; } \\
\text { VAN } \\
\text { WASSENHOVE, } \\
2018) \\
\end{array}$ \\
\hline 17 & $\begin{array}{c}\text { End-of-Life } \\
\text { Recycling Rates } \\
\text { (EoL-RRs) }\end{array}$ & Intrínseco & Genérico & Múltiplo & Quantitativo & $\begin{array}{l}\text { Fórmulas para } \\
\text { calcular }\end{array}$ & $\begin{array}{l}\text { Ambiental e } \\
\text { Econômico }\end{array}$ & $\begin{array}{l}\text { (GRAEDEL et } \\
\text { al., 2011) }\end{array}$ \\
\hline 18 & $\begin{array}{l}\text { Input-Output } \\
\text { Balance Sheet } \\
\text { (IOBS) }\end{array}$ & $\begin{array}{l}\text { Intrínseco e } \\
\text { impactos } \\
\text { (econômicos) }\end{array}$ & Genérico & Múltiplo & Quantitativo & $\begin{array}{l}\text { Ferramenta } \\
\text { computacional } \\
\text { (Contatar o } \\
\text { autor) }\end{array}$ & Ambiental & $\begin{array}{c}\text { (MARCOCAPEL } \\
\text { LINI, 2017) }\end{array}$ \\
\hline 19 & $\begin{array}{c}\text { Longevity and } \\
\text { Circularity (L\&C) }\end{array}$ & Intrínseco & Genérico & $\begin{array}{l}\text { Múltiplo } \\
\text { (longevida } \\
\text { de e } \\
\text { circularida } \\
\text { de) } \\
\end{array}$ & $\begin{array}{l}\text { Quantitativo } \\
\text { (tempo e \%) }\end{array}$ & $\begin{array}{l}\text { Fórmulas para } \\
\text { calcular }\end{array}$ & Ambiental & $\begin{array}{c}\text { (FIGGE et al., } \\
\text { 2018) }\end{array}$ \\
\hline 20 & $\begin{array}{c}\text { Material } \\
\text { Circularity } \\
\text { Indicator (MCI) }\end{array}$ & Intrínseco & Genérico & Único & $\begin{array}{c}\text { Quantitativo } \\
(\%)\end{array}$ & $\begin{array}{c}\text { Planilha } \\
\text { dinâmica do } \\
\text { Excel } \\
\text { (disponível } \\
\text { gratuitamente } \\
\text { online) } \\
\end{array}$ & Ambiental & $\begin{array}{c}\text { (ELLEN } \\
\text { MACARTHUR } \\
\text { FOUNDATION; } \\
\text { GRANTA, 2015) }\end{array}$ \\
\hline 21 & $\begin{array}{c}\text { Material } \\
\text { Reutilization Part } \\
(\mathrm{C} 2 \mathrm{C})\end{array}$ & $\begin{array}{l}\text { Intrínseco e } \\
\text { impactos } \\
\text { (energia } \\
\text { renovável, } \\
\text { água e justiça } \\
\text { social) } \\
\end{array}$ & Genérico & Único & $\begin{array}{l}\text { Qualitativo } \\
\text { (Certificação } \\
\text { Cradle-to- } \\
\text { Cradle) }\end{array}$ & $\begin{array}{l}\text { Fórmulas para } \\
\text { calcular }\end{array}$ & Ambiental & $(\mathrm{C} 2 \mathrm{C}, 2014)$ \\
\hline 22 & $\begin{array}{l}\text { Mine site MFA } \\
\text { Indicator (MI) }\end{array}$ & Intrínseco & Específico & Múltiplo & Quantitativo & $\begin{array}{l}\text { Fórmulas para } \\
\text { calcular }\end{array}$ & $\begin{array}{l}\text { Ambiental e } \\
\text { Econômico }\end{array}$ & $\begin{array}{c}\text { (LÈBRE; } \\
\text { CORDER; } \\
\text { GOLEV, 2017) } \\
\end{array}$ \\
\hline 23 & $\begin{array}{l}\text { Multidimensional } \\
\text { Indicator Set (MIS) }\end{array}$ & $\begin{array}{l}\text { Intrínseco e } \\
\text { Impactos } \\
\text { Ambientais }\end{array}$ & Específico & Múltiplo & Quantitativo & $\begin{array}{l}\text { Fórmulas para } \\
\text { calcular }\end{array}$ & Ambiental & $\begin{array}{l}\text { (NELEN et al., } \\
\text { 2014) }\end{array}$ \\
\hline 24 & $\begin{array}{c}\text { Product-Level } \\
\text { Circularity Metric } \\
\text { (PCM) }\end{array}$ & $\begin{array}{l}\text { Impactos } \\
\text { econômicos }\end{array}$ & Genérico & Único & $\begin{array}{c}\text { Quantitativo } \\
(\%)\end{array}$ & $\begin{array}{l}\text { Fórmulas para } \\
\text { calcular }\end{array}$ & Econômico & $\begin{array}{c}\text { (LINDER; } \\
\text { SARASINI; VAN } \\
\text { LOON, 2017) }\end{array}$ \\
\hline
\end{tabular}




\begin{tabular}{|c|c|c|c|c|c|c|c|c|}
\hline Cont & Indicador & Desempenho & Transversalidade & Dimensão & Unidade & Formato & Sustentabilidade & Referência \\
\hline 25 & $\begin{array}{l}\text { Recycling Indices } \\
\text { (RIs) }\end{array}$ & Intrínseco & Genérico & Único & $\begin{array}{c}\text { Quantitativo } \\
\text { (\%) }\end{array}$ & $\begin{array}{c}\text { Ferramenta } \\
\text { computacional } \\
\text { (Contatar o } \\
\text { autor) }\end{array}$ & Ambiental & $\begin{array}{l}\text { (VAN SCHAIK; } \\
\text { REUTER, 2016) }\end{array}$ \\
\hline 26 & $\begin{array}{l}\text { Recycling Rates } \\
\text { (RRs) }\end{array}$ & Intrínseco & $\begin{array}{l}\text { Genérico (porém } \\
\text { aplicado em } \\
\text { resíduos } \\
\text { domiciliares) }\end{array}$ & $\begin{array}{l}\text { Múltiplo } \\
\text { (taxas de } \\
\text { coleta e } \\
\text { reciclagem }\end{array}$ & $\begin{array}{c}\text { Quantitativo } \\
(\%)\end{array}$ & $\begin{array}{l}\text { Fórmulas para } \\
\text { calcular }\end{array}$ & Ambiental & $\begin{array}{l}\text { (HAUPT; } \\
\text { VADENBO; } \\
\text { HELLWEG, } \\
\text { 2017) }\end{array}$ \\
\hline 27 & $\begin{array}{l}\text { Resource Duration } \\
\text { Indicator (RDI) }\end{array}$ & Intrínseco & Genérico & $\begin{array}{c}\text { Único } \\
\text { (indicador } \\
\text { de } \\
\text { longevidad } \\
\text { e) } \\
\end{array}$ & $\begin{array}{l}\text { Quantitativo } \\
\text { (tempo) }\end{array}$ & $\begin{array}{l}\text { Fórmulas para } \\
\text { calcular }\end{array}$ & Ambiental & $\begin{array}{c}\text { (FRANKLIN- } \\
\text { JOHNSON; } \\
\text { FIGGE; } \\
\text { CANNING, } \\
\text { 2016) } \\
\end{array}$ \\
\hline 28 & $\begin{array}{l}\text { Reuse Potential } \\
\text { Indicator (RPI) }\end{array}$ & Intrínseco & $\begin{array}{l}\text { Genérico (porém } \\
\text { aplicado em } \\
\text { resíduos } \\
\text { domiciliares) }\end{array}$ & Único & $\begin{array}{c}\text { Quantitativo } \\
(\%)\end{array}$ & $\begin{array}{l}\text { Fórmulas para } \\
\text { calcular }\end{array}$ & $\begin{array}{l}\text { Ambiental e } \\
\text { Econômico }\end{array}$ & $\begin{array}{l}\text { (PARK; } \\
\text { CHERTOW, } \\
\text { 2014) }\end{array}$ \\
\hline 29 & $\begin{array}{l}\text { Set of Indicators to } \\
\text { Assess } \\
\text { Sustainability } \\
\text { (SIAS) }\end{array}$ & $\begin{array}{l}\text { Intrínseco e } \\
\text { Impactos } \\
\text { ambientais }\end{array}$ & Específico & Múltiplo & Quantitativo & $\begin{array}{l}\text { Fórmulas para } \\
\text { calcular }\end{array}$ & $\begin{array}{l}\text { Ambiental, } \\
\text { Econômico e } \\
\text { Social }\end{array}$ & $\begin{array}{l}\text { (GOLINSKA et } \\
\text { al., 2015) }\end{array}$ \\
\hline 30 & $\begin{array}{l}\text { Sustainability } \\
\text { Indicators (SI) }\end{array}$ & Intrínseco & Genérico & Múltiplo & Quantitativo & $\begin{array}{l}\text { Fórmulas para } \\
\text { calcular }\end{array}$ & $\begin{array}{l}\text { Ambiental e } \\
\text { Econômico }\end{array}$ & $\begin{array}{c}\text { (MESA; } \\
\text { ESPARRAGOZA } \\
\text {; MAURY, 2018) }\end{array}$ \\
\hline
\end{tabular}

Fonte: adaptado de Saidani et al. (2019) 
O BIM-based Whole-life Performance Estimator (BWPE) é um conjunto de indicadores aplicados em um modelo matemático a fim de avaliar o reuso e a reciclabilidade de materiais para a construção civil. Esse modelo é aplicado no projeto de estruturas a fim de avaliar o desempenho dos mesmos (AKANBI et al., 2018).

O Building Circularity Indicators (BCI) é um indicador quantitativo construído através de quatro indicadores: Material Circularity Indicator (MCI), Product Circularity Indicator (PCI), System Circularity Indicator (SCI), Building Circularity Indicator (BCI). O BCI pode ser calculado por meio de uma planilha dinâmica de Excel cuja fonte é uma dissertação holandesa de mestrado (VERBERNE, 2016). Os dados necessários para o cálculo do BCI são relacionados às especificações do material: tipo de entrada (virgem ou não), tipo de saída (reutilizável ou resíduo), durabilidade técnica dos materiais, possibilidades de desmontagem (funcional, técnica e física), ponderação (volume ou receita de vendas) e nível de importância de cada sistema (SAIDANI et al., 2019).

O Circular Economy Index (CEI) é um valor quantitativo e provém da razão entre o valor material obtido pelo produto reciclado (valor de mercado) e o valor do material que entra na empresa de reciclagem. Ou seja, o CEI mede a circularidade em termos da razão do valor do material reciclado (proveniente de fim de vida de produtos) comparado com o valor total do material no processo de reciclagem necessário para produzir novas versões do mesmo produto (SAIDANI et al., 2019). Os dados de entrada para o cálculo do indicador permeiam informações detalhadas dos valores dos componentes e materiais em cada produto que entra na recicladora e como eles tornam-se matérias primas recicladas. Sendo assim, ele tem foco econômico e é voltado preponderantemente para a reciclagem (DI MAIO; REM, 2015).

O Circular Economy Indicator Prototype (CEIP) é um indicador calculado por meio de uma planilha dinâmica Excel cuja interface permeia um questionário composto por quinze perguntas, baseadas em 5 categorias: design e redesign, manufatura, comercialização, uso e fim de vida. Possui como saídas gráfico de radar e ranking de circularidade. Foi desenvolvido inicialmente para empresas de produtos tangíveis (SAIDANI et al., 2019) e cujos dados de entrada são a lista de materiais, e demais conhecimentos qualitativos sobre o ciclo de vida do produto. O uso desse indicador está voltado para avaliar o desempenho dos produtos de acordo com os princípios da EC (CAYZER; GRIFFITHS; BEGHETTO, 2017; GRIFFITHS; CAYZER, 2016).

O Circular Economy Measurement Scale (CEMS) é uma escala de medida aplicada na construção civil. Foi desenvolvido a partir de dados da literatura e validação com especialistas. Ele é composto por um questionário dividido em sete partes: geral, materiais, 
energia, água, 3R's, emissão e resíduos. As respostas são em escala likert (de 1 a 7 sendo "discordo plenamente" e "concordo plenamente", respectivamente) (NUNEZ-CACHO et al., 2018).

O Circular Economy Performance Indicator (CEPI) é um indicador aplicável a termoplásticos calculado pela razão entre o benefício ambiental real (ou seja, o benefício aplicável devido à opção do tratamento de resíduo) e o benefício ambiental ideal, de acordo com a qualidade do termoplástico, assumindo que a opção I (reciclagem em ciclo fechado ${ }^{9}$ é mais preferível do que a opção IV (incineração) (SAIDANI et al., 2019). O cálculo do CEPI é baseado na técnica de ACV para computar impactos ambientais, ou seja, como dados de entrada são necessárias as entradas e saídas presentes no inventário (HUYSMAN et al., 2017).

O Circular Economy Toolkit (CET) é uma ferramenta online de avaliação que analisa os produtos e serviços de uma empresa e proporciona um guia para potenciais melhoramentos usando um questionário que cobre todas as etapas do ciclo de vida do produto ou serviço (SAIDANI et al., 2019). Sendo assim, o CET permite destacar em baixo, médio e alto potencial de melhoria na circularidade. É baseado em 33 questões divididas em sete categorias: design, manufatura e distribuição; uso; manter e reparar; reutilizar e redistribuir; remanufaturar; reciclagem; e produto como serviço. As respostas das questões são baseadas na porcentagem do produto que atendem as especificações dessas sete categorias. Sendo assim, os dados necessários para utilizar o CET são voltados para o conhecimento qualitativo do ciclo de vida do produto (EVANS; BOCKEN, 2013).

O Circular Pathfinder (CP) permite identificar, por meio de um questionário online, as melhores práticas circulares para o projeto e manufatura de um produto de uma empresa. É uma ferramenta de ideação estratégica, cujos conhecimentos necessários são os voltados para o produto propriamente dito e estratégias de marketing associadas (SAIDANI et al., 2019). Além disso, ele mostra empresas que aplicaram as práticas recomendadas para o produto (RESCOM, 2017a).

O Circularity Calculator (CC) foi desenvolvido para visualizar, desenvolver e comparar PSS em diferentes cenários de negócios. A proposta é auxiliar os designers a entender como estratégias de decisão de design podem influenciar o grau de circularidade do fluxo de recursos e potenciais valores capturados por meio do PSS (SAIDANI et al., 2019). Além disso, o CC é uma ferramenta que possibilita descobrir diferentes cenários visualizando

${ }^{9}$ A reciclagem em ciclo fechado significa que o material será utilizado para a produção do mesmo produto. A reciclagem em ciclo aberto indica que o material reciclado será utilizado em outro produto (DESCHAMPS et al., 2018). 
fluxos materiais e valores financeiros dos fechamentos de ciclos, como coleta, recondicionamento, remanufatura e reciclagem. A ferramenta proporciona quantificação de circularidade, valor capturado, conteúdo reciclado e índice de reuso (RESCOM, 2017b).

O Circularity Index (CI) é um indicador que mede a circularidade levando em consideração a multiplicação de dois fatores $(\alpha \beta)$ : $\alpha=$ material recuperado após fim de vida/demanda total do material; $\beta=1$ - energia requerida para recuperar o material/energia requerida para produção primária. Sendo assim, os dados para o cálculo referem-se à produção e reciclagem do material (CULLEN, 2017).

O Circularity Potential Indicator (CPI) é um indicador desenvolvido por meio de um questionário baseado nos quatro Building blocks da EC: 1) Design circular, 2) Novos modelos de negócios, 3) Ciclos reversos e 4) Condições facilitadoras e favoráveis do sistema (ELLEN MACARTHUR FOUNDATION, 2013b). O CPI objetiva avaliar o potencial de circularidade de produtos e providenciar características para melhoramentos (SAIDANI et al., 2019), além disso, monitorar a circularidade de produtos e práticas de negócios (SAIDANI et al., 2017).

O Closed Loop Calculator (CLC) foi desenvolvido por meio de dez perguntas que objetivam averiguar o quanto "fechado" pode ser o ciclo de um produto em particular (SAIDANI et al., 2019). As perguntas incluem: origem do produto, se ele pode ser alugado ou reparado e se pode ser desmontado em partes ou componentes. Esse indicador foi base para a criação do CEIP. Os conhecimento requerido para aplicar o indicador envolve a lista de materiais, tipo de embalagem, uso do produto e fim de vida (KINGFISHER, 2014).

O Ease of Disassembly Metric (eDiM) foi desenvolvido para o cálculo do tempo de desmonte de produtos. Foram propostas algumas categorias para esse indicador, sendo possível calcular em que etapa da desmontagem do produto há maior consumo de tempo. $\mathrm{O}$ objetivo do indicador é fazer com que as empresas que trabalham com a manutenção, recondicionamento e remanufatura, dentro do escopo da Economia Circular, possam avaliar com acurácia o tempo necessário para o desmonte e desenvolver estratégias de design que facilitem o mesmo (VANEGAS et al., 2018).

O Eco-efficient Value Ratio (EVR) é um valor baseado em modelos econômicos e na $\mathrm{ACV}$, ele mede a sustentabilidade em três dimensões: custos, valor de mercado e eco-costs que são custos requeridos para reduzir a poluição ou a depleção de materiais de um produto a um nível que esteja em equilíbrio com a capacidade suporte do meio (VOGTLÄNDER; BREZET; HENDRIKS, 2001). O EVR modela as ligações entre produção e problemas ambientais também com o lado do consumidor (SAIDANI et al., 2019). Um produto ou serviço pode ser "limpo" de acordo com um intervalo especificado. Os dados de entrada são: 
lista de materiais, preço de mercado, informação ambiental e práticas de negócio (SCHEEPENS; VOGTLÄNDER; BREZET, 2016).

O Economic-Environmental Indicators (EEI) é um conjunto de indicadores baseados em ACV e Custeio do Ciclo de Vida $(\mathrm{CCV})^{10}$ que permeiam as dimensões econômicas e ambientais. A proposta é aplicar indicadores em cada dimensão e em uma conjunção das duas, através da aplicação do método do Custo Global, incluindo, em termos monetários, os impactos ambientais (calculados como Energia Incorporada e Carbono Incorporado), custos de eliminação / desmantelamento e valor residual. O trabalho apresenta um estudo de caso com dois cenários aplicados na construção civil no norte da Itália (FREGONARA et al., 2017).

O Economic-environmental remanufacturing (EER) é uma ferramenta que permite que fornecedores possam avaliar rapidamente se a remanufatura é econômica e ambientalmente atraente comparada à produção de novos componentes. A ferramenta é aplicável a uma ampla variedade de fornecedores e indústrias que remanufaturam seus módulos ou subconjuntos, ou estão explorando a opção de participar de operações de remanufatura (VAN LOON; VAN WASSENHOVE, 2018).

O End-of-Life Recycling Rates (EoL-RRs) é a porcentagem do metal descartado que é realmente reciclado (reciclagem funcional) (SAIDANI et al., 2019). Os autores ainda sugerem um conjunto de métricas, discutindo relevantes aspectos de processos de reciclagem, e estimativas de taxas globais de reciclagem, além de: conteúdo reciclado, taxas de entradas de reciclagem e taxas de sucatas antigas (parcela de sucatas antigas no fluxo total de sucata). Os dados de entrada estão relacionados ao fluxo de materiais reciclados durante a produção e o fim de vida, ou seja, AFM (GRAEDEL et al., 2011).

O Input-Output Balance Sheet (IOBS) é um projeto piloto para medir a circularidade de produtos. É realizado por meio de avaliação de entradas e saídas de todos os recursos utilizados nas fases de instalação, manutenção e disposição final. Os tipos de recursos utilizados (renováveis e não renováveis) são quantificados e avaliados bem como a circularidade de materiais usados (reciclados, permanentemente reciclados e recicláveis) e se são biodegradáveis ou compostáveis (SAIDANI et al., 2019).

O Longevity and Circularity $(L \& C)$ mostra um gráfico com a combinação de dois indicadores, o de circularidade que inclui uso inicial, remanufatura e reciclagem e o de longevidade que inclui a duração inicial do produto, a duração acrescentada devido à

${ }^{10} \mathrm{O}$ Custeio do Ciclo de Vida (CCV) quantifica os impactos econômicos de um sistema de produto desde a aquisição de matérias-primas até o final da vida (ASIEDU; GU, 1998). 
remanufatura e a duração acrescentada devido à reciclagem. Ambos os indicadores possuem como saídas valores quantitativos (FIGGE et al., 2018).

O Material Circularity Indicator (MCI) é baseado na AFM e avalia preponderantemente produtos. Como entradas para se obter o indicador estão: porcentagem da matéria prima reutilizada ou remanufaturada, porcentagem da matéria prima reciclada, eficiência da reciclagem, porcentagem do pós-uso que pode ser reutilizável e porcentagem do pós-uso que pode ser reciclável. Além disso, há a vida útil do produto e sua unidade funcional. Como saída para o indicador há um valor entre 0 e 1, em que quanto maior esse valor, mais circular é o produto (ELLEN MACARTHUR FOUNDATION; GRANTA, 2015).

O Material Reutilization Part (C2C) é um dos cinco princípios da certificação Cradleto-Cradle (C2C, 2014). Além disso, certificação é também possui os outros quatro princípios de: Materiais Saudáveis; Energia Renovável; Gestão da Água e Responsabilidade Social. A certificação proporciona avaliar por meio de indicadores as condições dos negócios, do meio ambiente e dos impactos sociais de produtos. Dependendo da pontuação da empresa, essa pode ser avaliada em três níveis (ordem crescente de evolução): Básico, Bronze, Prata, Ouro e Platina. Dentro do princípio de Material Reutilization Part (materiais reutilizados), é proposto o seguinte cálculo: ( $\%$ do produto considerado reciclável ou compostável $) * 2+(\%$ do conteúdo reciclado ou rapidamente renovável)) $/ 3 * 100$. Sendo assim, dependendo do intervalo que o valor desse cálculo assume, o produto é classificado em um dos níveis (Básico, Bronze, Prata, Ouro e Platina) (C2C, 2014).

O Mine site MFA Indicator (MI) é um conjunto de indicadores aplicado na mineração e criados por meio da AFM. O trabalho apresenta indicadores que levam em consideração a produção, a reciclagem, os resíduos gerados, as perdas, a eficiência material, a área impactada, etc. Sendo assim busca mesclar elementos ambientais e econômicos (LÈBRE; CORDER; GOLEV, 2017).

O Multidimensional Indicator Set (MIS) é um conjunto de indicadores aplicados a resíduos de equipamentos eletroeletrônicos. É composto por quatro dimensões: Recuperação em peso do material alvo, Recuperação de materiais escassos, Fechamento de ciclos materiais e Impactos ambientais evitados. Esses indicadores podem ser concatenados em um índice único (NELEN et al., 2014).

O Product-Level circularity Metric (PCM) é um valor quantitativo que varia de 0 a 1. É uma métrica dada pela razão entre o valor econômico das partes recirculadas do produto e valor econômico de todas as partes. Sendo que a circularidade é definida como a fração do produto proveniente de produtos usados (ciclos abertos ou fechados). Os dados de entrada 
para o indicador permeiam a lista de materiais envolvendo custos para estimar o valor econômico (LINDER; SARASINI; VAN LOON, 2017).

O Recycling Indices (RIs) expressa a taxa total de reciclagem, com base nos elementos individuais recuperados (Material-RI) pelo processo para um produto específico. Os dados de entrada para calcular o indicador são baseados na lista de materiais e no fim de vida dos materiais. Os dados de saída do indicador podem ser vistos por meio de um gráfico que classifica cada elemento recuperado segundo a eficiência de reciclagem e também um resultado geral que varia de "A" a "G" para o produto, sendo "A" o mais eficiente e "G" o menos eficiente (VAN SCHAIK; REUTER, 2016).

O Recycling Rates (RRs) é dado pela razão entre os materiais reciclados e os resíduos gerados. Ele pode ser dividido entre ciclo aberto ou fechado. Para subsidiar esses cálculos é necessária a realização de uma AFM (HAUPT; VADENBO; HELLWEG, 2017). Além disso, leva-se também em consideração as taxas de coleta desses resíduos. Os dados de entrada do indicador são os materiais coletados que entram no processo de reciclagem e recursos secundários disponíveis produzidos a partir dos processos de reciclagem (SAIDANI et al., 2019).

O Resource Duration Indicator (RDI) é um valor quantitativo e ilustra o período de tempo durante o qual um material é retido em um sistema de produto (FRANKLINJOHNSON; FIGGE; CANNING, 2016). É uma métrica que ilustra a contribuição da retenção do material baseado na quantidade de tempo em que ele continua em uso. O indicador é composto pelos seguintes componentes: vida útil inicial, vida adicionada por meio do recondicionamento e da reciclagem (SAIDANI et al., 2019).

O Reuse Potential Indicator (RPI) é um valor quantitativo que varia entre 0 e 1 e indica a razão entre a porção economicamente reutilizável e o nível atual de geração, segundo a tecnologia vigente. É baseada, portanto em critérios econômicos e demonstra foco no reuso de materiais (PARK; CHERTOW, 2014). Sendo assim, o RPI indica o quanto um material é mais próximo de um recurso do que um resíduo por meio da tecnologia atual disponível, ou seja, quantifica a reutilização técnica. Como dados de entrada deve-se ter a lista de materiais, informações de toxicidade e tecnologias para o fim de vida (SAIDANI et al., 2019).

O Set of Indicators to Assess Sustainability (SIAS) é um grupo de indicadores baseados nas três dimensões da sustentabilidade: econômica, ambiental e social aplicado aos processos de remanufatura. Além disso, propõe um modelo de decisão para a empresa ser classificada em três níveis de sustentabilidade (GOLINSKA et al., 2015). 
O Sustainability Indicators (SI) é um grupo de indicadores em Economia Circular que leva em consideração o desenho e a modularidade de famílias de produtos, levantando aspectos também como a sua funcionalidade, reconfiguração, reuso e reciclabilidade (MESA; ESPARRAGOZA; MAURY, 2018).

Vale salientar que a indicadores focados especificamente na circularidade estão em um estágio inicial de desenvolvimento (ELIA; GNONI; TORNESE, 2017; GIURCO et al., 2014). A aplicação de alguns desses indicadores pode ser obtida em alguns trabalhos da literatura (LONCA et al., 2018; WALKER et al., 2018). Porém vale enfatizar que a Economia Circular por princípio é sistêmica, sendo necessária a aplicação de um conjunto de indicadores ao invés de um indicador único (GRIFFITHS; CAYZER, 2016).

No Quadro 2 estão descritos os indicadores de Economia Circular e suas vantagens e desvantagens de acordo com os seguintes critérios: relação com os princípios da Economia Circular, facilidade de uso e disponibilidade.

Quadro 2 - Análise dos indicadores de Economia Circular no nível micro

\begin{tabular}{|c|c|c|c|}
\hline & Indicador & Vantagens & Desvantagens \\
\hline 1 & $\begin{array}{l}\text { BIM-based } \\
\text { Whole-life } \\
\text { Performance } \\
\text { Estimator } \\
\text { (BWPE) }\end{array}$ & $\begin{array}{l}\text { Avaliação do desempenho de } \\
\text { projetos de construção civil. }\end{array}$ & $\begin{array}{l}\text { Restrição da Economia } \\
\text { Circular apenas no âmbito } \\
\text { do reuso e reciclagem. }\end{array}$ \\
\hline 2 & $\begin{array}{c}\text { Building } \\
\text { Circularity } \\
\text { Indicators (BCI) }\end{array}$ & $\begin{array}{c}\text { Aplicação de alguns } \\
\text { princípios da EC no contexto } \\
\text { da construção civil, levando } \\
\text { em consideração os tipos de } \\
\text { materiais utilizados. }\end{array}$ & $\begin{array}{l}\text { Necessidade de } \\
\text { conhecimento técnico prévio } \\
\text { acerca dos indicadores de } \\
\text { circularidade utilizados. } \\
\text { Disponibilização da planilha } \\
\text { Excel para cômputo do BCI } \\
\text { dependente do autor. }\end{array}$ \\
\hline 3 & $\begin{array}{l}\text { Circular Economy } \\
\text { Index(CEI) }\end{array}$ & $\begin{array}{l}\text { Possibilidade de avaliar a } \\
\text { reciclagem em termos } \\
\text { econômicos. }\end{array}$ & $\begin{array}{c}\text { Restrição da Economia } \\
\text { Circular apenas no âmbito } \\
\text { da reciclagem, além da } \\
\text { dificuldade de aplicação do } \\
\text { indicador devido a } \\
\text { inexistência de templates } \\
\text { mais práticos para aplicação } \\
\text { na empresa. }\end{array}$ \\
\hline 4 & $\begin{array}{l}\text { Circular Economy } \\
\text { Indicator }\end{array}$ & $\begin{array}{l}\text { Desenvolvido de acordo com } \\
\text { princípios da EC. Facilidade }\end{array}$ & $\begin{array}{l}\text { Disponibilização da planilha } \\
\text { de cálculo dependente do }\end{array}$ \\
\hline
\end{tabular}




\begin{tabular}{|c|c|c|c|}
\hline & Prototype (CEIP) & $\begin{array}{c}\text { de uso devido à planilha } \\
\text { desenvolvida para o cálculo. }\end{array}$ & autor. \\
\hline 5 & $\begin{array}{l}\text { Circular Economy } \\
\text { Measurement } \\
\text { Scale (CEMS) }\end{array}$ & $\begin{array}{l}\text { Desenvolvido para medir } \\
\text { práticas de EC no âmbito da } \\
\text { construção civil por meio de } \\
\text { um questionário em escala } \\
\text { likert. }\end{array}$ & $\begin{array}{c}\text { Falta de plataformas } \\
\text { (templates ou softwares) que } \\
\text { viabilizem os cálculos. }\end{array}$ \\
\hline 6 & $\begin{array}{l}\text { Circular Economy } \\
\text { Performance } \\
\text { Indicator (CEPI) }\end{array}$ & Baseado na técnica de ACV. & $\begin{array}{c}\text { Necessidade de } \\
\text { conhecimento técnico prévio } \\
\text { acerca da ACV e falta de } \\
\text { plataformas(templates ou } \\
\text { softwares) que viabilizem os } \\
\text { cálculos. }\end{array}$ \\
\hline 7 & $\begin{array}{l}\text { Circular Economy } \\
\text { Toolkit (CET) }\end{array}$ & $\begin{array}{l}\text { Baseado no ciclo de vida do } \\
\text { produto ou serviço. Facilidade } \\
\text { de acesso e aplicabilidade. }\end{array}$ & $\begin{array}{l}\text { Proporciona áreas para } \\
\text { melhoria segundo o ciclo de } \\
\text { vida do produto ou serviço } \\
\text { porém não indica quais } \\
\text { podem ser as melhorias ou } \\
\text { como podem ser aplicadas. }\end{array}$ \\
\hline 8 & $\begin{array}{c}\text { Circular } \\
\text { Pathfinder (CP) }\end{array}$ & $\begin{array}{l}\text { Baseado em práticas da EC, } \\
\text { como: prolongar, atualizar, } \\
\text { reutilizar, reparar, } \\
\text { recondicionar, remanufaturar, } \\
\text { reciclar e biodegradar. Fácil } \\
\text { acesso e utilização. }\end{array}$ & $\begin{array}{c}\text { Proporciona melhorias para } \\
\text { o produto apenas para o } \\
\text { redesign ou design do } \\
\text { mesmo. }\end{array}$ \\
\hline 9 & $\begin{array}{c}\text { Circularity } \\
\text { Calculator }(\mathrm{CC})\end{array}$ & $\begin{array}{l}\text { Desenvolvido segundo } \\
\text { práticas da EC voltadas para o } \\
\text { PSS e proporciona adequada } \\
\text { visão gráfica dos fluxos } \\
\text { materiais e financeiros. Além } \\
\text { de proporcionar valor } \\
\text { quantitativos de saída } \\
\text { referentes à circularidade, } \\
\text { valor capturado, conteúdo } \\
\text { reciclado e índice de reuso. }\end{array}$ & $\begin{array}{l}\text { Necessário investimento } \\
\text { financeiro para uso ilimitado } \\
\text { do indicador. Uso gratuito } \\
\text { limitado a um tempo } \\
\text { estabelecido e à algumas } \\
\text { ferramentas do indicador. } \\
\text { Além disso não disponibiliza } \\
\text { claramente os } \\
\text { procedimentos de cálculo } \\
\text { para obtenção das saídas } \\
\text { (circularidade, valor } \\
\text { capturado, conteúdo } \\
\text { reciclado e índice de reuso). }\end{array}$ \\
\hline 10 & $\begin{array}{l}\text { Circularity Index } \\
\text { (CI) }\end{array}$ & $\begin{array}{c}\text { Fórmulas práticas para cálculo } \\
\text { do indicador. }\end{array}$ & $\begin{array}{c}\text { Restrição da Economia } \\
\text { Circular apenas no âmbito } \\
\text { da reciclagem. }\end{array}$ \\
\hline 11 & Circularity & Desenvolvido através dos & Disponibilidade dependente \\
\hline
\end{tabular}




\begin{tabular}{|c|c|c|c|}
\hline & $\begin{array}{c}\text { Potential } \\
\text { Indicator (CPI) }\end{array}$ & $\begin{array}{l}\text { Building Blocks da EC. } \\
\text { Interface de uso prática para } \\
\text { usuários. }\end{array}$ & do autor. \\
\hline 12 & $\begin{array}{l}\text { Closed Loop } \\
\text { Calculator (CLC) }\end{array}$ & $\begin{array}{l}\text { Protótipo inicial de indicador } \\
\text { baseado em } 10 \text { perguntas. }\end{array}$ & $\begin{array}{c}\text { Dificuldade na } \\
\text { disponibilização do } \\
\text { indicador, pois os autores } \\
\text { pertencem a uma empresa } \\
\text { privada. Materiais escassos } \\
\text { para compreender os } \\
\text { critérios de cálculo } \\
\text { utilizados. }\end{array}$ \\
\hline 13 & $\begin{array}{c}\text { Ease of } \\
\text { Disassembly } \\
\text { Metric (eDiM) }\end{array}$ & $\begin{array}{l}\text { Indicador voltado para } \\
\text { importantes práticas da EC } \\
\text { como a desmontagem de } \\
\text { produtos. }\end{array}$ & $\begin{array}{l}\text { Disponibilização da planilha } \\
\text { de cálculo dependente do } \\
\text { autor. }\end{array}$ \\
\hline 14 & $\begin{array}{l}\text { Eco-efficient } \\
\text { Value Ratio } \\
\text { (EVR) }\end{array}$ & $\begin{array}{c}\text { Baseado em ACV e } \\
\text { informações econômicas. }\end{array}$ & $\begin{array}{c}\text { Alta complexidade para } \\
\text { aplicação. Necessidade de } \\
\text { conhecimento prévio de } \\
\text { ACV. }\end{array}$ \\
\hline 15 & $\begin{array}{c}\text { Economic- } \\
\text { Environmental } \\
\text { Indicators (EEI) }\end{array}$ & $\begin{array}{l}\text { Baseado em ACV e CCV } \\
\text { incorporando indicadores nas } \\
\text { dimensões ambiental e } \\
\text { econômica e interconectando } \\
\text { as duas. }\end{array}$ & $\begin{array}{l}\text { Alta complexidade para } \\
\text { aplicação. Necessidade de } \\
\text { conhecimento prévio de } \\
\text { ACV e CCV. }\end{array}$ \\
\hline 16 & $\begin{array}{l}\text { Economic- } \\
\text { environmental } \\
\text { remanufacturing } \\
\text { (EER) }\end{array}$ & $\begin{array}{l}\text { Permite acoplar aspectos } \\
\text { ambientais e econômicos à } \\
\text { remanufatura. }\end{array}$ & $\begin{array}{l}\text { Restrição da Economia } \\
\text { Circular apenas no âmbito } \\
\text { da remanufatura. }\end{array}$ \\
\hline 17 & $\begin{array}{l}\text { End-of-Life } \\
\text { Recycling Rates } \\
\text { (EoL-RRs) }\end{array}$ & $\begin{array}{l}\text { Indicador prático cujos } \\
\text { procedimentos de cálculo } \\
\text { estão disponíveis. }\end{array}$ & $\begin{array}{c}\text { Restrição da Economia } \\
\text { Circular apenas no âmbito } \\
\text { da reciclagem. }\end{array}$ \\
\hline 18 & $\begin{array}{l}\text { Input-Output } \\
\text { Balance Sheet } \\
\text { (IOBS) }\end{array}$ & $\begin{array}{l}\text { Baseados em informações } \\
\text { acerca da quantidade e } \\
\text { qualidade dos recursos } \\
\text { utilizados (renováveis e não } \\
\text { renováveis, reciclados, } \\
\text { permanentemente reciclados e } \\
\text { recicláveis, biodegradáveis e } \\
\text { compostáveis). }\end{array}$ & $\begin{array}{c}\text { Dificuldade na } \\
\text { disponibilização do } \\
\text { indicador, pois os autores } \\
\text { pertencem a uma empresa } \\
\text { privada. }\end{array}$ \\
\hline 19 & $\begin{array}{c}\text { Longevity and } \\
\text { Circularity (L\&C) }\end{array}$ & $\begin{array}{c}\text { Dois indicadores } \\
\text { desenvolvidos para medir o }\end{array}$ & $\begin{array}{l}\text { Dificuldades para a obtenção } \\
\text { de alguns dados de entrada }\end{array}$ \\
\hline
\end{tabular}




\begin{tabular}{|c|c|c|c|}
\hline & & $\begin{array}{l}\text { uso de produtos e a } \\
\text { durabilidade segundo algumas } \\
\text { práticas da EC, como } \\
\text { recondicionamento }\end{array}$ & $\begin{array}{l}\text { como a eficiência da } \\
\text { reciclagem, além de falta de } \\
\text { uma interface prática (como } \\
\text { uma planilha) disponível } \\
\text { para cálculo do mesmo. }\end{array}$ \\
\hline 20 & $\begin{array}{c}\text { Material } \\
\text { Circularity } \\
\text { Indicator (MCI) }\end{array}$ & $\begin{array}{l}\text { Facilidade de acesso e } \\
\text { utilização do indicador. } \\
\text { Aplicação rápida e prática, } \\
\text { caso sejam obtidos todos os } \\
\text { dados de entrada. }\end{array}$ & $\begin{array}{l}\text { Restrição da EC em apenas } \\
\text { algumas práticas como reuso } \\
\text { e reciclagem. Dificuldade da } \\
\text { obtenção de dados de } \\
\text { entrada, tais como: } \\
\text { destinação do produto após } \\
\text { o uso e eficiência do } \\
\text { processo de reciclagem. }\end{array}$ \\
\hline 21 & $\begin{array}{l}\text { Material } \\
\text { Reutilization Part } \\
\text { (C2C) }\end{array}$ & $\begin{array}{l}\text { Indicador qualitativo que } \\
\text { indica o nível de reutilização } \\
\text { em que o produto se encontra. }\end{array}$ & $\begin{array}{c}\text { Certificação por empresa } \\
\text { terceirizada, restringindo a } \\
\text { EC à práticas de reciclagem. }\end{array}$ \\
\hline 22 & $\begin{array}{l}\text { Mine site MFA } \\
\text { Indicator (MI) }\end{array}$ & $\begin{array}{l}\text { Conjunto de indicadores } \\
\text { aplicados na mineração } \\
\text { pautados na dimensão } \\
\text { econômica e ambiental. }\end{array}$ & $\begin{array}{l}\text { Restrição da EC apenas no } \\
\text { gerenciamento de resíduos. } \\
\text { Falta de ferramentas para } \\
\text { cômputo dos indicadores. }\end{array}$ \\
\hline 23 & $\begin{array}{l}\text { Multidimensional } \\
\text { Indicator Set } \\
\text { (MIS) }\end{array}$ & $\begin{array}{l}\text { Indicador quantitativo } \\
\text { multidimensional aplicado a } \\
\text { resíduos eletroeletrônicos. }\end{array}$ & $\begin{array}{l}\text { Restrição da EC apenas na } \\
\text { reciclagem. Falta de } \\
\text { ferramentas para cômputo } \\
\text { do indicador. }\end{array}$ \\
\hline 24 & $\begin{array}{l}\text { Product-Level } \\
\text { circularity Metric } \\
\text { (PCM) }\end{array}$ & $\begin{array}{l}\text { Relação entre recirculação de } \\
\text { materiais e valor econômico. }\end{array}$ & $\begin{array}{l}\text { Restrição da EC em apenas } \\
\text { algumas práticas como } \\
\text { reuso, remanufatura e } \\
\text { reciclagem. }\end{array}$ \\
\hline 25 & $\begin{array}{l}\text { Recycling Indices } \\
\text { (RIs) }\end{array}$ & $\begin{array}{c}\text { Indicador que expressa em } \\
\text { porcentagem a reciclagem de } \\
\text { um produto por meio de seus } \\
\text { elementos. }\end{array}$ & $\begin{array}{l}\text { Restrição da EC apenas no } \\
\text { âmbito da reciclagem. } \\
\text { Disponibilidade da } \\
\text { ferramenta dependente do } \\
\text { autor. }\end{array}$ \\
\hline 26 & $\begin{array}{l}\text { Recycling Rates } \\
\text { (RRs) }\end{array}$ & $\begin{array}{l}\text { Indicador que leva em } \\
\text { consideração a reciclagem em } \\
\text { ciclo aberto e fechado, além } \\
\text { das taxas de coleta dos } \\
\text { resíduos. }\end{array}$ & $\begin{array}{l}\text { Necessário conhecimento } \\
\text { prévio de AFM. Restrição da } \\
\text { EC apenas no âmbito da } \\
\text { reciclagem. }\end{array}$ \\
\hline 27 & $\begin{array}{c}\text { Resource } \\
\text { Duration } \\
\text { Indicator (RDI) }\end{array}$ & $\begin{array}{l}\text { Indicador que ilustra a } \\
\text { quantidade de tempo um } \\
\text { material permanece no }\end{array}$ & $\begin{array}{l}\text { Dificuldade de obtenção de } \\
\text { alguns dados de entrada, } \\
\text { como a eficiência do }\end{array}$ \\
\hline
\end{tabular}




\begin{tabular}{|c|c|c|c|}
\hline & & $\begin{array}{l}\text { sistema de produto. Ou seja, } \\
\text { quantificação de uma prática } \\
\text { importante para a EC, a } \\
\text { longevidade do produto. }\end{array}$ & processo de reciclagem. \\
\hline 28 & $\begin{array}{l}\text { Reuse Potential } \\
\text { Indicator (RPI) }\end{array}$ & $\begin{array}{c}\text { Indicador que leva em } \\
\text { consideração a tecnologia } \\
\text { disponível para tratar o } \\
\text { resíduo. }\end{array}$ & $\begin{array}{l}\text { Dificuldades na obtenção } \\
\text { dos dados de entrada, como } \\
\text { por exemplo a qualidade do } \\
\text { material usado na aplicação } \\
\text { específica e razões de } \\
\text { substituição. }\end{array}$ \\
\hline 29 & $\begin{array}{l}\text { Set of Indicators } \\
\text { to Assess } \\
\text { Sustainability } \\
\text { (SIAS) }\end{array}$ & $\begin{array}{l}\text { Grupo de indicadores em três } \\
\text { dimensões (econômica, social e } \\
\text { ambiental) voltado para a } \\
\text { prática de remanufatura. }\end{array}$ & $\begin{array}{l}\text { Falta de ferramentas } \\
\text { computacionais para facilitar } \\
\text { os cálculos. Restrição à uma } \\
\text { prática da EC (remanufatura). }\end{array}$ \\
\hline 30 & $\begin{array}{l}\text { Sustainability } \\
\text { Indicators (SI) }\end{array}$ & $\begin{array}{l}\text { Grupo de indicadores voltado } \\
\text { para práticas da EC como } \\
\text { design e a modularidade de } \\
\text { produtos, incluindo } \\
\text { funcionalidade, reconfiguração, } \\
\text { reuso, reciclabilidade. }\end{array}$ & $\begin{array}{l}\text { Dificuldades na obtenção de } \\
\text { dados, principalmente em } \\
\text { relação aos aspectos de fim } \\
\text { de vida dos produtos. }\end{array}$ \\
\hline
\end{tabular}

Fonte: traduzido de Rossi et al. (2019).

Dessa maneira, esses indicadores no nível micro ao se corresponderem aos componentes do modelo de negócios, mostram uma preponderância nos seguintes: atividades principais, recursos principais e proposta de valor, como visto na Figura 12.

Figura 12 - Relação dos indicadores micro com os componentes do modelo de negócio 


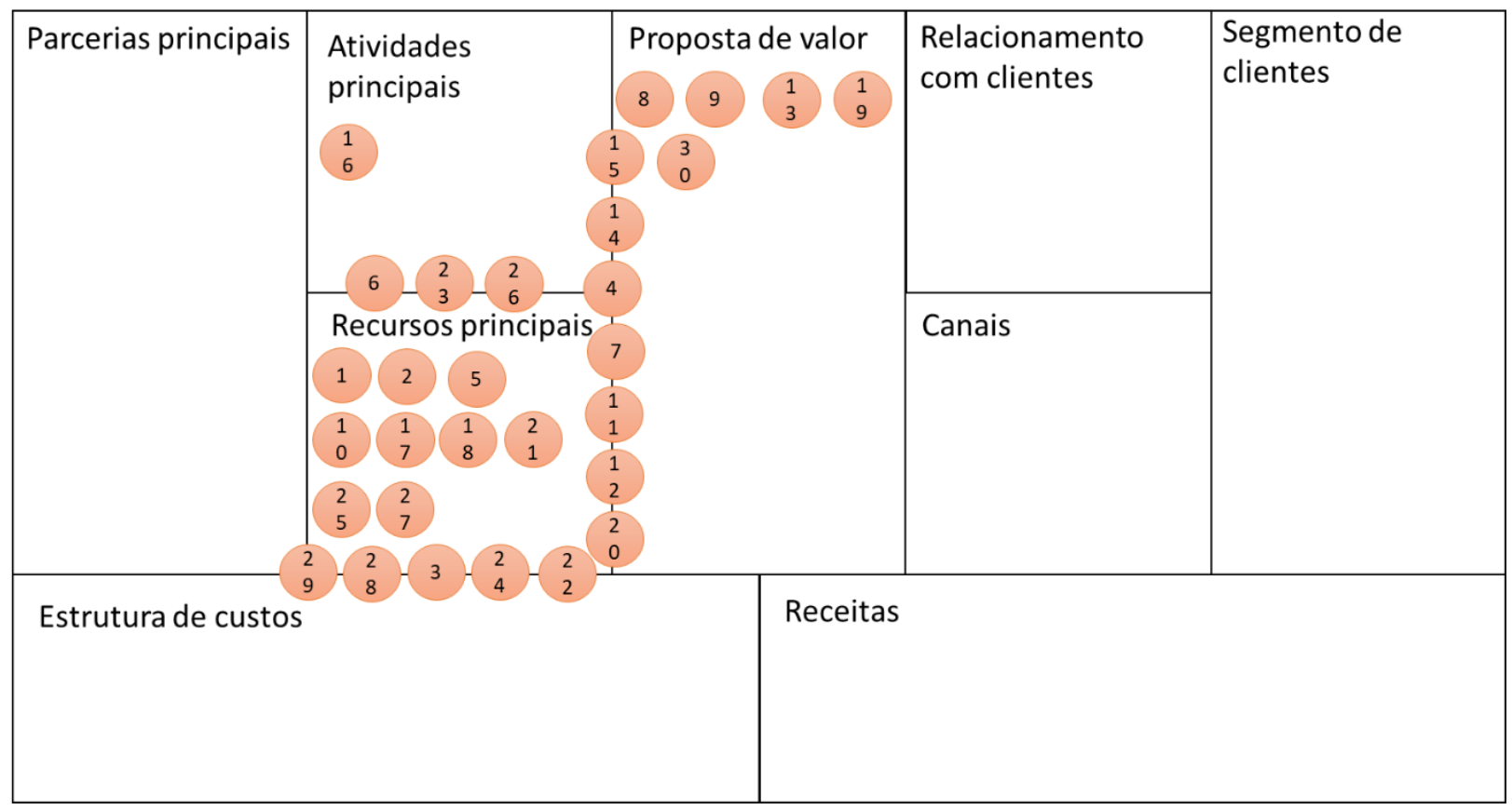

Fonte: elaboração própria.

Vale salientar que existem dois indicadores que ainda estão em testes de desenvolvimento. São estes: o Circulytics (ELLEN MACARTHUR FOUNDATION, 2020) e o Circular Transition Indicators (CTI) (WBCSD, 2020). O Circulytics permeia 18 indicadores nos seguintes temas: estratégia e planejamento, pessoas e habilidades, sistemas, processos e infraestrutura e engajamento externo. Além de 3 a 11 indicadores de entradas e saídas. Já o CTI é preponderantemente voltado para fluxos de materiais e energia, avaliando: entradas e saídas, circulação de água, energia renovável, materiais críticos e recuperação e circulação de materiais. Entretanto as plataformas para o uso de tais indicadores ainda são relativamente restritas.

\subsubsection{Indicadores no nível meso}

Os indicadores do nível meso descritos a seguir foram levantados por meio de pesquisa bibliográfica, vide Quadro 3 (PARCHOMENKO et al., 2019; SAIDANI et al., 2019). 
Quadro 3 - Indicadores de Economia Circular do nível meso

\begin{tabular}{|c|c|c|c|c|c|c|c|c|}
\hline & Indicador & Desempenho & Transversalidade & Dimensão & Unidade & Formato & Sustentabilidade & Referência \\
\hline 1 & $\begin{array}{l}\text { Assessing } \\
\text { Circular } \\
\text { Trade-offs } \\
\text { (ACT) }\end{array}$ & $\begin{array}{c}\text { Impactos } \\
\text { (benefícios da } \\
\text { EC) }\end{array}$ & Genérico & Múltiplo & Quantitativo & $\begin{array}{l}\text { Ferramenta } \\
\text { computacional } \\
\text { (contatar } \\
\text { autor) }\end{array}$ & $\begin{array}{l}\text { Ambiental e } \\
\text { Econômico }\end{array}$ & $\begin{array}{c}\text { (CIRCLE } \\
\text { ECONOMY, } \\
2015)\end{array}$ \\
\hline 2 & $\begin{array}{l}\text { Assessing } \\
\text { resource } \\
\text { productivity } \\
\text { for industrial } \\
\text { parks using } \\
\text { raw material } \\
\text { consumption } \\
\text { (ARMC) }\end{array}$ & $\begin{array}{l}\text { Impactos } \\
\text { ambientais }\end{array}$ & Genérico & Múltiplo & Quantitativo & $\begin{array}{l}\text { Fórmulas para } \\
\text { calcular }\end{array}$ & Ambiental & $\begin{array}{l}\text { (HU et al., } \\
\text { 2017) }\end{array}$ \\
\hline 3 & $\begin{array}{c}\text { Circle } \\
\text { Assessment } \\
\text { (CA) }\end{array}$ & $\begin{array}{c}\text { Impactos } \\
\text { (Econômicos) }\end{array}$ & Genérico & Múltiplo & Quantitativo & Website & Ambiental & $\begin{array}{c}\text { (CIRCLE } \\
\text { ECONOMY, } \\
2014)\end{array}$ \\
\hline 4 & $\begin{array}{c}\text { Circular } \\
\text { Benefits Tool } \\
\text { (CBT) }\end{array}$ & $\begin{array}{l}\text { Intrínseco e } \\
\text { Impactos } \\
\text { (Ambientais e } \\
\text { econômicos) }\end{array}$ & Genérico & Múltiplo & Quantitativo & $\begin{array}{c}\text { Fórmulas para } \\
\text { calcular }\end{array}$ & $\begin{array}{l}\text { Ambiental e } \\
\text { Econômico }\end{array}$ & $\begin{array}{c}\text { (ADVANCING } \\
\text { SUSTAINABIL } \\
\text { ITY LTD, } \\
2013 \text { ) }\end{array}$ \\
\hline 5 & $\begin{array}{c}\text { Circular } \\
\text { Economic } \\
\text { Value (CEV) } \\
\end{array}$ & Intrínseco & Genérico & Único & Quantitativo & $\begin{array}{l}\text { Fórmulas para } \\
\text { calcular }\end{array}$ & Ambiental & $\begin{array}{l}\text { (FOGARASSY } \\
\text { et al., 2017) }\end{array}$ \\
\hline 6 & $\begin{array}{l}\text { Circular } \\
\text { Economy } \\
\text { Company } \\
\text { Assessment } \\
\text { Criteria } \\
\text { (CECAC) } \\
\end{array}$ & Intrínseco & Genérico & Múltiplo & Qualitativo & $\begin{array}{l}\text { Ferramenta } \\
\text { computacional } \\
\text { (contatar } \\
\text { autor) }\end{array}$ & Social & (VBDO, 2015) \\
\hline 7 & $\begin{array}{l}\text { Circular } \\
\text { Economy } \\
\text { Toolbox US } \\
\text { (CETUS) }\end{array}$ & $\begin{array}{l}\text { Intrínseco e } \\
\text { Impactos } \\
\text { (Ambientais e } \\
\text { econômicos) }\end{array}$ & Genérico & Múltiplo & Quantitativo & $\begin{array}{c}\text { Fórmulas para } \\
\text { calcular }\end{array}$ & $\begin{array}{l}\text { Ambiental e } \\
\text { Econômico }\end{array}$ & $\begin{array}{c}\text { (US } \\
\text { CHAMBER OF } \\
\text { COMMERCE } \\
\text { FOUNDATION } \\
, 2017) \\
\end{array}$ \\
\hline
\end{tabular}




\begin{tabular}{|c|c|c|c|c|c|c|c|c|}
\hline Cont & Indicador & Desempenho & Transversalidade & Dimensão & Unidade & Formato & Sustentabilidade & Referência \\
\hline 8 & $\begin{array}{l}\text { Circularity } \\
\text { Assessment } \\
\text { Tool (CAT) }\end{array}$ & $\begin{array}{l}\text { Impactos } \\
\text { (valor) }\end{array}$ & Genérico & Múltiplo & Quantitativo & $\begin{array}{c}\text { Ferramenta } \\
\text { computacional } \\
\text { (contatar } \\
\text { autor) }\end{array}$ & Econômico & (PGGM, 2015) \\
\hline 9 & $\begin{array}{c}\text { Circularity } \\
\text { Indicator } \\
\text { Project (ICT) }\end{array}$ & $\begin{array}{l}\text { Intrínseco e } \\
\text { Impactos } \\
\text { (Econômicos) }\end{array}$ & Genérico & Múltiplo & Quantitativo & $\begin{array}{c}\text { Fórmulas para } \\
\text { calcular } \\
\text { (contatar } \\
\text { autor) } \\
\end{array}$ & $\begin{array}{l}\text { Ambiental e } \\
\text { Econômico }\end{array}$ & $\begin{array}{c}\text { (VIKTORIA } \\
\text { SWEDISH ICT, } \\
\text { 2015) }\end{array}$ \\
\hline 10 & $\begin{array}{c}\text { Circularity } \\
\text { material } \\
\text { indicator } \\
\text { (CIRC) }\end{array}$ & Intrínseco & Genérico & Único & Quantitativo & $\begin{array}{l}\text { Fórmulas para } \\
\text { calcular }\end{array}$ & Ambiental & $\begin{array}{c}\text { (PAULIUK et } \\
\text { al., 2017) }\end{array}$ \\
\hline 11 & $\begin{array}{c}\text { Emergy } \\
\text { analysis of an } \\
\text { industrial park } \\
\text { (EAIP) }\end{array}$ & $\begin{array}{l}\text { Intrínseco e } \\
\text { impactos } \\
\text { ambientais }\end{array}$ & Genérico & Múltiplo & Quantitativo & $\begin{array}{l}\text { Fórmulas para } \\
\text { calcular }\end{array}$ & Ambiental & $\begin{array}{l}\text { (GENG et al., } \\
\text { 2010) }\end{array}$ \\
\hline 12 & $\begin{array}{l}\text { Evaluation } \\
\text { Indicator } \\
\text { System of } \\
\text { Circular } \\
\text { Economy } \\
\text { (EISCE) } \\
\end{array}$ & Intrínseco & Específico & Múltiplo & Quantitativo & $\begin{array}{l}\text { Fórmulas para } \\
\text { calcular }\end{array}$ & $\begin{array}{l}\text { Ambiental e } \\
\text { Social }\end{array}$ & $\begin{array}{l}\text { (ZHOU; CHEN; } \\
\text { XIAO, 2013) }\end{array}$ \\
\hline 13 & $\begin{array}{l}\text { Five Category } \\
\text { Index Method } \\
\text { (FCIM) }\end{array}$ & Impactos & Genérico & Único & Quantitativo & $\begin{array}{l}\text { Fórmulas para } \\
\text { calcular }\end{array}$ & $\begin{array}{c}\text { Ambiental, } \\
\text { Econômico e } \\
\text { Social } \\
\end{array}$ & (LI; SU, 2012) \\
\hline 14 & $\begin{array}{c}\text { Hybrid LCA } \\
\text { Model } \\
\text { (HLCAM) }\end{array}$ & $\begin{array}{l}\text { Impactos } \\
\text { ambientais }\end{array}$ & Genérico & Múltiplo & Quantitativo & $\begin{array}{l}\text { Fórmulas para } \\
\text { calcular }\end{array}$ & Ambiental & $\begin{array}{c}\text { (GENOVESE et } \\
\text { al., 2017) }\end{array}$ \\
\hline
\end{tabular}




\begin{tabular}{|c|c|c|c|c|c|c|c|c|}
\hline Cont & Indicador & Desempenho & Transversalidade & Dimensão & Unidade & Formato & Sustentabilidade & Referência \\
\hline 15 & $\begin{array}{c}\text { Indicator } \\
\text { standards for } \\
\text { sector- } \\
\text { integrated } \\
\text { eco-industrial } \\
\text { parks (ISSEP) }\end{array}$ & $\begin{array}{l}\text { Intrínseco e } \\
\text { Impactos } \\
\text { (Ambientais, } \\
\text { econômicos e } \\
\text { sociais) }\end{array}$ & Genérico & Múltiplo & Quantitativo & $\begin{array}{l}\text { Fórmulas para } \\
\text { calcular }\end{array}$ & $\begin{array}{l}\text { Ambiental, } \\
\text { Econômico e } \\
\text { Social }\end{array}$ & $\begin{array}{l}\text { (GENG et al., } \\
\text { 2009) }\end{array}$ \\
\hline 16 & $\begin{array}{l}\text { Industrial } \\
\text { Park Circular } \\
\text { Economy } \\
\text { Indicator } \\
\text { System } \\
\text { (IPCEIS) } \\
\end{array}$ & $\begin{array}{l}\text { Intrínseco e } \\
\text { Impactos }\end{array}$ & Específico & Múltiplo & Quantitativo & $\begin{array}{c}\text { Fórmulas para } \\
\text { calcular }\end{array}$ & $\begin{array}{l}\text { Ambiental e } \\
\text { Econômico }\end{array}$ & $\begin{array}{l}\text { (GENG et al., } \\
\text { 2012) }\end{array}$ \\
\hline 17 & $\begin{array}{l}\text { Resource } \\
\text { Productivity } \\
\text { (RP) }\end{array}$ & Intrínseco & Genérico & Único & Quantitativo & $\begin{array}{l}\text { Fórmulas para } \\
\text { calcular }\end{array}$ & $\begin{array}{l}\text { Ambiental e } \\
\text { Econômico }\end{array}$ & $\begin{array}{c}\text { (WEN; MENG, } \\
\text { 2015) }\end{array}$ \\
\hline 18 & $\begin{array}{l}\text { Sustainable } \\
\text { Circular Index } \\
\text { (SCI) }\end{array}$ & $\begin{array}{l}\text { Intrínseco e } \\
\text { Impactos } \\
\text { (Sociais, } \\
\text { Ambientais e } \\
\text { Econômicos) }\end{array}$ & Genérico & $\begin{array}{c}\text { Único } \\
\text { (formado } \\
\text { por vários } \\
\text { indicadores } \\
\text { ) }\end{array}$ & Quantitativo & $\begin{array}{l}\text { Fórmulas para } \\
\text { calcular }\end{array}$ & $\begin{array}{l}\text { Ambiental, } \\
\text { Econômico e } \\
\text { Social }\end{array}$ & $\begin{array}{l}\text { (AZEVEDO; } \\
\text { GODINA; } \\
\text { MATIAS, 2017) }\end{array}$ \\
\hline 19 & $\begin{array}{l}\text { Value-based } \\
\text { Resource } \\
\text { Efficiency } \\
\text { (VRE) }\end{array}$ & $\begin{array}{l}\text { Impactos } \\
\text { (valor) }\end{array}$ & Genérico & Único & $\begin{array}{l}\text { Quantitativo } \\
(\% \text {, razão })\end{array}$ & $\begin{array}{l}\text { Fórmulas para } \\
\text { calcular }\end{array}$ & $\begin{array}{l}\text { Ambiental e } \\
\text { Econômico }\end{array}$ & $\begin{array}{l}\text { (DI MAIO et } \\
\text { al., 2017) }\end{array}$ \\
\hline
\end{tabular}

Fonte: adaptado de Saidani et al. (2019) 
O Assessing Circular Trade-offs (ACT) permite avaliar os efeitos de atividades circulares. A ferramenta analisa cenários de fim de vida de produtos além de oferecer propostas para recuperar o valor do produto modificando as circunstâncias de mercado e custos de produção. Sendo assim, a ferramenta permite: identificar casos de negócio e tradeoffs para diferentes cenários de reuso, avaliar efeitos de mudanças de variáveis de entrada, biblioteca com casos padrão para possibilitar oportunidades para construção de novos casos (CIRCLE ECONOMY, 2015).

O Assessing resource productivity for industrial parks using raw material consumption (ARMC) é um conjunto de indicadores voltados para materiais e energia para parques industriais. Eles foram aplicados em um parque industrial na China (HU et al., 2017).

O Circle Assessment (CA) permite que stakeholders avaliem as organizações baseados em como eles incorporam os princípios de EC e implementam em suas políticas. O CA é realizado por meio de uma pesquisa online que possibilita as organizações quantificarem níveis de circularidade e identificarem oportunidades para minimizar riscos futuros, adotando práticas de negócio circulares (SAIDANI et al., 2019).

O Circular Benefits Tool (CBT) é um modelo que permite calcular os resíduos não gerados, o uso evitado de material virgem, e as emissões evitadas de gás carbônico. Além disso, busca capturar o valor financeiro diretamente capturado. Como dados de entrada devese ter o Inventário do Ciclo de Vida do produto estudado (SAIDANI et al., 2019).

O Circular Economic Value (CEV) é um indicador baseado em fatores materiais e energéticos. É divido em dois componentes principais: fluxo de materiais buscando o fechamento de ciclos (taxas de uso de materiais virgens) e produção de resíduos. Além disso, há entradas e saídas para fluxos de energia, também (FOGARASSY et al., 2017).

O Circular Economy Company Assessment Criteria (CECAC) é um indicador qualitativo dividido em quatro áreas: estratégia e governança, implementação, inovação e comunicação e envolvimento. É formado por um conjunto de perguntas em cada uma dessas áreas com seus respectivos pesos (VBDO, 2015).

O Circular Economy Toolbox US (CETUS) é um conjunto de onze indicadores: quantidade de materiais recuperados, pegada de carbono, ganhos econômicos de custos por locação, impactos evitados, produção de $\mathrm{kWh}$, tempo de retorno, composição percentual do material, porcentagem recuperada, porcentagem reciclável, progresso através de objetivos e retorno do investimento (US CHAMBER OF COMMERCE FOUNDATION, 2017).

O Circularity Assessment Tool (CAT) busca estabelecer um padrão global para auxiliar investidores e companhias a avaliar as organizações para criar valor por meio dos princípios 
da EC, compreendendo quão resilientes estão de acordo com riscos sistêmicos. A ferramenta permite avaliar o desempenho de qualquer organização diante dos objetivos da EC. Os resultados permitem que os investidores analisem a circularidade das empresas em seu portfólio e colaborem para melhorar seu desempenho, a fim de reduzir riscos, capitalizar novas oportunidades e permitir crescimento à longo prazo (SAIDANI et al., 2019).

O Circularity Indicator Project (ICT) considera três aspectos: valor retido, uso de materiais recirculados e ciclo de oferta de produto. O primeiro aspecto implica em como o modelo de negócio permite que a companhia mantenha o valor do produto ao invés de transferi-lo ao consumidor. O segundo mede a quantidade de matéria prima que foi recirculada. E o último refere-se à ciclagem que o produto oferece (SAIDANI et al., 2019).

O Circularity material indicator (CIRC) é um indicador de medida relativa da massa acumulada de aço presente em um sistema durante um certo intervalo de tempo em termos de um caso de referência ideal, onde todo o aço permanece em aplicações funcionais durante todo o período contábil (PAULIUK et al., 2017).

O Emergy analysis of an industrial park (EAIP) é um conjunto de indicadores baseado em análises de emergia ${ }^{11}$. O método desenvolvido possibilita avaliar o desempenho ambiental e os demais aspectos da sustentabilidade. Foi realizado um estudo de caso para exemplificar a aplicação dos indicadores em um ecoparque industrial na China (GENG et al., 2010).

O Evaluation Indicator System of Circular Economy (EISCE) é composto por três índices: entrada de recurso e consumo, fluxo de recurso e reciclagem e saída de recurso e gestão (ZHOU; CHEN; XIAO, 2013).

O Five Category Index Method (FCIM) é um conjunto de indicadores formados por cinco categorias: desenvolvimento econômico, exploração de recursos, redução de poluição, eficiência ecológica e potencial de desenvolvimento. Cada categoria possui indicadores específicos e ao final, por meio de uma ponderação, há o cálculo de um índice único, ranqueado entre baixo, médio, bom e excelente, de acordo com o desenvolvimento da EC nas empresas químicas na China (LI; SU, 2012).

O Hybrid LCA Model (HLCAM) combina ACV tradicional com análise ambiental input-output ${ }^{12}$ para comparar o desempenho de sistemas de produção linear e circular. O foco do estudo refere-se a emissões de gás carbônico e a aplicação foi feita em dois estudos de caso na indústria química e de alimentos (GENOVESE et al., 2017).

\footnotetext{
${ }^{11}$ A Emergia é baseada na energia e qualidade de energia como as principais forças motrizes por trás dos sistemas e ecossistemas (GENG et al., 2010).

${ }^{12}$ A análise Input-output é uma técnica que atribui a poluição ou uso de recursos para a demanda final por meio de uma estrutura definida, ou seja, contabiliza pressões ambientais (WIEDMANN, 2009).
} 
O Indicator standards for sector-integrated eco-industrial parks (ISSEP) é um conjunto de vinte e um indicadores divididos em quatro categorias: desenvolvimento econômico, redução de materiais e reciclagem, controle da poluição e gestão e administração. Possui a explicação dos cálculos dos indicadores e como realizar a coleta de dados, porém não traz exemplos de estudos de caso (GENG et al., 2009).

O Industrial Park Circular Economy Indicator System (IPCEIS) é um conjunto de indicadores divididos em quatro categorias: taxa de saída de recursos, taxa de consumo de recursos, taxa de utilização de recursos e emissão de poluentes e disposição de resíduos. Dessas categorias, há especificação de 12 indicadores. O IPCEIS é baseado na AFM. (GENG et al., 2012).

O Resource Productivity (RP) (quantidade de materiais ou serviços obtida através de recursos unitários, em termos monetários) foi aplicado conjuntamente com o Substance Flow Analysis (SFA) ${ }^{13}$, para avaliar a contribuição da simbiose industrial para o desenvolvimento da EC. Através de questionários e levantamentos de campo em empresas chinesas, foram aplicados o Substance Flow Analysis (SFA) com o Resource Productivity (RP) em materiais básicos (cobre, água e energia) na produção de placas de circuito impresso sob dois cenários: excluindo a utilização de resíduos. e incluindo a utilização de resíduos (WEN; MENG, 2015).

O Sustainable Circular Index (SCI) é um índice formado por quatro dimensões: Social, Econômico, Ambiental e Circularidade. Cada dimensão possui seus indicadores. Para o cálculo do índice são realizados processos de ponderação, normalização e agregação dos indicadores. $\mathrm{O}$ índice foi criado para ser usado em empresas de manufatura. Entretanto, não há estudos de caso para exemplificar o cálculo (AZEVEDO; GODINA; MATIAS, 2017).

O Value-based Resource Efficiency (VRE) é a razão entre o valor adicionado e o valor das entradas. A circularidade é expressa como a porcentagem do valor de recursos escassos incorporados em um serviço ou produto que retorna após seu fim de vida. O trabalho compara o VRE com o tradicional indicador de eficiência de recursos (valor adicionado/kg de entrada de materiais) (DI MAIO et al., 2017).

No Quadro 4 estão descritos os indicadores de Economia Circular e suas vantagens e desvantagens de acordo com os seguintes critérios: relação com os princípios da Economia Circular, facilidade de uso e disponibilidade.

Quadro 4 - Análise dos indicadores de Economia Circular no nível meso.

13 Substance Flow Analysis (SFA) é similar à AFM, porém aplicado a substâncias individuais (elementos químicos ou componentes) (BRUNNER, 2012). 


\begin{tabular}{|c|c|c|c|}
\hline & Indicador & Vantagens & Desvantagens \\
\hline 1 & $\begin{array}{l}\text { Assessing } \\
\text { Circular Trade- } \\
\text { offs (ACT) }\end{array}$ & $\begin{array}{l}\text { Ferramenta que possibilita criar } \\
\text { diversos cenários para todo o } \\
\text { ciclo de vida do produto. }\end{array}$ & $\begin{array}{c}\text { Disponibilização da } \\
\text { ferramenta dependente do } \\
\text { autor. }\end{array}$ \\
\hline 2 & $\begin{array}{l}\text { Assessing } \\
\text { resource } \\
\text { productivity } \\
\text { for industrial } \\
\text { parks using } \\
\text { raw material } \\
\text { consumption } \\
\text { (ARMC) }\end{array}$ & $\begin{array}{l}\text { Conjunto de indicadores } \\
\text { materiais desenvolvidos para } \\
\text { parques industriais. }\end{array}$ & $\begin{array}{l}\text { Restrição da EC apenas no } \\
\text { âmbito material. Falta de } \\
\text { ferramentas computacionais } \\
\text { para facilitar os cálculos. }\end{array}$ \\
\hline 3 & $\begin{array}{l}\text { Circle } \\
\text { Assessment } \\
\quad(\mathrm{CA})\end{array}$ & $\begin{array}{l}\text { Ferramenta desenvolvida } \\
\text { segundo princípios da EC. }\end{array}$ & $\begin{array}{c}\text { Disponibilização da } \\
\text { ferramenta dependente do } \\
\text { autor. }\end{array}$ \\
\hline 4 & $\begin{array}{l}\text { Circular } \\
\text { Benefits Tool } \\
\quad(\mathrm{CBT})\end{array}$ & $\begin{array}{l}\text { Modelo voltado para quantificar } \\
\text { impactos evitados no ciclo de } \\
\text { vida do produto. }\end{array}$ & $\begin{array}{c}\text { Disponibilização da } \\
\text { ferramenta dependente do } \\
\text { autor. }\end{array}$ \\
\hline 5 & $\begin{array}{c}\text { Circular } \\
\text { Economic } \\
\text { Value (CEV) }\end{array}$ & $\begin{array}{c}\text { Indicador que leva em } \\
\text { consideração fluxo de materiais e } \\
\text { energia para o ciclo de vida do } \\
\text { produto. }\end{array}$ & $\begin{array}{l}\text { Falta de ferramentas } \\
\text { computacionais para facilitar } \\
\text { os cálculos. }\end{array}$ \\
\hline 6 & $\begin{array}{l}\text { Circular } \\
\text { Economy } \\
\text { Company } \\
\text { Assessment } \\
\text { Criteria } \\
\text { (CECAC) }\end{array}$ & $\begin{array}{l}\text { Indicador qualitativo composto } \\
\text { por estratégia e governança, } \\
\text { implementação, inovação e } \\
\text { comunicação e envolvimento. }\end{array}$ & $\begin{array}{c}\text { Disponibilização da } \\
\text { ferramenta dependente do } \\
\text { autor. }\end{array}$ \\
\hline 7 & $\begin{array}{l}\text { Circular } \\
\text { Economy } \\
\text { Toolbox US } \\
\text { (CETUS) }\end{array}$ & $\begin{array}{c}\text { Conjunto de indicadores voltados } \\
\text { para impactos ambientais e } \\
\text { econômicos. }\end{array}$ & $\begin{array}{l}\text { Falta de ferramentas } \\
\text { computacionais para facilitar } \\
\text { os cálculos. }\end{array}$ \\
\hline 8 & $\begin{array}{l}\text { Circularity } \\
\text { Assessment } \\
\text { Tool (CAT) }\end{array}$ & $\begin{array}{l}\text { Conjunto de indicadores que } \\
\text { busca atrelar a criação de valor } \\
\text { diante dos princípios da EC. }\end{array}$ & $\begin{array}{c}\text { Disponibilização da } \\
\text { ferramenta dependente do } \\
\text { autor. }\end{array}$ \\
\hline 9 & $\begin{array}{l}\text { Circularity } \\
\text { Indicator } \\
\text { Project (ICT) }\end{array}$ & $\begin{array}{l}\text { Conjunto de indicadores que } \\
\text { busca medir o valor nos modelos } \\
\text { de negócio para o fechamento de } \\
\text { ciclos. }\end{array}$ & $\begin{array}{l}\text { Falta de ferramentas } \\
\text { computacionais para facilitar } \\
\text { os cálculos. } \\
\text { Disponibilização do material }\end{array}$ \\
\hline
\end{tabular}




\begin{tabular}{|c|c|c|c|}
\hline & & & dependente do autor. \\
\hline 10 & $\begin{array}{l}\text { Circularity } \\
\text { material } \\
\text { indicator } \\
(\text { CIRC) }\end{array}$ & $\begin{array}{c}\text { Indicador que leva em } \\
\text { consideração o ciclo de vida do } \\
\text { material. }\end{array}$ & $\begin{array}{l}\text { Restrição da EC apenas no } \\
\text { âmbito material. Falta de } \\
\text { ferramentas computacionais } \\
\text { para facilitar os cálculos. }\end{array}$ \\
\hline 11 & $\begin{array}{c}\text { Emergy } \\
\text { analysis of an } \\
\text { industrial park } \\
\text { (EAIP) }\end{array}$ & $\begin{array}{l}\text { Indicador baseado em análises de } \\
\text { emergia para parques industriais. }\end{array}$ & $\begin{array}{l}\text { Necessidade de } \\
\text { conhecimento técnico prévio } \\
\text { acerca de emergia. Falta de } \\
\text { ferramentas computacionais } \\
\text { para facilitar os cálculos. }\end{array}$ \\
\hline 12 & $\begin{array}{l}\text { Evaluation } \\
\text { Indicator } \\
\text { System of } \\
\text { Circular } \\
\text { Economy } \\
\text { (EISCE) }\end{array}$ & $\begin{array}{l}\text { Conjunto de indicadores que } \\
\text { buscam medir as entradas e } \\
\text { saídas de materiais. }\end{array}$ & $\begin{array}{l}\text { Restrição da EC apenas no } \\
\text { âmbito material. Falta de } \\
\text { ferramentas computacionais } \\
\text { para facilitar os cálculos. }\end{array}$ \\
\hline 13 & $\begin{array}{l}\text { Five Category } \\
\text { Index Method } \\
\text { (FCIM) }\end{array}$ & $\begin{array}{c}\text { Índice que mensura o } \\
\text { desenvolvimento da EC por meio } \\
\text { de cinco categorias. }\end{array}$ & $\begin{array}{c}\text { Falta de ferramentas } \\
\text { computacionais para facilitar } \\
\text { os cálculos. Dificuldade na } \\
\text { obtenção de alguns dados de } \\
\text { entrada. }\end{array}$ \\
\hline 14 & $\begin{array}{l}\text { Hybrid LCA } \\
\text { Model } \\
\text { (HLCAM) }\end{array}$ & $\begin{array}{l}\text { Baseado em ACV e Análise } \\
\text { Input-output. }\end{array}$ & $\begin{array}{l}\text { Restrição da EC apenas no } \\
\text { âmbito material. } \\
\text { Necessidade de } \\
\text { conhecimento técnico prévio } \\
\text { de ACV e Análise Input- } \\
\text { output. }\end{array}$ \\
\hline 15 & $\begin{array}{l}\text { Indicator } \\
\text { standards for } \\
\quad \text { sector- } \\
\text { integrated eco- } \\
\text { industrial parks } \\
\quad \text { (ISSEP) }\end{array}$ & $\begin{array}{c}\text { Desenvolvido para mensurar } \\
\text { ecoparques industriais nas } \\
\text { dimensões da sustentabilidade. }\end{array}$ & $\begin{array}{c}\text { Falta de ferramentas } \\
\text { computacionais para facilitar } \\
\text { os cálculos. }\end{array}$ \\
\hline 16 & $\begin{array}{l}\text { Industrial Park } \\
\text { Circular } \\
\text { Economy } \\
\text { Indicator } \\
\text { System } \\
\text { (IPCEIS) }\end{array}$ & Baseado na AFM. & $\begin{array}{l}\text { Restrição da EC apenas no } \\
\text { âmbito material. } \\
\text { Necessidade de } \\
\text { conhecimento técnico prévio } \\
\text { de AFM. }\end{array}$ \\
\hline 17 & $\begin{array}{l}\text { Resource } \\
\text { Productivity }\end{array}$ & $\begin{array}{l}\text { Baseado no Substance Flow } \\
\text { Analysis (SFA) com o Resource }\end{array}$ & $\begin{array}{c}\text { Necessidade de } \\
\text { conhecimentos técnicos }\end{array}$ \\
\hline
\end{tabular}




\begin{tabular}{|c|c|c|c|}
\hline & (RP) & $\begin{array}{c}\text { Productivity (RP) para avaliar } \\
\text { simbiose industrial. }\end{array}$ & acerca de SFA e RP. \\
\hline 18 & $\begin{array}{c}\text { Sustainable } \\
\text { Circular Index } \\
\text { (SCI) }\end{array}$ & $\begin{array}{c}\text { Índice pautado nas dimensões da } \\
\text { sustentabilidade e na } \\
\text { circularidade. }\end{array}$ & $\begin{array}{c}\text { Falta de ferramentas } \\
\text { computacionais para facilitar } \\
\text { os cálculos. Falta de } \\
\text { exemplos para aplicação } \\
\text { prática. }\end{array}$ \\
\hline 19 & $\begin{array}{c}\text { Value-based } \\
\text { Resource }\end{array}$ & Indicador baseado no valor de \\
Efficiency & recursos. & $\begin{array}{c}\text { Falta de ferramentas } \\
\text { computacionais para facilitar } \\
\text { os cálculos. }\end{array}$ \\
& (VRE) & & \\
\hline
\end{tabular}

Fonte: elaboração própria.

Dessa maneira, esses indicadores no nível meso, ao se corresponderem aos componentes do modelo de negócio, mostram uma preponderância nos seguintes: atividades principais, recursos principais e proposta de valor, como visto na Figura 13.

Figura 13 - Relação dos indicadores meso com os componentes do modelo de negócio

\begin{tabular}{|c|c|c|c|c|c|}
\hline \multirow[t]{2}{*}{ Parcerias principais } & $\begin{array}{l}\text { Atividades } \\
\text { principais }\end{array}$ & \multirow{2}{*}{\multicolumn{2}{|c|}{$\begin{array}{l}\text { Proposta de valor } \\
8\end{array}$}} & $\begin{array}{l}\text { Relacionamento } \\
\text { com clientes }\end{array}$ & $\begin{array}{l}\text { Segmento de } \\
\text { clientes }\end{array}$ \\
\hline & Recursos & & & Canais & \\
\hline Estrutura de custos & & & Receita & & \\
\hline
\end{tabular}

Fonte: elaboração própria. 
5 RESULTADOS E DISCUSSÃO

\subsection{Primeira versão do índice para Economia Circular}

Para a primeira versão do índice, adotou-se as variáveis presentes no Quadro 5. 
Quadro 5 - Proposta para elementos chave a serem medidos

\begin{tabular}{|c|c|c|c|c|}
\hline & Princípioo $^{14}$ & Elementos chaves & Resposta $^{15}$ & Referência \\
\hline \multirow{4}{*}{$\begin{array}{l}\text { Modelo de } \\
\text { negócio }\end{array}$} & 3 & O modelo de negócio é circular? & Sim-1; Não-0 & $\begin{array}{c}\text { (CONFEDERAÇÃO } \\
\text { NACIONAL DA INDÚSTRIA, } \\
\text { 2018) }\end{array}$ \\
\hline & 3 & $\begin{array}{l}\text { Há ganhos econômicos com o modelo de } \\
\text { negócio? }\end{array}$ & Sim-1; Não-0 & Elaboração própria \\
\hline & 3 & Há ganhos sociais com o modelo de negócio? & Sim-1; Não-0 & Elaboração própria \\
\hline & 3 & $\begin{array}{l}\text { Há ganhos ambientais com o modelo de } \\
\text { negócio? }\end{array}$ & Sim-1; Não-0 & (HUYSMAN et al., 2017) \\
\hline \multirow{7}{*}{$\begin{array}{l}\text { Planejament } \\
\text { o do produto }\end{array}$} & 1 & O produto é modular? & Sim-1; Não-0 & $\begin{array}{c}\text { (DE LOS RIOS; CHARNLEY, } \\
\text { 2017) }\end{array}$ \\
\hline & 3 & O produto é facilmente desmontável? & Sim-1; Não-0 & (EVANS; BOCKEN, 2013) \\
\hline & 2 & O produto é desenhado para reuso? & Sim-1; Não-0 & $\begin{array}{c}\text { (DE LOS RIOS; CHARNLEY, } \\
\text { 2017) }\end{array}$ \\
\hline & 2 & O produto é mais leve que sua versão anterior? & Sim-1; Não-0 & (GRIFFITHS; CAYZER, 2016) \\
\hline & 2 & O produto é desenhado para ser durável? & Sim-1; Não-0 & Elaboração própria \\
\hline & 3 & O produto é desenhado para ser reciclado? & Sim-1; Não-0 & $\begin{array}{l}\text { (DE LOS RIOS; CHARNLEY, } \\
\text { 2017) }\end{array}$ \\
\hline & 1 & Há uso da biomimética? & Sim-1; Não-0 & $\begin{array}{l}\text { (DE LOS RIOS; CHARNLEY, } \\
\text { 2017) }\end{array}$ \\
\hline Extração & 1 & Qual a porcentagem do produto é proveniente & $0-100 \%$ & (ELLEN MACARTHUR \\
\hline
\end{tabular}

${ }^{14}$ Ellen MacArthur Foundation et al. (2015), sendo Princípio 1: Preservar e aumentar o capital natural, controlando estoques finitos e equilibrando os fluxos de recursos renováveis. Princípio 2: Otimizar a produção de recursos, fazendo circular produtos, componentes e materiais no mais alto nível de utilidade o tempo todo, tanto no ciclo técnico quanto no biológico. Princípio 3: Fomentar a efetividade do sistema, revelando as externalidades negativas e excluindo-as dos projetos.

${ }^{15}$ Respostas das empresas e pontuação recebida. 


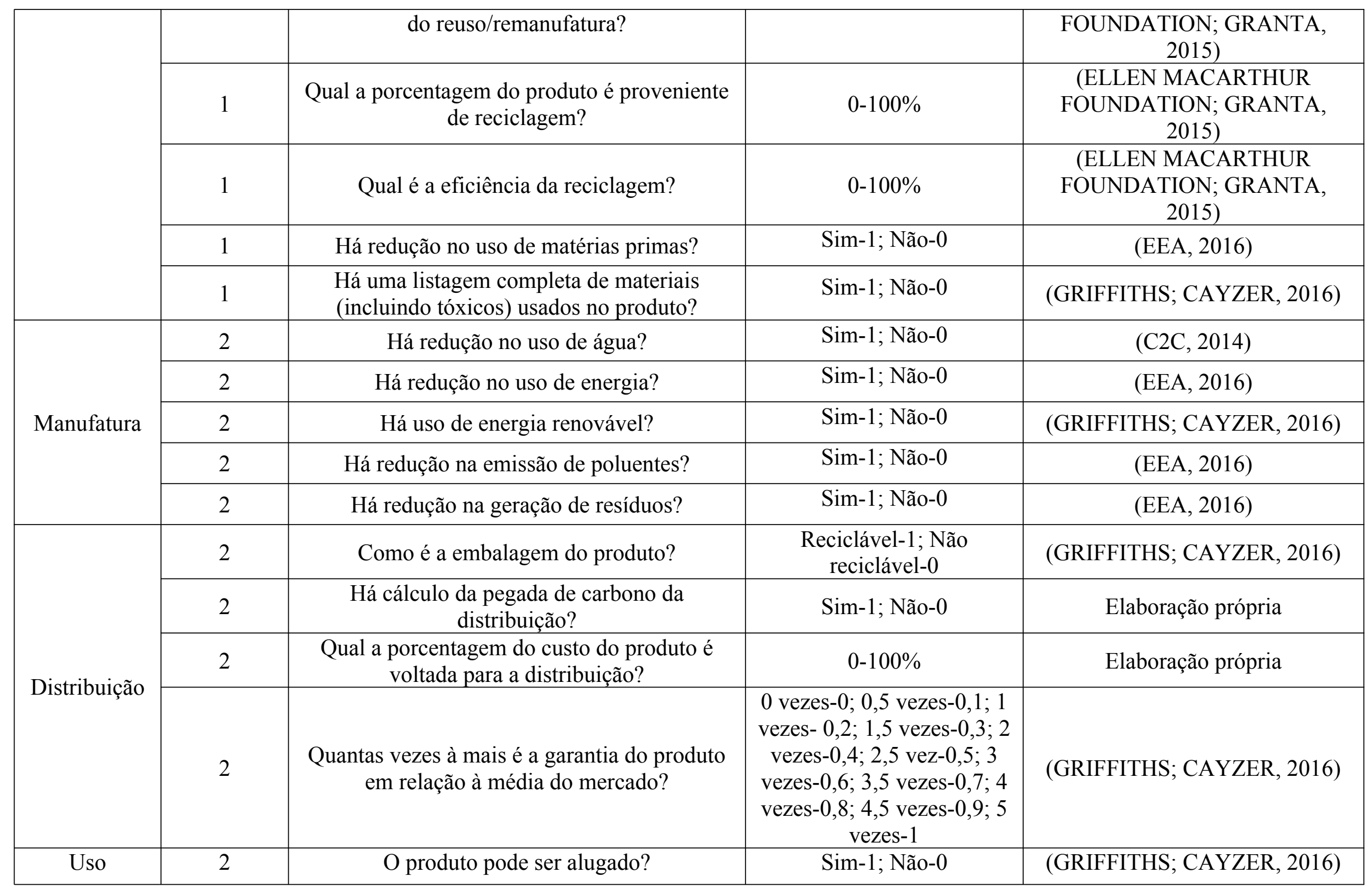




\begin{tabular}{|c|c|c|c|c|}
\hline & 2 & O produto pode ser desmaterializado? & Sim-1; Não-0 & Elaboração própria \\
\hline & 2 & $\begin{array}{l}\text { Quantas vezes à mais é a durabilidade do } \\
\text { produto em relação à média do mercado? }\end{array}$ & $\begin{array}{c}0 \text { vezes- } 0 ; 0,5 \text { vezes- } 0,1 ; 1 \\
\text { vezes- } 0,2 ; 1,5 \text { vezes- } 0,3 ; 2 \\
\text { vezes- } 0,4 ; 2,5 \text { vez- } 0,5 ; 3 \\
\text { vezes- } 0,6 ; 3,5 \text { vezes- } 0,7 ; 4 \\
\text { vezes- } 0,8 ; 4,5 \text { vezes- } 0,9 ; 5 \\
\quad \text { vezes- } 1 \\
\end{array}$ & $\begin{array}{l}\text { (ELLEN MACARTHUR } \\
\text { FOUNDATION; GRANTA, } \\
\text { 2015; FRANKLIN-JOHNSON; } \\
\text { FIGGE; CANNING, 2016) }\end{array}$ \\
\hline & 2 & Há medição de circularidade do produto? & Sim-1; Não-0 & (FIGGE et al., 2018) \\
\hline & 2 & O produto gasta menos energia no seu uso? & Sim-1; Não-0 & (EVANS; BOCKEN, 2013) \\
\hline & 2 & $\begin{array}{l}\text { Há oferecimento de manutenção para o } \\
\text { produto? }\end{array}$ & Sim-1; Não-0 & (GRIFFITHS; CAYZER, 2016) \\
\hline \multirow{7}{*}{ Fim de vida } & 3 & $\begin{array}{l}\text { Há oferecimento de logística reversa para o } \\
\text { produto? }\end{array}$ & Sim-1; Não-0 & (GRIFFITHS; CAYZER, 2016) \\
\hline & 3 & $\begin{array}{l}\text { Qual é a porcentagem dos produtos que } \\
\text { retornam? }\end{array}$ & $0-100 \%$ & (FIGGE et al., 2018) \\
\hline & 3 & $\begin{array}{l}\text { Há incentivos financeiros para o consumidor } \\
\text { para a logística reversa? }\end{array}$ & Sim-1; Não-0 & Elaboração própria \\
\hline & 3 & $\begin{array}{l}\text { Qual é a porcentagem do produto que pode ser } \\
\text { reutilizável após seu uso? }\end{array}$ & $0-100 \%$ & $\begin{array}{c}\text { (LINDER; SARASINI; VAN } \\
\text { LOON, 2017) }\end{array}$ \\
\hline & 3 & $\begin{array}{l}\text { Qual é a porcentagem do produto que pode ser } \\
\text { reciclável após seu uso? }\end{array}$ & $0-100 \%$ & (DI MAIO; REM, 2015) \\
\hline & 3 & Qual é a eficiência da reciclagem? & $0-100 \%$ & $\begin{array}{c}\text { (ELLEN MACARTHUR } \\
\text { FOUNDATION; GRANTA, } \\
2015) \\
\end{array}$ \\
\hline & 3 & O produto pode ser remanufaturado? & $1-\mathrm{S} ; 0-\mathrm{N}$ & $\begin{array}{l}\text { (GEHIN; ZWOLINSKI; } \\
\text { BRISSAUD, 2008) }\end{array}$ \\
\hline
\end{tabular}


Esses elementos chaves foram dispostos em um template em Excel que proporcionou que os resultados fossem ranqueados em uma escala que variava de "Muito baixa" à "Excelente" e por meio de gráfico de radar é possível averiguar em qual das etapas do ciclo de vida do produto seria passível de melhorias, Figura 14.

\section{Figura 14 - Template}

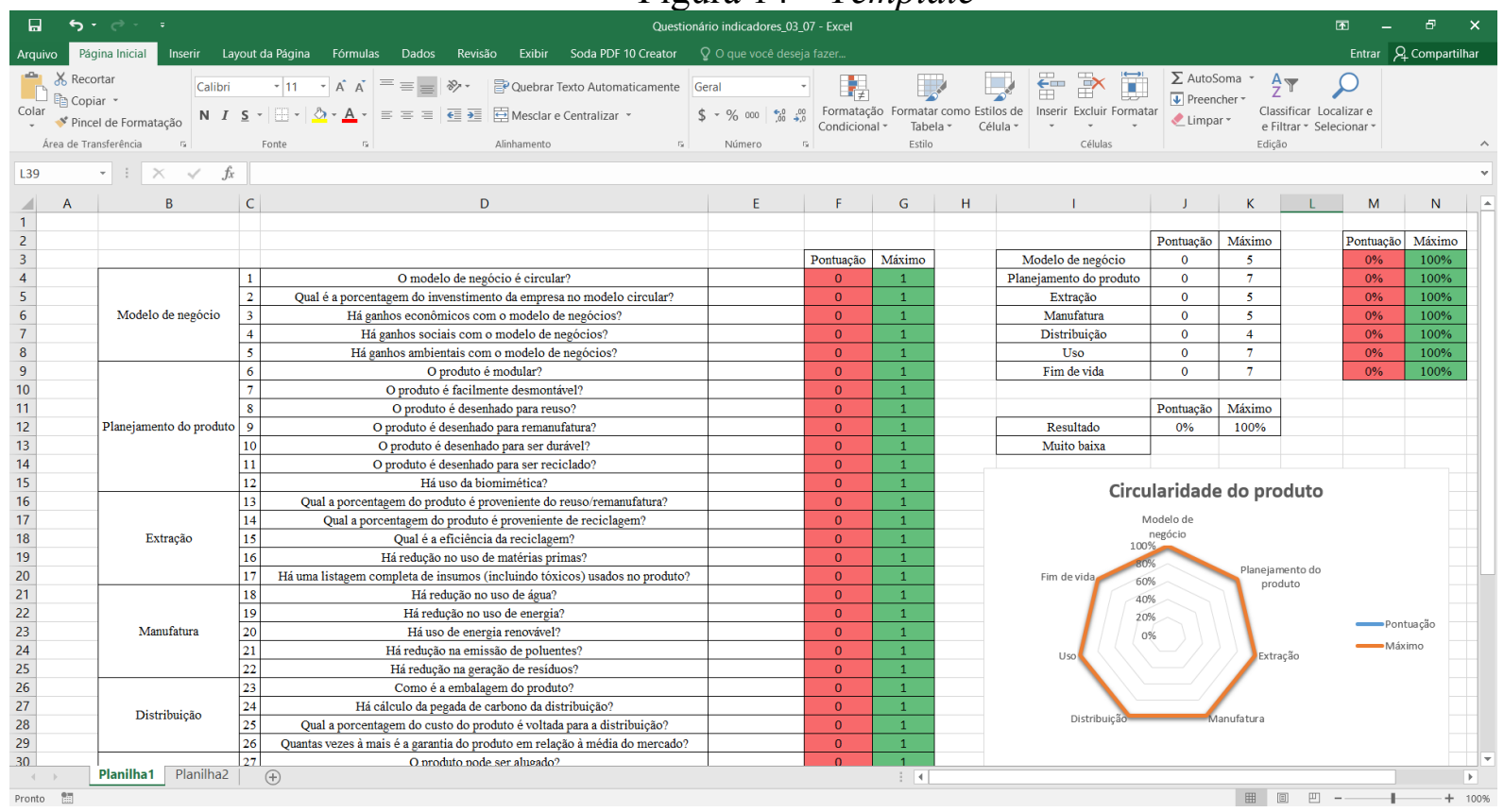

Fonte: Elaboração própria.

\subsection{Estudos de caso exploratórios}

Foram realizados dois estudos de caso exploratórios (Empresa A e B) a fim de se compreender como os indicadores de Economia Circular estavam sendo aplicados em empresas. O critério de escolha das empresas é elas possuírem modelos de negócio circulares.

\subsubsection{Empresa A}

\section{Bloco 1: Informações sobre a empresa}

\begin{tabular}{|l|l|}
\hline Setor & $\begin{array}{l}\text { Revestimentos Metálicos e Peças Especiais Resistentes } \\
\text { ao Desgaste. }\end{array}$ \\
\hline $\mathrm{N}^{\text {o de funcionários }}$ & 22 \\
\hline País (es) & Brasil \\
\hline Produtos & $\begin{array}{l}\text { Serviços de Metalização em Geral, Peças para } \\
\text { Colhedoras de Cana, Peças para Tratores e Britadores, }\end{array}$ \\
\hline
\end{tabular}


Aluguel de Componentes de Colhedora de Cana.

Informações sobre o entrevistado e área de atuação

\begin{tabular}{|l|l|}
\hline Função/Cargo & Diretor \\
\hline Tempo no cargo & Sócio fundador \\
$\begin{array}{l}\text { Tempo de experiência (em } \\
\text { outras empresas) }\end{array}$ & $\begin{array}{l}18 \text { anos. Desenvolvimento de produtos e último cargo } \\
\text { diretor industrial. }\end{array}$ \\
\hline $\begin{array}{l}\text { Estrutura organizacional da área } \\
\text { de meio ambiente }\end{array}$ & N/A \\
\hline
\end{tabular}

A empresa A nasceu em um contexto de buscar o prolongamento da vida útil de equipamentos, evitando o desgaste de peças. Ela já contava com uma tecnologia para a deposição em peças por meio de laser e com a colaboração de uma outra empresa que atuava na reciclagem de sucatas, fechando o ciclo.

Dessa forma, houve uma crescente pesquisa em materiais e ligas para cada produto a ser aplicado em diversas áreas, como mineração, agricultura, mais precisamente com colhedoras de cana. Além de trabalhos em campo para averiguar a durabilidade de produtos.Portanto, a empresa já nasceu dentro da ótica de um dos princípios da Economia Circular que é de estender a vida útil de produtos. Foi ao longo do tempo que houve a necessidade de mudar o mindset de acionistas e demais stakeholders para a Economia Circular.

Sendo assim, houve o estabelecimento de um programa chamado "Clean cut for life" onde buscou-se aprimorar o corte da cana, já que a queima foi proibida no Brasil. A empresa trabalhou junto à necessidade de resolver o problema dos clientes em relação à quantidade de impurezas proveniente da ineficiência do corte tradicional.

Pesquisas, trabalhos de campo e busca por aplicar conceitos da Economia Circular proporcionaram o redesenho dos componentes do sistema de corte de cana. A faca foi redesenhada, afastada do solo, seu ângulo foi aprimorado e essa tecnologia foi patenteada. Além disso, foi incorporado o modelo de negócio Product Service System (PSS) ou servitização, em que há o oferecimento do aluguel do sistema de corte para cana ao invés de vender o equipamento para o corte. Sendo assim, após o uso, o sistema de corte retorna à 
empresa para recuperação dos componentes e o material que não é utilizado é enviado para a empresa responsável pela reciclagem.

Com isso, verificaram em campo diminuição concreta de impurezas no corte, economia de combustível, aumento da vida útil do canavial, entre outros benefícios.

\section{Bloco 2: Análise das melhorias no desempenho da organização advindas da implementação dos princípios da economia circular}

A implementação do programa "Clean cut for life" ainda está em fases iniciais de implantação, porém a empresa visa melhorar a vida útil de produtos, como um dos princípios da Economia Circular. Dentre as oportunidades encontradas está que por ser um modelo de negócio inovador (PSS) há pouca concorrência. Para conseguir implantar o modelo há uma constante necessidade de conseguir parcerias, sendo muito importante esse processo colaborativo, promovendo uma maior simbiose entre diversas empresas proporcionando inovação e trabalhando na cadeia de valor.

A empresa não possui indicadores específicos para a Economia Circular, ela apenas mede o aspecto econômico e financeiro por meio de Retorno Sobre Investimento (ROI) e Retorno Sobre Ativos (ROA). E possuem projeções otimistas para resultados financeiros favoráveis no modelo de negócio circular.

\section{Bloco 3: Levantamento de elementos a serem medidos na Economia Circular}

Por meio da aplicação do questionário presente no Apêndice A, foi possível obter o seguinte gráfico de radar presente na Figura 15.

Figura 15 - Gráfico de radar mostrando a pontuação da empresa A quanto à circularidade do produto 


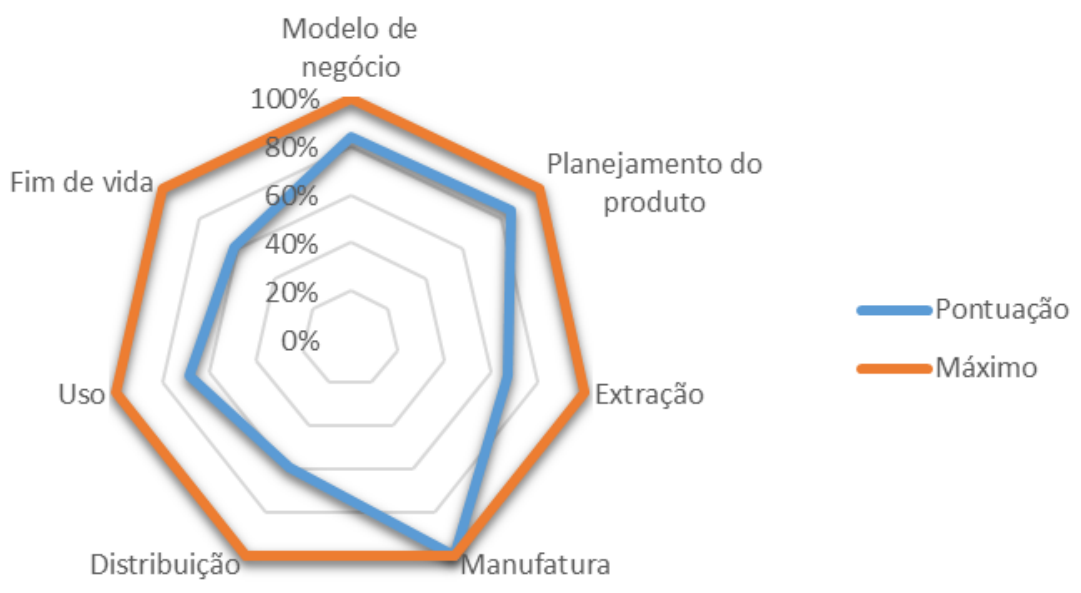

Fonte: Elaboração própria.

Pode-se visualizar que a empresa possui pontuação máxima na Manufatura pois atendeu a todos os requisitos solicitados. $\mathrm{O}$ aspecto mais crítico foi na Distribuição do produto, mostrando-se como maior forma de oportunidade de melhoria. A classificação final da empresa foi de "Excelente", atribuindo uma pontuação de $88 \%$, conforme template do Apêndice A.

Outros pontos importantes de melhoria para a empresa podem ser elencados:

- Aumentar o investimento no modelo de negócio circular;

- Utilizar a biomimética no planejamento do produto;

- Aumentar a taxa de retorno dos produtos após o uso, podendo se utilizar de incentivos financeiros para o cliente;

- Aumentar o uso de materiais reciclados em sua matéria prima;

- Realizar cálculos de pegada de carbono na Distribuição;

- Realizar medição da circularidade do produto.

Além disso, foram obtidos os seguintes dados para o cálculo dos seguintes indicadores:

- Produtos que retornam para a empresa após o uso: 50\%

- Dos que retornam, produtos que são remanufaturados: $65 \%$

- Porcentagem dos produtos que retornam que são reciclados: $35 \%$

- Eficiência da reciclagem: $85 \%$

- Tempo inicial de duração do uso: 10 meses

- Tempo de duração do uso após remanufatura: 10 meses 
- Porcentagem da matéria prima (para a fabricação do sistema novo) proveniente da reciclagem: $50 \%$

- Durabilidade do produto: 2x a mais do que a média do mercado

Foram aplicados também alguns indicadores encontrados na literatura, a fim de averiguar o produto. Esses indicadores foram o MCI (ELLEN MACARTHUR FOUNDATION; GRANTA, 2015) e o Longevity and Circularity (FIGGE et al., 2018). Tais indicadores foram selecionados por serem mais pragmáticos e de acordo com a estratégia da empresa de fechamento de ciclo, remanufatura e reciclagem de materiais.

Dessa maneira, o cálculo do MCI (ELLEN MACARTHUR FOUNDATION; GRANTA, 2015) foi obtido por meio de um template, inserindo os dados de entrada requisitados, obtendo um valor de 0,87 . Esse valor varia de 0 a 1 , sendo que 1 indica a máxima circularidade do produto.

O outro indicador obtido foi o de longevity e circularity (FIGGE et al., 2018), expresso por meio da Figura 16. Nota-se que a remanufatura aumentou em 32,5\% a longevidade e a circularidade do produto, e a reciclagem aumentou em 19,7\% a longevidade e a circularidade do produto.

Figura 16 - Longevity e Circularity

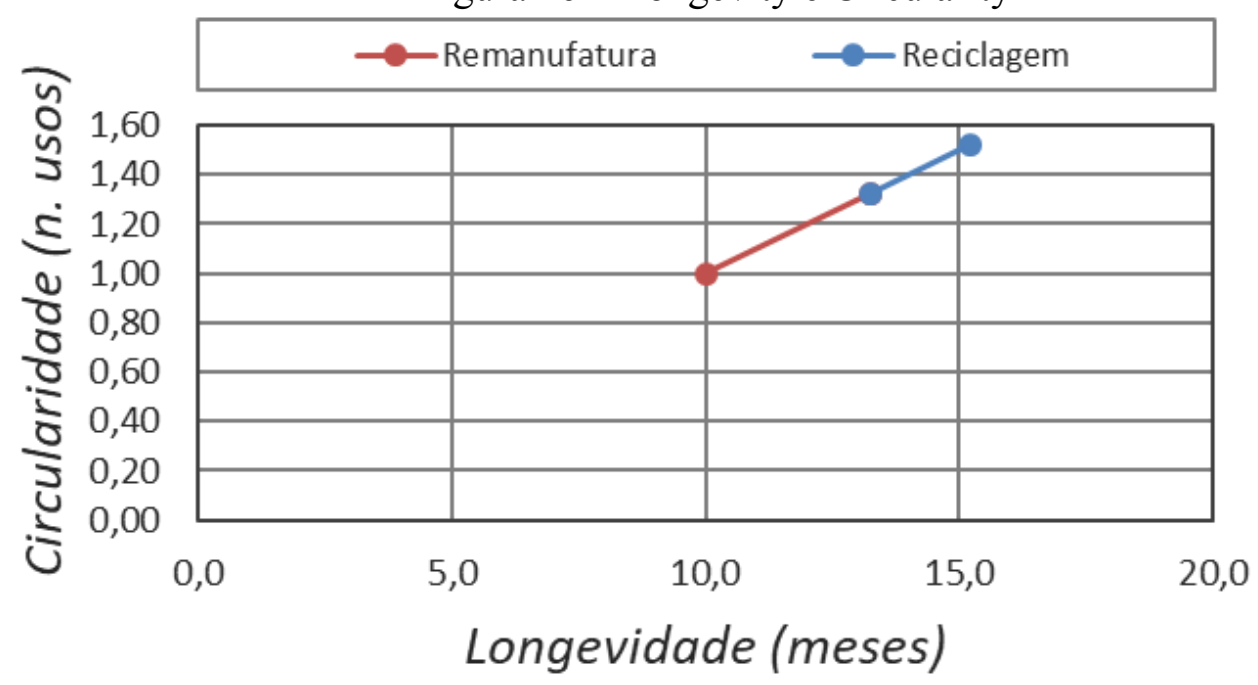

Fonte: adaptado de Figge (2018)

Por fim, vale salientar que nesse estudo de caso, indicadores apenas voltados para o produto não são suficientes para expressar os ganhos da Economia Circular. Entrevistas com a empresa possibilitaram aferir que ganhos positivos na entrega final de valor (elemento central do modelo de negócio) eram mais expressivos do que avaliar os produtos propriamente ditos, 
pois a entrega de valor traz consigo muitos outros elementos do modelo de negócio. Ou seja, o aumento da vida útil do canavial era mais expressivo do que melhorias pontuais no produto.

\subsubsection{Empresa B}

Bloco 1: Informações sobre a empresa

\begin{tabular}{|l|l|}
\hline Setor & Minero-Metalúrgico \\
\hline $\mathrm{N}^{\mathrm{o}}$ de funcionários & Mais de 10.000 \\
\hline País (es) & Multinacional presente no Brasil \\
\hline Produtos & Aço \\
\hline
\end{tabular}

Informações sobre o entrevistado e área de atuação

\begin{tabular}{|l|l|}
\hline Função/Cargo & Especialista de Meio Ambiente \\
\hline Tempo no cargo & 1 ano (+11 como Analista de Meio Ambiente) \\
$\begin{array}{l}\text { Tempo de experiência (em } \\
\text { outras empresas) }\end{array}$ & Ao todo 15 anos de experiência profissional \\
\hline $\begin{array}{l}\text { Estrutura organizacional da área } \\
\text { de meio ambiente }\end{array}$ & $\begin{array}{l}\text { Gerência Geral de Meio Ambiente (área corporativa) } \\
\text { com escopo de todas as atividades }\end{array}$ \\
\hline
\end{tabular}

A empresa B é uma multinacional presente em vários países cuja estratégia da empresa está baseada em três pilares: Liderança, Qualidade e Sustentabilidade. Além disso, há o gerenciamento de ciclos técnicos e biológicos por meio da interação entre a mineração e florestas no sentido de suprir a demanda de carvão vegetal em seu sistema produtivo e proporcionar captura de carbono. Além do modelo tradicional de venda de produtos, a empresa possui também o aluguel de alguns produtos, no sentido de incorporar princípios da Economia Circular.

Como metas da empresa encontram-se: reduzir emissões e promover a diminuição do peso do produto (mantendo a função) buscando aços mais leves e com as mesmas características de durabilidade e flexibilidade. Outro aspecto importante é a atuação da empresa no fechamento de ciclos, utilizando a sucata como insumo de seu processo produtivo.

Os fatores que impulsionaram a mudança para a EC foram: concorrência entre materiais, exigências do cliente, rótulos ambientais, crescimento da demanda e pressão por 
recursos naturais. A empresa busca de valores que vão além do lucro, incluindo sociais e ambientais.

Outro aspecto importante é a realização de parcerias e colaboração, principalmente no retorno da sucata a ser utilizada como insumo no processo produtivo, ou seja, na cadeia reversa.

\section{Bloco 2: Análise das melhorias no desempenho da organização advindas da implementação dos princípios da economia circular}

A empresa B ainda está avaliando o seu desempenho na Economia Circular, já que é um termo bem recente. A empresa já aplicava muitos conceitos da Economia Circular muito anteriormente à consolidação da mesma, principalmente no fechamento de ciclos. Mas podese citar que no âmbito da abordagem estratégica da empresa, a Economia Circular já se apresenta mais consolidada, especialmente em como desenvolver os negócios da empresa. Dessa forma, traz benefícios mais aparentes no setor econômico. Algumas estratégias da Economia Circular como o reuso, a modularidade e o design de produtos traz também benefícios, mas ainda não há resultados concretos, pois são projetos mais novos e pioneiros.

Vale salientar que a empresa ainda não possui nem aplica nenhum indicador específico para a circularidade, vendo a necessidade da estruturação desse indicador.

\section{Bloco 3: Levantamento de elementos a serem medidos na Economia Circular}

A aplicação do questionário por meio do template da Figura 14

possibilitou o gráfico de radar da Figura 17. O produto analisado foi o vergalhão utilizado na construção civil.

Figura 17 - Gráfico de radar mostrando a pontuação da empresa B quanto à circularidade do produto 


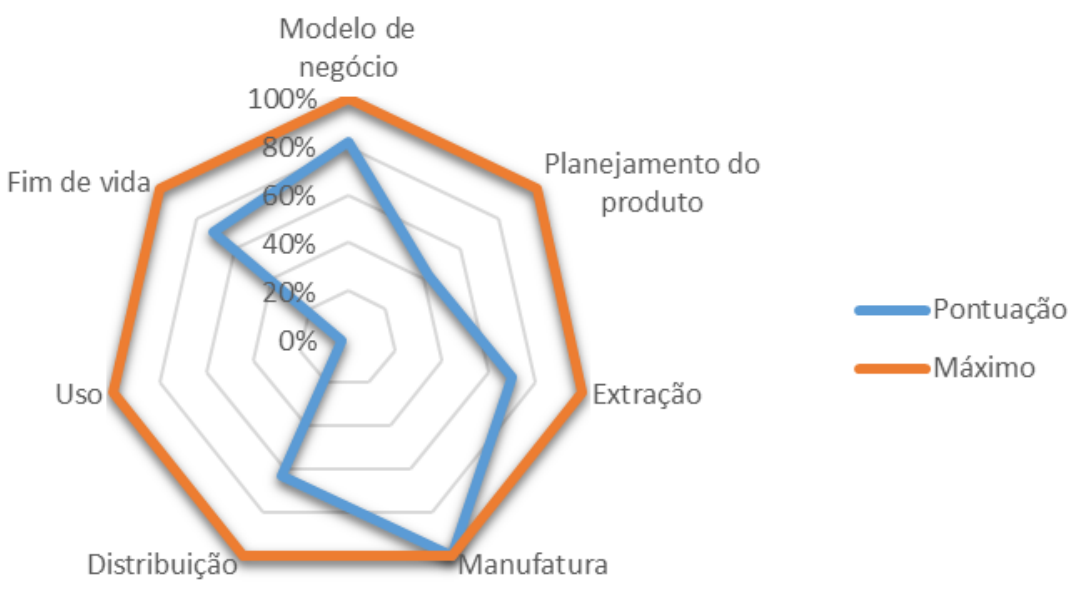

Fonte: Elaboração própria.

Pode-se notar que a empresa obteve nota máxima na Manufatura por atender a todos os requisitos citados. A pontuação mais crítica foi no Uso, mostrando a maior oportunidade de melhoria. A classificação final da empresa foi de "Muito boa", obtendo uma pontuação final de $69 \%$, de acordo com o template do Apêndice A.

Vale salientar as seguintes oportunidades de melhoria:

- Possibilidade de modularidade do produto, uso de biomimética, incluindo a possibilidade de mudança do modelo de negócio, como o PSS.

- Aumento do uso de matéria prima reciclada.

- Aplicar indicadores de circularidade e longevidade no produto.

- Adicionar mecanismos de incentivo financeiro para a logística reversa. 


\subsection{Segunda versão para indicadores de Economia Circular}

É notável a relação entre Economia Circular e os Objetivos de Desenvolvimento Sustentável (ODS) (KORHONEN; HONKASALO; SEPPÄLÄ, 2018; RODRIGUEZANTON et al., 2019). Porém há escassez de métricas que aliem a Economia Circular aos três pilares da Sustentabilidade (CORONA et al., 2019; KRISTENSEN; MOSGAARD, 2020). A proposta final dos indicadores buscou contemplar os princípios de EC descritos na Norma Britânica BSI (BSI, 2017) e foram divididos em três dimensões: meio ambiente (da perspectiva material), econômico e social (ROSSI et al., 2019), descritos na listagem a seguir.

\section{I) Material ${ }^{16}$}

1.Redução do uso de materiais: tem como objetivo medir a redução de matéria-prima nos seguintes termos:

a. Processo de fabricação: refere-se à quantidade de material reduzido nos processos de fabricação.

b. Produto: refere-se à quantidade de material reduzido no produto.

2. Renovabilidade: tem como objetivo medir a quantidade de insumos renováveis (materiais e energia) no processo de fabricação e no produto.

a. Energia renovável: porcentagem das fontes renováveis em relação a energia total utilizada nos processos de fabricação.

b. Matéria-prima renovável: porcentagem de matéria prima oriunda de fontes renováveis em função de todos os materiais utilizados em um produto (Ex. bioplástico).

3. Reciclabilidade: tem como objetivo medir a porcentagem de utilização de materiais e o potencial de reciclabilidade do produto.

a. Materiais reciclados: porcentagem de utilização de materiais reciclados na composição do produto.

b. Potencial de reciclabilidade do produto: porcentagem de materiais que podem ser reciclados.

4. Redução de substâncias tóxicas: tem como objetivo quantificar a redução do uso de substâncias tóxicas considerando a RoHS (Restriction of Certain Hazardous Substances).

5. Reuso: tem como objetivo quantificar a reutilização dos fluxos de matérias dos processos de fabricação e de reuso do produto aplicável a:

a. Processo de fabricação: refere -se a quantidade de material reutilizado na cadeia produtiva;

${ }^{16}$ Traduzido de Rossi et al. (2019) 
b. Produto: refere-se à quantidade de material reutilizado no produto.

6. Remanufatura: tem como objetivo quantificar os produtos remanufaturados especificados.

7. Recondicionamento: tem como objetivo quantificar a recuperação total ou de partes (componentes) do produto, sem passar, necessariamente, por todas as etapas da remanufatura. O indicador é expresso pela especificação e quantidade dos produtos e partes recondicionadas. 8. Longevidade do produto: tem como objetivo quantificar o tempo acrescentado de uso do produto. Obs. Este indicador pode ser obtido a partir de informações de consumidores, e/ou da própria empresa a partir de informações de retorno de produtos, tempo médio de vida, substituição ou compra de novo produto, ou tempo para reposição.

9. Estrutura e diversidade de partes interessadas na cadeia de valor circular: tem como objetivo:

a. Estrutura: este indicador pode ser obtido de forma qualitativa, como por exemplo sobre as estruturas e sinergias e/ou simbiose dos negócios de uma empresa com outras associadas à sua cadeia por exemplo.

b. Partes interessadas: mapear as partes interessadas presentes na cadeia de valor circular.

\section{II) Econômica}

1. Resultados financeiros: tem como objetivo descrever os principais resultados financeiros da organização relacionados ao modelo circular, como eles estão evoluindo e se sustentam.

a. Redução de custo: valor referente a redução de custo proveniente do modelo de negócio circular, considerando a redução de uso de matérias primas, energia, etc.

b. Geração de receita: porcentagem do faturamento gerado pelos modelos circulares.

- Vantagem competitiva: porcentagem da parcela do mercado ocupada pelo negócio circular em comparação aos concorrentes;

- Riscos: mapear os principais riscos relacionados ao modelo de negócio circular.

- Novas receitas: indicar a geração de novas receitas provenientes do novo modelo de negócio.

c. Rentabilidade: referente ao lucro líquido do retorno sobre ativos (ROA) e patrimônio líquido.

2. Tributação ou marcos regulatórios: tem como objetivo apontar tributos e marcos regulatórios que subsidiam o modelo de negócio circular. 
3. Investimento Circular: tem como objetivo quantificar em valores monetários os recursos financeiros investidos para a mudança do modelo de negócio, desde as ações estratégicas e de gestão até capacitação, operacional e manutenção.

a. Inovação: tem como objetivo quantificar os investimentos decorrentes do processo de inovação.

III) Social

1. Geração de emprego: tem como objetivo quantificar os empregos gerados provenientes do modelo de negócio circular. Exemplo: tipo e Quantidade de empregos gerados com as atividades da cadeia reversa (manutenção, logística reversa, reuso, remanufatura, recondicionamento, etc.)

2. Renda relativa aos empregos gerados: tem como objetivo quantificar em valores monetários a renda gerada proveniente da geração de empregos criados no modelo de negócio circular.

3. Participação dos funcionários no modelo circular: tem como objetivo quantificar a porcentagem de empregos da organização e o nível hierárquico relacionado à economia circular.

4. Caracterização do mercado: tem como objetivo caracterizar o mercado através de:

a. Cliente: indicador associado à caracterização e diversidade do tipo de cliente (ex. nível social, regiões geográficas, faixa etária, entre outros, de acordo com os usos do produto).

b. Valor: mapeamento dos valores percebidos e capturados para cada tipo de cliente, ou seja, benefícios gerados para os clientes.

c. Comunicação: coleta de dados ou informações coletadas a partir de pesquisas de consumidores, SAC, e outros canais, identificando as correlações com informações sobre adoção de práticas "circulares" ou associadas a sustentabilidade, as quais são comunicadas ou disponíveis aos consumidores que tomam decisões de compra a partir das informações disponíveis aos mesmos.

5. Participação das partes interessadas nos processos de decisão: tem como objetivo caracterizar descritiva/qualitativamente as partes interessadas que participam em geral do modelo de negócio e aquelas que participam efetivamente das tomadas de decisão da organização. Estratificar as partes interessadas de acordo com cada elemento do modelo de negócio: estratégia e gestão, econômica, operacional e de inovação.

6. Mudança do Mindset/cultural: tem como objetivo descrever o processo de mudança decorrente da implementação do modelo de negócio circular. Especialmente mudança cultural e de mindset. 
Esses indicadores podem ser relacionados aos componentes do modelo de negócio, de acordo com a Figura 18, sendo que os destacados em verde são da dimensão material, em laranja social e em azul, econômico.

Figura 18 - Indicadores e suas correspondências aos componentes do modelo de negócio CANVAS

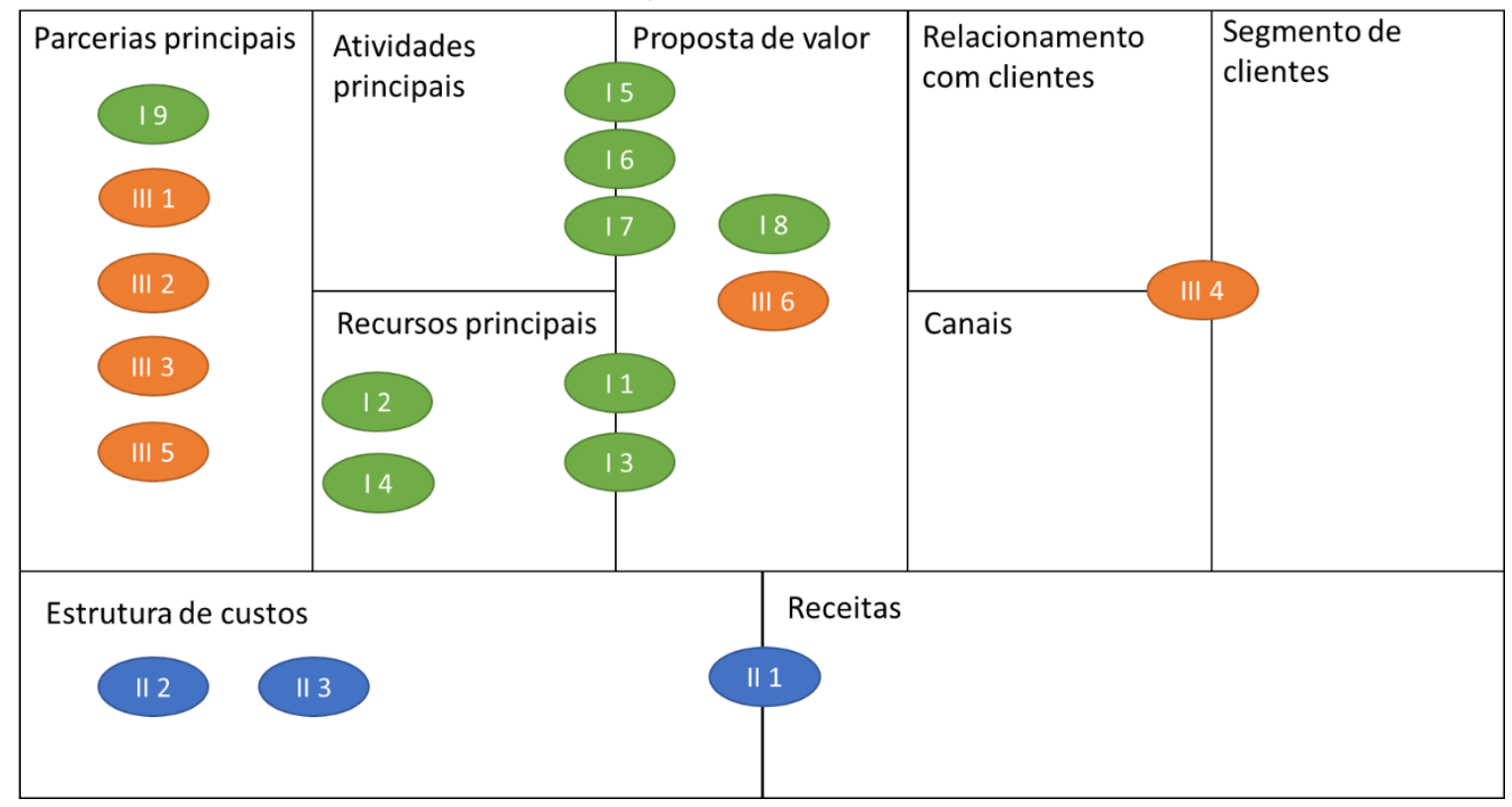

Fonte: adaptado de Rossi et al. (2019)

A definição das métricas estabeleceram critérios facilitadores descritos no Quadro 6 (NEELY; ADAMS; KENNERLEY, 2002). Nota-se que devido à complexidade da EC, os indicadores não podem ser vistos isoladamente, mas em sua totalidade. Posto isso, o Quadro 6 mostra os atributos dos indicadores, suas fórmulas, a fim de facilitar sua aplicação nas empresas (KRAVCHENKO; PIGOSSO; MCALOONE, 2020). Além disso, o quadro também demonstra a relação entre os indicadores, ou seja, para avaliar a EC não basta apenas obter a melhoria de um indicador isolado, mas todos de forma sistêmica. 
Quadro 6 - Definição das métricas

\begin{tabular}{|c|c|c|c|c|c|c|}
\hline Indicador & Nome & Princípio $^{17}$ & $\begin{array}{l}\text { Relacionado ao } \\
\text { indicadores }\end{array}$ & Fórmula & Exemplo & Área funcional \\
\hline $\mathrm{I} 1$ & $\begin{array}{l}\text { Redução do uso } \\
\text { de materiais }\end{array}$ & 1,3 e 5 & $\begin{array}{l}\text { I3, I4, I5, I6, I7, } \\
\text { I8, I9, III } 1 \text { II2, } \\
\text { II3, III } 1, \text { III6 }\end{array}$ & $\begin{array}{c}\text { Porcentagem da } \\
\text { massa de materiais } \\
\text { reduzida no processo } \\
\text { ou no produto }\end{array}$ & $\begin{array}{l}\text { Redução de } 3 \% \text { em } \\
\text { massa do produto }\end{array}$ & $\begin{array}{l}\text { Desenvolvimento do } \\
\text { produto e processo }\end{array}$ \\
\hline $\mathrm{I} 2$ & Renovabilidade & $1,2,3$ e 5 & $\begin{array}{l}\text { I5, I7, I8, I9, } \\
\text { II1, II2, II3, } \\
\text { III1, III4, III6 }\end{array}$ & $\begin{array}{c}\text { Porcentagem da } \\
\text { utilização de energia e } \\
\text { materiais renováveis }\end{array}$ & $\begin{array}{l}\text { Utilização de } 65 \% \\
\text { energia solar }\end{array}$ & $\begin{array}{l}\text { Desenvolvimento do } \\
\text { produto e processo }\end{array}$ \\
\hline $\mathrm{I} 3$ & Reciclabilidade & $1,2,3,4$ e 5 & $\begin{array}{l}\text { I4, I5, I6, I7, I9, } \\
\text { II1, II2, II3, } \\
\text { III1, III2, Iii3, } \\
\text { III4, III6 }\end{array}$ & $\begin{array}{l}\text { Porcentagem de } \\
\text { massa de materiais } \\
\text { reciclados e potencial } \\
\text { de reciclagem no } \\
\text { produto }\end{array}$ & $\begin{array}{l}\text { Utilização de } 80 \% \\
\text { de papel reciclado } \\
\text { no produto }\end{array}$ & $\begin{array}{l}\text { Desenvolvimento do } \\
\text { produto }\end{array}$ \\
\hline I4 & $\begin{array}{l}\text { Redução de } \\
\text { substâncias } \\
\text { tóxicas }\end{array}$ & 1,3 e 5 & $\begin{array}{l}\text { I5, I6, I8, II1, } \\
\text { II3, III4, III6 }\end{array}$ & $\begin{array}{c}\text { Porcentagem da } \\
\text { massa de materiais } \\
\text { tóxicos reduzidos no } \\
\text { produto }\end{array}$ & $\begin{array}{c}\text { Substituição de } \\
100 \% \text { do mercúrio } \\
\text { por outra substância }\end{array}$ & $\begin{array}{l}\text { Desenvolvimento do } \\
\text { produto }\end{array}$ \\
\hline $\mathrm{I} 5$ & Reuso & $1,3,4$ e 5 & $\begin{array}{l}\text { I6, I7, I8, } \\
\text { III1,III4, III6 }\end{array}$ & $\begin{array}{c}\text { Porcentagem de } \\
\text { materiais reutilizados } \\
\text { no processo ou no } \\
\text { produto }\end{array}$ & $\begin{array}{l}\text { Utilização de } 50 \% \\
\text { do produto original }\end{array}$ & $\begin{array}{c}\text { Desenvolvimento do } \\
\text { produto e processo }\end{array}$ \\
\hline I6 & Remanufatura & $1,2,3$ e 5 & $\begin{array}{l}\text { I7, I8, II1, II3, } \\
\text { III1, III4, III6 }\end{array}$ & $\begin{array}{l}\text { Porcentagem de } \\
\text { produtos } \\
\text { remanufaturados }\end{array}$ & $\begin{array}{l}\text { Remanufatura de } \\
80 \% \text { dos produtos }\end{array}$ & $\begin{array}{l}\text { Desenvolvimento do } \\
\text { produto }\end{array}$ \\
\hline I7 & $\begin{array}{l}\text { Recondicionamen } \\
\text { to }\end{array}$ & $1,2,3$ e 5 & I8, II1, III4, III6 & $\begin{array}{l}\text { Porcentagem de } \\
\text { componentes do } \\
\text { produto que são } \\
\text { recondicionados }\end{array}$ & $\begin{array}{l}\text { Recondicionamento } \\
\text { de } 20 \% \text { dos } \\
\text { componentes }\end{array}$ & $\begin{array}{l}\text { Desenvolvimento do } \\
\text { produto }\end{array}$ \\
\hline
\end{tabular}

${ }^{17} 1$ - Pensamento sistêmico, 2 - Inovação, 3 - Gerenciamento, 4 - Colaboração, 5 - Otimização de valor, 6 - Transparência (BSI, 2017). 


\begin{tabular}{|c|c|c|c|c|c|c|}
\hline I8 & Longevidade & $1,2,3$ e 5 & $\begin{array}{l}\text { I9, II1, II3, III1, } \\
\text { III4, III5, III6 }\end{array}$ & $\begin{array}{l}\text { Porcentagem de vida } \\
\text { útil adicionada ao } \\
\text { produto (a mais que a } \\
\text { média do mercado) }\end{array}$ & $\begin{array}{c}\text { Durabilidade de } 1,2 \mathrm{x} \\
\text { a mais que a média } \\
\text { do mercado }\end{array}$ & $\begin{array}{l}\text { Desenvolvimento do } \\
\text { produto }\end{array}$ \\
\hline I9 & $\begin{array}{c}\text { Estrutura e } \\
\text { diversidade das } \\
\text { partes } \\
\text { interessadas } \\
\end{array}$ & $1,2,3,4$ e 6 & $\begin{array}{l}\text { II1, II2, II3, } \\
\text { III1, III2, III3, } \\
\text { III5, III6 }\end{array}$ & $\begin{array}{l}\text { Mapeamento de partes } \\
\text { interessadas }\end{array}$ & & Recursos humanos \\
\hline II1 & $\begin{array}{l}\text { Resultados } \\
\text { Financeiros }\end{array}$ & $1,3,5$ e 6 & $\begin{array}{l}\text { II2, II3, III2, } \\
\text { III4, III5, III6 }\end{array}$ & $\begin{array}{l}\text { Quantitativo da } \\
\text { redução de custos, } \\
\text { geração de receita e } \\
\text { rentabilidade }\end{array}$ & $\begin{array}{l}\text { Redução de } 8 \text { mil } \\
\text { reais }\end{array}$ & Financeiro \\
\hline II 2 & Tributação & 1,4 e 6 & II3, III1 & $\begin{array}{l}\text { Impostos cobrados e } \\
\text { taxas relacionadas às } \\
\text { atividades circulares }\end{array}$ & $\begin{array}{c}\text { ISS } 2 \%+ \\
\text { PIS/COFINS } 9.65 \% \\
+ \text { eventual INSS } \\
\end{array}$ & Financeiro \\
\hline II3 & $\begin{array}{l}\text { Investimento } \\
\text { Circular }\end{array}$ & $1,2,3,4$ e 5 & $\begin{array}{l}\text { III1, III2, III3, } \\
\text { III4, III5, III6 }\end{array}$ & $\begin{array}{l}\text { Quantitativo } \\
\text { monetário do } \\
\text { investimento }\end{array}$ & $\begin{array}{l}\text { Investimento de } 10 \\
\text { mil reais }\end{array}$ & Financeiro \\
\hline III1 & $\begin{array}{l}\text { Geração de } \\
\text { empregos }\end{array}$ & 1,2 e 4 & $\begin{array}{l}\text { III2, III4, III5, } \\
\text { III6 }\end{array}$ & $\begin{array}{l}\text { Quantitativo do } \\
\text { número de } \\
\text { funcionários diretos e } \\
\text { indiretos do modelo } \\
\text { de negócios circular }\end{array}$ & $\begin{array}{c}\text { Criação de } 50 \\
\text { empregos diretos e } \\
150 \text { indiretos } \\
\text { (cooperativas) }\end{array}$ & Recursos humanos \\
\hline III2 & $\begin{array}{l}\text { Renda relativa } \\
\text { aos empregos } \\
\text { gerados } \\
\end{array}$ & 1,3 e 5 & $\begin{array}{l}\text { III3, III4, III5, } \\
\text { III6 }\end{array}$ & $\begin{array}{l}\text { Quantidade de renda } \\
\text { relativa aos empregos } \\
\text { gerados }\end{array}$ & $\begin{array}{c}\text { Renda de } \\
\text { aproximadamente } \\
20.000 \text { reais } \\
\end{array}$ & Financeiro \\
\hline III3 & $\begin{array}{l}\text { Participação dos } \\
\text { funcionários no } \\
\text { modelo circular }\end{array}$ & $1,4,5$ e 6 & III5 & $\begin{array}{l}\text { Relação entre } \\
\text { empregos gerados } \\
\text { com o nível } \\
\text { hierárquico }\end{array}$ & $\begin{array}{l}\text { Estratégico (2), } \\
\text { tático (5) e } \\
\text { operacional (20) }\end{array}$ & Recursos humanos \\
\hline III4 & $\begin{array}{l}\text { Caracterização do } \\
\text { mercado }\end{array}$ & 1 e 3 & III6 & $\begin{array}{l}\text { Caracterização do } \\
\text { cliente (motivação e }\end{array}$ & $\begin{array}{l}\text { Cliente de faixa } \\
\text { etária 15-25 anos, }\end{array}$ & Marketing \\
\hline
\end{tabular}




\begin{tabular}{|c|c|c|c|c|c|c|}
\hline & & & & $\begin{array}{c}\text { intenção), valor } \\
\text { percebido do produto } \\
\text { e canais de } \\
\text { comunicação }\end{array}$ & $\begin{array}{c}\text { classe } \mathrm{B} \text {, disposição } \\
\text { a comprar produtos } \\
\text { com rotulagem } \\
\text { ambiental, canal de } \\
\text { comunicação } \\
\text { internet }\end{array}$ & \\
\hline III5 & $\begin{array}{c}\text { Participação das } \\
\text { partes } \\
\text { interessadas nos } \\
\text { processos de } \\
\text { decisão }\end{array}$ & $1,2,3,4$ e 6 & III6 & $\begin{array}{c}\text { Relação entre as } \\
\text { partes interessadas e } \\
\text { as tomadas de decisão } \\
\text { na organização } \\
\text { (estratégia e gestão, } \\
\text { econômica, } \\
\text { operacional e de } \\
\text { inovação.) }\end{array}$ & $\begin{array}{l}\text { Tomadas de decisão } \\
\text { estratégica (interno), } \\
\text { econômica } \\
\text { (consultoria e } \\
\text { interno), operacional } \\
\text { (cooperativas, } \\
\text { interno), inovação } \\
\text { (universidades e } \\
\text { interno) }\end{array}$ & $\begin{array}{l}\text { Recursos humanos e } \\
\text { responsabilidade } \\
\text { social }\end{array}$ \\
\hline III6 & $\begin{array}{l}\text { Mudança do } \\
\text { Mindset/cultural }\end{array}$ & $1,2,4,5$ e 6 & $\begin{array}{l}\text { I1, I2, I3, I4, I5, } \\
\text { I6, I7, I8, II1, } \\
\text { II3, III1, III2, } \\
\text { III4 e III5. }\end{array}$ & $\begin{array}{c}\text { Descrição de como } \\
\text { ocorreu a mudança de } \\
\text { mindset/cultural na } \\
\text { organização }\end{array}$ & $\begin{array}{l}\text { A mudança ocorreu } \\
\text { por meio de } \\
\text { workshop com } \\
\text { Universidade no } \\
\text { sentido de inserir a } \\
\text { Economia Circular } \\
\text { em um novo modelo } \\
\text { de negócio da } \\
\text { empresa. }\end{array}$ & Gestão da mudança \\
\hline
\end{tabular}

Fonte: traduzido de Rossi et al. (2019) 


\subsection{Terceira versão de índices para Economia Circular}

Após a aplicação dos indicadores descritos no item anterior, notou-se a necessidade da criação de um índice que reunisse todas as variáveis dispostas nos princípios da Economia Circular, além de adicionar impactos positivos e a questão dos modelos de negócio circulares.

Para tanto, o índice proposto no estudo de caso exploratório foi ampliado, sendo possível a adequação do mesmo e a construção de dois templates excel. O primeiro é voltado para o produto, Figura 19 e Quadro 7. O índice de produto possui um valor final variando de 0-100\%, sendo que de 0 a 20\% (Muito baixa), 20\% a 40\% (Baixa), de 40\% a 60\% (Razoável), de $60 \%$ a $80 \%$ (Muito boa) e acima de $80 \%$ (Excelente).

Figura 19 - Índice do produto circular

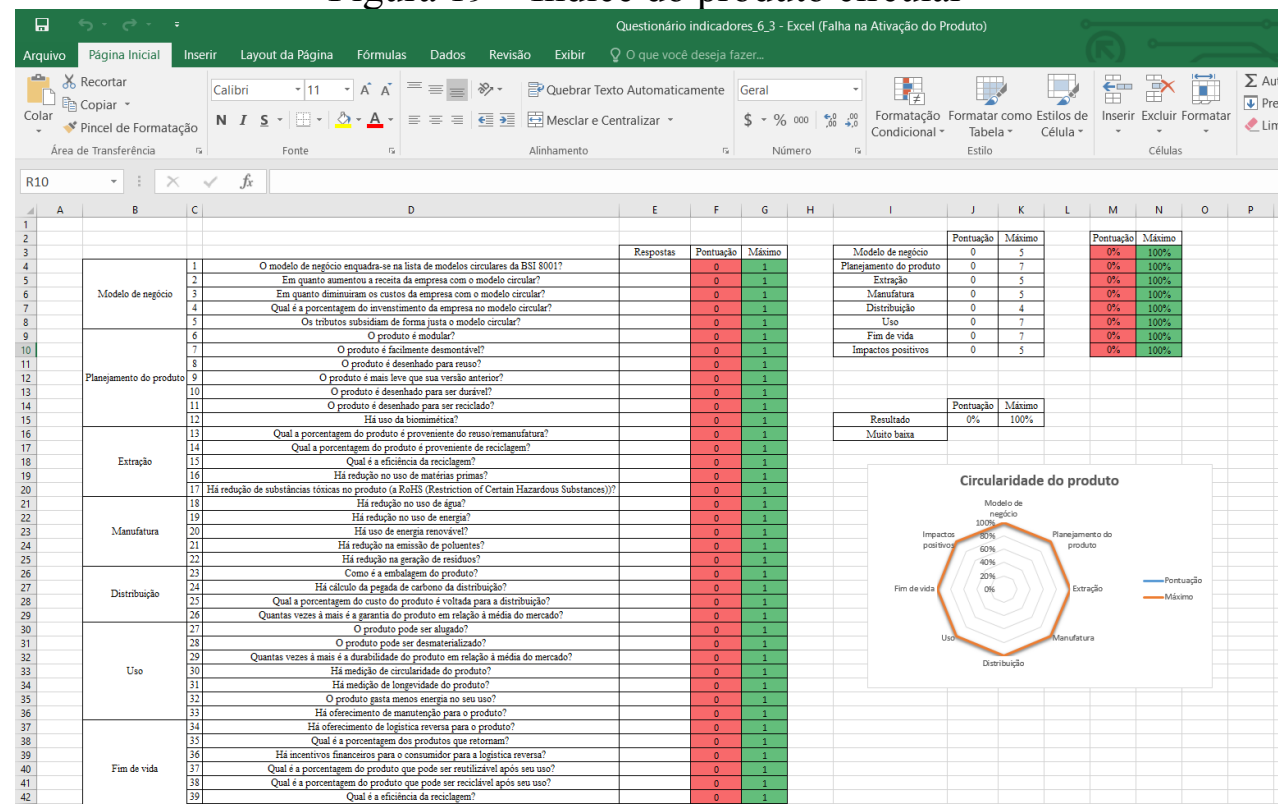

Fonte: Elaboração própria. 
Quadro 7 - Questionário do índice de produto para Economia Circular

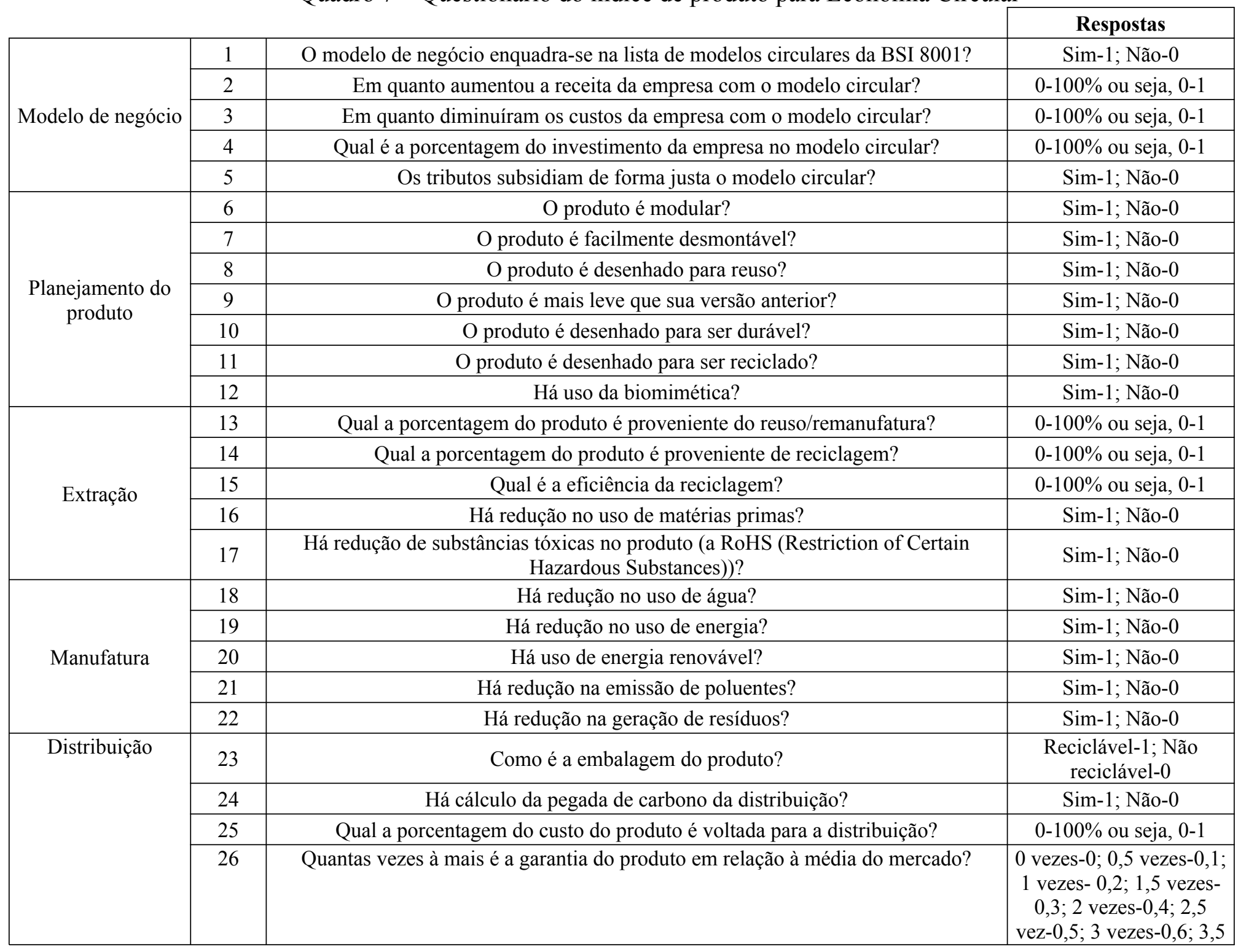




\begin{tabular}{|c|c|c|c|}
\hline & & & $\begin{array}{r}\text { vezes- } 0,7 ; 4 \text { vezes- } 0,8 \\
4,5 \text { vezes- } 0,9 ; 5 \text { vezes- } 1\end{array}$ \\
\hline \multirow{7}{*}{ Uso } & 27 & O produto pode ser alugado? & Sim-1; Não-0 \\
\hline & 28 & O produto pode ser desmaterializado? & Sim-1; Não-0 \\
\hline & 29 & Quantas vezes à mais é a durabilidade do produto em relação à média do mercado? & $\begin{array}{c}0 \text { vezes- } 0 ; 0,5 \text { vezes- } 0,1 ; \\
1 \text { vezes- } 0,2 ; 1,5 \text { vezes- } \\
0,3 ; 2 \text { vezes- } 0,4 ; 2,5 \\
\text { vez- } 0,5 ; 3 \text { vezes- } 0,6 ; 3,5 \\
\text { vezes- } 0,7 ; 4 \text { vezes- } 0,8 ; \\
4,5 \text { vezes- } 0,9 ; 5 \text { vezes- } 1\end{array}$ \\
\hline & 30 & Há medição de circularidade do produto? & Sim-1; Não-0 \\
\hline & 31 & Há medição de longevidade do produto? & Sim-1; Não-0 \\
\hline & 32 & O produto gasta menos energia no seu uso? & Sim-1; Não-0 \\
\hline & 33 & Há oferecimento de manutenção para o produto? & Sim-1; Não-0 \\
\hline \multirow{7}{*}{ Fim de vida } & 34 & Há oferecimento de logística reversa para o produto? & Sim-1; Não-0 \\
\hline & 35 & Qual é a porcentagem dos produtos que retornam? & $0-100 \%$ ou seja, $0-1$ \\
\hline & 36 & Há incentivos financeiros para o consumidor para a logística reversa? & Sim-1; Não-0 \\
\hline & 37 & Qual é a porcentagem do produto que pode ser reutilizável após seu uso? & $0-100 \%$ ou seja, $0-1$ \\
\hline & 38 & Qual é a porcentagem do produto que pode ser reciclável após seu uso? & $0-100 \%$ ou seja, $0-1$ \\
\hline & 39 & Qual é a eficiência da reciclagem? & $0-100 \%$ ou seja, $0-1$ \\
\hline & 40 & O produto pode ser remanufaturado? & Sim-1; Não-0 \\
\hline \multirow{5}{*}{ Impactos positivos } & 41 & Há geração de empregos com o modelo circular? & Sim-1; Não-0 \\
\hline & 42 & Há mapeamento das partes interessadas no modelo circular? & Sim-1; Não-0 \\
\hline & 43 & $\begin{array}{l}\text { Há melhoria ambiental com o modelo circular? (sequestro de carbono, melhoria da } \\
\text { qualidade da água, etc)? }\end{array}$ & Sim-1; Não-0 \\
\hline & 44 & Há mudança de mindset com o modelo circular? & Sim-1; Não-0 \\
\hline & 45 & Há comunicação do modelo circular de forma clara aos consumidores? & Sim-1; Não-0 \\
\hline
\end{tabular}

Fonte: elaboração própria 
E o índice para modelos de negócio circulares mostra-se na Figura 20 e Quadro 8. O índice para modelos de negócio varia de 0 a 100, sendo que cada resposta vale no máximo 5, e para cada componente do modelo de negócio (proposta de valor, parcerias principais, recursos e atividades principais, canais e clientes) se faz a média das respostas computadas.

Figura 20 - Índice para modelos de negócio circular

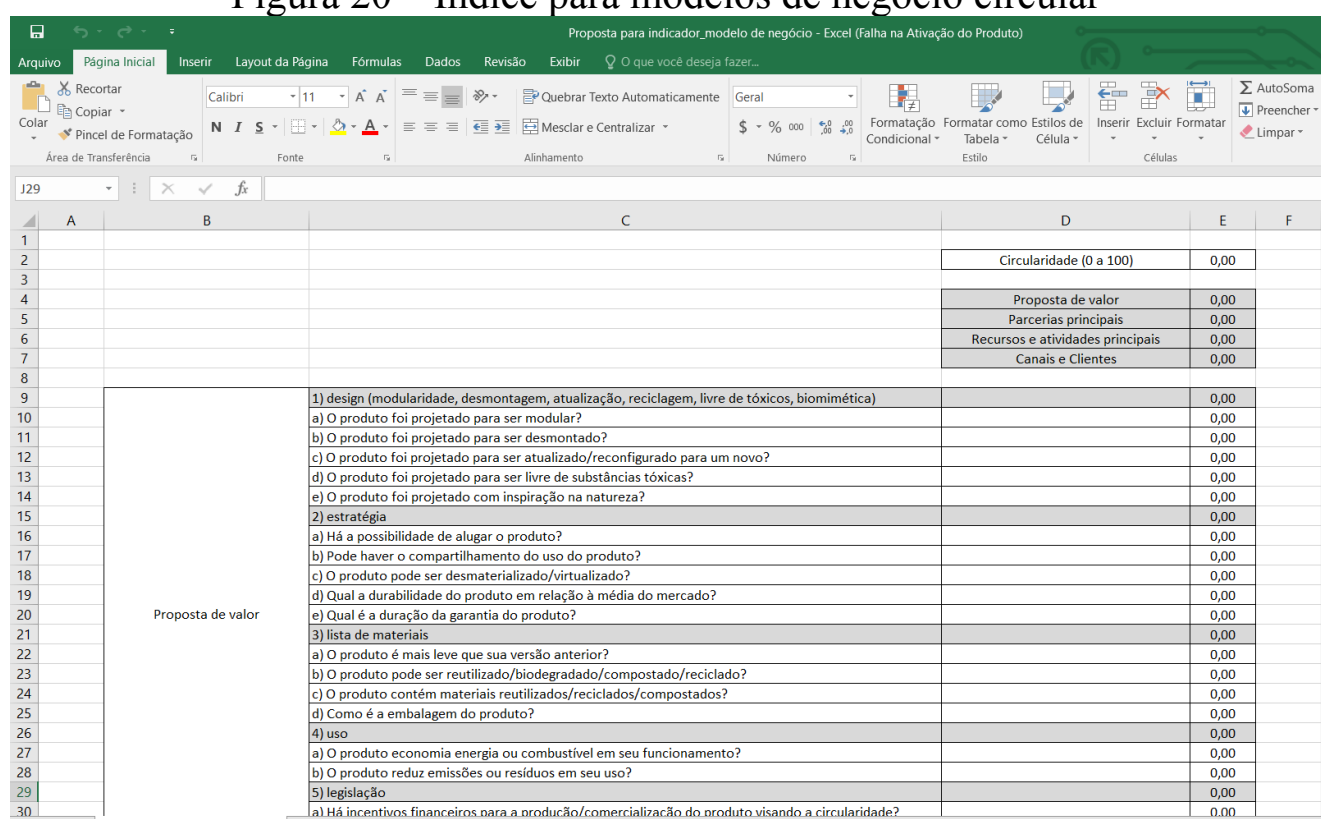

Fonte: Elaboração própria. 
Quadro 8- Questionário para índice de modelos de negócio circulares

\begin{tabular}{|c|c|c|}
\hline & & Respostas \\
\hline \multirow[t]{22}{*}{ Proposta de valor } & 1) design (modularidade, desmontagem, atualização, reciclagem, livre de tóxicos, biomimética) & \\
\hline & a) O produto foi projetado para ser modular? & Sim - 5, Não - 0 \\
\hline & b) O produto foi projetado para ser desmontado? & Sim -5 , Não - 0 \\
\hline & c) O produto foi projetado para ser atualizado/reconfigurado para um novo? & Sim - 5, Não - 0 \\
\hline & d) O produto foi projetado para ser livre de substâncias tóxicas? & Sim - 5, Não - 0 \\
\hline & e) O produto foi projetado com inspiração na natureza? & Sim - 5, Não - 0 \\
\hline & 2) estratégia & \\
\hline & a) Há a possibilidade de alugar o produto? & Sim - 5, Não - 0 \\
\hline & b) Pode haver o compartilhamento do uso do produto? & Sim - 5, Não - 0 \\
\hline & c) O produto pode ser desmaterializado/virtualizado? & Sim - 5, Não - 0 \\
\hline & d) Qual a durabilidade do produto em relação à média do mercado? & "1x" - 0; "2x" - 2,5 e "3x" - 5 \\
\hline & e) Qual é a duração da garantia do produto? & $\begin{array}{c}\text { "0,5 ano" - } 0 \text {; "1 ano" - 1,25; "1,5 ano" } \\
\text { - 2,5; " } 2 \text { anos" - 3,75 e "Mais de } 2 \\
\text { anos" - } 5 \\
\end{array}$ \\
\hline & 3) lista de materiais & \\
\hline & a) $\mathrm{O}$ produto é mais leve que sua versão anterior? & Sim -5 , Não -0 \\
\hline & b) O produto pode ser reutilizado/biodegradado/compostado/reciclado? & Sim - 5, Não - 0 \\
\hline & c) O produto contém materiais reutilizados/reciclados/compostados? & Sim - 5, Não - 0 \\
\hline & d) Como é a embalagem do produto? & $\begin{array}{l}\text { "Embalagem não reciclável" - 0; } \\
\text { "Embalagem feita de múltiplos } \\
\text { materiais e reciclável" - 1,67; } \\
\text { "Embalagem feita apenas de materiais } \\
\text { reciclados" - 3,33; "Embalagem } \\
\text { desnecessária" - 5 }\end{array}$ \\
\hline & 4) uso & \\
\hline & a) O produto economia energia ou combustível em seu funcionamento? & Sim - 5, Não - 0 \\
\hline & b) O produto reduz emissões ou resíduos em seu uso? & Sim - 5, Não - 0 \\
\hline & 5) legislação & \\
\hline & a) Há incentivos financeiros para a produção/comercialização do produto visando a & Sim - 5, Não - 0 \\
\hline
\end{tabular}




\begin{tabular}{|c|c|c|}
\hline & circularidade? & \\
\hline & b) Há rotulagem ambiental do produto? & Sim -5 , Não -0 \\
\hline \multirow{13}{*}{ Parcerias principais } & 1) seleção de fornecedores & \\
\hline & a) Há critérios claros para a seleção de fornecedores? & Sim - 5, Não - 0 \\
\hline & b) São critérios circulares? & $\begin{array}{c}\text { "Não" - 0; "Parcialmente" -1,67; } \\
\text { "Principalmente" -3,33; "Totalmente" } \\
-5\end{array}$ \\
\hline & 2) diversidade nos stakeholders (social, cadeias reversas) & \\
\hline & a) Há interação entre os diversos stakeholders? & Sim - 5, Não - 0 \\
\hline & $\begin{array}{l}\text { b) Busca-se integrar stakeholders das cadeias reversas (coleta, reciclagem, logística reversa, } \\
\text { etc)? }\end{array}$ & Sim - 5, Não - 0 \\
\hline & 3) plataformas de compartilhamento/infraestrutura & \\
\hline & a) Há compartilhamento de banco de dados entre os parceiros principais? & Sim - 5, Não - 0 \\
\hline & b) Há compartilhamento de infraestrutura para a manufatura do produto? & Sim - 5, Não - 0 \\
\hline & 4) parcerias para fechamento de ciclos & \multirow{5}{*}{ "Informalmente" - 0; "Formalmente" - } \\
\hline & a) Como são firmadas as parcerias para o fechamento de ciclo? & \\
\hline & 5) canais de comunicação & \\
\hline & a) Como são os canais de comunicação entre os stakeholders? & \\
\hline \multirow{8}{*}{$\begin{array}{c}\text { Recursos e } \\
\text { atividades principais }\end{array}$} & 1) insumos circulares & \\
\hline & a) Há preferência no uso de matérias primas recicladas/renováveis? & $\begin{array}{c}\text { "Não" - 0; "Parcialmente" -1,67; } \\
\text { "Principalmente" -3,33; "Totalmente" } \\
-5\end{array}$ \\
\hline & 2) processos de manufatura em ciclo fechado & \\
\hline & a) Há processos de manufatura em ciclo fechado (água, resíduos, etc)? & $\begin{array}{c}\text { "Não" - 0; "Parcialmente" -1,67; } \\
\text { "Principalmente" -3,33; "Totalmente" } \\
-5\end{array}$ \\
\hline & 3) quantificação de impactos (ACV, AFM, pegada ecológica) & \\
\hline & a) Há quantificação de impactos ambientais (ACV, AFM, pegada ecológica)? & Sim - 5, Não - 0 \\
\hline & b) Há metas para diminuição de impactos? & Sim - 5, Não - 0 \\
\hline & 4) redução de matérias primas e resíduos & \\
\hline
\end{tabular}




\begin{tabular}{|c|c|c|}
\hline & a) Há quantificação de redução matérias primas e resíduos? & Sim - 5, Não - 0 \\
\hline & 5) uso de energia renovável & \\
\hline & a) Há preferência no uso de energia renovável? & $\begin{array}{c}\text { "Não" - 0; "Parcialmente" -1,67; } \\
\text { "Principalmente" -3,33; "Totalmente" } \\
-5\end{array}$ \\
\hline \multirow{14}{*}{ Canais e clientes } & 1) ciclos reversos(reutilização, reparo, recondicionamento, remanufatura) & \\
\hline & a) Há oferecimento de serviços de manutenção/reparo? & Sim - 5, Não - 0 \\
\hline & b) Há oferecimento de serviços de recondicionamento e remanufatura? & Sim - 5 , Não - 0 \\
\hline & 2) mindset (problemas ambientais, sustentabilidade, circularidade) & \\
\hline & a) Os clientes são comunicados quantos aos benefícios ambientais do produto? & Sim - 5, Não - 0 \\
\hline & $\begin{array}{l}\text { b) Há evidências da preocupação ambiental, sustentável ou circular dos produtos pelos } \\
\text { clientes? }\end{array}$ & Sim - 5, Não - 0 \\
\hline & 3) relacionamento com clientes & \\
\hline & a) Como é o canal de comunicação com os clientes? & $\begin{array}{l}\text { "Nenhum" - 0; "Internet" - 1,67; } \\
\text { "Telefone" - 3,33; "Pessoal" - } 5\end{array}$ \\
\hline & b) Há utilização do feedback dos clientes para melhoramento do produto ou serviço? & Sim -5, Não -0 \\
\hline & 4) logística reversa & \\
\hline & a) Há incentivos para a logística reversa? & $\begin{array}{l}\text { "Não" -0; "A empresa oferece postos } \\
\text { de recebimento gratuitos" - 2,5; "A } \\
\text { empresa oferece incentivos financeiros } \\
\text { para recebimento" - } 5\end{array}$ \\
\hline & 5) Mercado & \\
\hline & a) Há mercado para os produtos remanufaturados/recondicionados? & Sim - 5, Não - 0 \\
\hline & b) Há peças para reposição disponíveis para os clientes? & Sim - 5, Não - 0 \\
\hline
\end{tabular}

Fonte: elaboração própria 
As respostas das perguntas encontradas nos templates, possibilitaram desenvolver uma escala de circularidade, mostrando a maturidade da empresa estudada. Os índices foram aplicados na Empresa B e os resultados estão disponíveis no item 5.5.2.

\subsection{Estudos de caso}

\subsubsection{Empresas C, D e E}

Foram aplicados a segunda versão dos indicadores, item 5.3 em três empresas de estudo, sendo Empresa C (setor eletroeletrônico), Empresa D (setor têxtil) e Empresa E (setor plástico). Cada uma delas se encaixa em um modelo de negócio circular, respectivamente, Produto como serviço/Recuperação de matérias primas secundárias, Extensão da vida do produto/Recuperação de matérias primas secundárias e Recuperação de matérias primas secundárias (ROSSI et al., 2019).

Os resultados podem ser analisados no Quadro 9. 
Quadro 9-Resultado da aplicação dos indicadores

\begin{tabular}{|c|c|c|c|c|c|}
\hline Dimensão & Indicador & Sub-indicador & Empresa C & Empresa D & Empresa E \\
\hline \multirow[t]{3}{*}{ I) Material } & \multirow[t]{2}{*}{$\begin{array}{l}\text { 1.Redução do uso } \\
\text { de materiais }\end{array}$} & $\begin{array}{l}\text { a. Processo de } \\
\text { fabricação }\end{array}$ & $\begin{array}{l}\text { Deixou de comprar mais de } 681 \text { mil caixas de } \\
\text { papelão. Reutilização de pallets: preservação } \\
\text { de cerca de } 7,5 \text { mil árvores, o que evitou a } \\
\text { extração de aproximadamente } 1.500 \text { toneladas } \\
\text { de madeira nos últimos três anos. Todas } \\
\text { ferramentas de aço desenvolvidas ao final do } \\
\text { uso, são recicladas, reduzindo mais de } 1.6 \text { mil } \\
\text { toneladas de matéria-prima. Diminuição de } \\
8 \% \text { na intensidade de uso de materiais para } \\
\text { sistemas pessoais. Diminuição de } 6 \% \text { na } \\
\text { intensidade de uso de materiais. Pegada } \\
\text { hídrica diminuiu } 1 \% \text { em relação a } 2016 .\end{array}$ & $\begin{array}{c}\text { Redução de perdas nos } \\
\text { processos produtivos, e } \\
\text { consequentemente no } \\
\text { consumo de matérias-primas } \\
\text { virgens, e uso de matérias- } \\
\text { primas recicladas } \\
\text { aproximadamente } 7 \% .\end{array}$ & $\begin{array}{l}\text { Redução do consumo de } \\
\text { matérias-primas virgens acima } \\
\text { de } 75 \% \text { dependente da linha de } \\
\text { produto. Redução do uso da } \\
\text { água na linha de moagem do } \\
\text { material. }\end{array}$ \\
\hline & & b. Produto & $\begin{array}{l}\text { O consumo de energia dos produtos de } \\
\text { sistemas pessoais caiu em média } 43 \% \text {. Além } \\
\text { disso, foi reduzido o consumo de energia } \\
\text { anual de um produto em } 52 \% \text { e de outro em } \\
\text { sua versão menor em } 51 \% \text {. }\end{array}$ & $\begin{array}{c}\text { Redução de } 0,06 \mathrm{Kg} / \mathrm{Peça} \mathrm{em} \\
3 \text { anos }\end{array}$ & $\begin{array}{l}\text { Reduções na utilização de } \\
\text { insumos nas formulações de } \\
\text { diversos produtos. }\end{array}$ \\
\hline & 2. Renovabilidade & $\begin{array}{l}\text { a. Energia } \\
\text { renovável }\end{array}$ & $\begin{array}{l}50 \% \text { da energia utilizada nas operações } \\
\text { globais é proveniente de fontes renováveis. }\end{array}$ & $\begin{array}{l}\text { Uso de } 100 \% \text { de energia } \\
\text { renovável nos processos } \\
\text { produtivos (ainda tem GN e } \\
\text { óleo diesel em caso de } \\
\text { emergência); redução entre } 12 \\
\text { a } 15 \% \text { consumo de energia } \\
\text { elétrica nos últimos } 3 \text { anos. }\end{array}$ & $\begin{array}{c}\text { 100\% da energia é proveniente } \\
\text { de fontes de energias renováveis } \\
\text { (Pequenas Centrais } \\
\text { Hidrelétricas, energia eólica, } \\
\text { energia solar e termelétricas a } \\
\text { partir da queima do bagaço da } \\
\text { cana-de-açúcar) }\end{array}$ \\
\hline
\end{tabular}




\begin{tabular}{|c|c|c|c|c|}
\hline & & & $\begin{array}{l}\text { Substituição de óleo BPF por } \\
\text { gás natural desde } 2000 .\end{array}$ & \\
\hline & $\begin{array}{l}\text { b. Matéria- } \\
\text { prima renovável }\end{array}$ & Não disponível & Não disponível & Não disponível \\
\hline \multirow[b]{2}{*}{ 3. Reciclabilidade } & $\begin{array}{l}\text { a. Materiais } \\
\text { reciclados }\end{array}$ & $\begin{array}{l}\text { Um produto manufaturado no Brasil apresenta } \\
\text { atualmente cerca de } 12 \% \text { de material reciclado } \\
\text { em sua composição em massa, com um } \\
\text { potencial de uso de material reciclado de até } \\
32 \% \text {, também em massa. }\end{array}$ & $\begin{array}{l}\text { - Resíduos gerados são } \\
\text { reciclados e projetos em } \\
\text { desenvolvimento para } \\
\text { fechamento do ciclo (100\% do } \\
\text { resíduo têxtil reciclado) }\end{array}$ & $\begin{array}{l}95 \% \text { dos insumos industriais } \\
\text { são reciclados }\end{array}$ \\
\hline & $\begin{array}{l}\text { b. Potencial de } \\
\text { reciclabilidade } \\
\text { do produto }\end{array}$ & $\begin{array}{l}95 \% \text { de todos os resíduos são reciclados, } \\
\text { sendo os outros } 5 \% \text { destinados para cogeração } \\
\text { de energia. }\end{array}$ & $\begin{array}{l}\text { Redução entre } 5 \text { a } 15 \% \text { dos } \\
\text { resíduos de produção gerados, } \\
\text { dependendo da modalidade de } \\
\text { produto produzido. Processo } \\
\text { de secagem do lodo da ETE, } \\
\text { que reduz o volume para } 1 / 7 \\
\text { do normal. Peças podem } \\
\text { conter de } 12 \text { - } 50 \% \text { de sua } \\
\text { composição, de material } \\
\text { reciclado (PET ou desfibrado) }\end{array}$ & $\begin{array}{l}\text { Menos que } 5 \% \text { do volume } \\
\text { utilizado de matérias-primas se } \\
\text { transformam em resíduo }\end{array}$ \\
\hline $\begin{array}{l}\text { 4. Redução de } \\
\text { substâncias } \\
\text { tóxicas }\end{array}$ & & Não utiliza substâncias tóxicas. & $\begin{array}{l}\text { Não existem regulações } \\
\text { nacionais para tal medida, } \\
\text { contudo o Plano } 2020 \text { prevê } \\
\text { meta de restrição conforme } \\
\text { legislação internacional }\end{array}$ & $\begin{array}{c}\text { Porcentagem de resíduo seco } \\
\text { (classe I) destinado a aterros em } \\
\text { relação a quantidade recebida é } \\
\text { de } 13 \%\end{array}$ \\
\hline 5. Reuso & $\begin{array}{l}\text { a. Processo de } \\
\text { fabricação }\end{array}$ & $\begin{array}{l}\text { Os plásticos dos equipamentos e suprimentos } \\
\text { em fim de vida útil são enviados a reciclagem }\end{array}$ & $\begin{array}{l}\text { Programa de reuso de água no } \\
\text { processo produtivo desde }\end{array}$ & Não aplicável \\
\hline
\end{tabular}




\begin{tabular}{|c|c|c|c|c|}
\hline & & $\begin{array}{l}\text { e transformam-se em novas partes e peças de } \\
\text { produtos e embalagens. }\end{array}$ & $\begin{array}{l}\text { 2003, sistema que possui } \\
\text { capacidade nominal de } \\
\text { reutilização de até } 200 \\
\text { milhões de litros de água por } \\
\text { ano (representa } 25 \% \text { do total } \\
\text { de água utilizado), e operam, } \\
\text { em regime normal, com } 75 \% \\
\text { da capacidade nominal do } \\
\text { sistema }\end{array}$ & \\
\hline & b. Produto & $\begin{array}{l}\text { Um produto utiliza cerca de } 12 \% \text { de material } \\
\text { reciclado }\end{array}$ & Não aplicável & Não aplicável \\
\hline 6. Remanufatura & & Não disponível & Não aplicável & Não aplicável \\
\hline $\begin{array}{c}7 \\
\text { Recondicionamen } \\
\text { to }\end{array}$ & & $\begin{array}{l}\text { Em } 2016 \text { um produto pontuou 10/10 na escala } \\
\text { de reparabilidade do iFixit e em } 2018 \text { outro } \\
\text { produto pontuou } 10 / 10 .\end{array}$ & Não aplicável & Não aplicável \\
\hline $\begin{array}{l}\text { 8. Longevidade } \\
\text { do produto }\end{array}$ & & $\begin{array}{l}\text { O tempo médio de uso aumenta, em média, de } \\
3 \text { para } 5 \text { anos de vida útil }\end{array}$ & $\begin{array}{l}\text { Os produtos têm uma vida útil } \\
\text { de aproximadamente } 30 \text { ciclos } \\
\text { de lavagem, podendo ser } \\
\text { estendida de acordo com a } \\
\text { linha do produto. }\end{array}$ & $\begin{array}{l}\text { Produtos possuem longevidade } \\
\text { compatíveis com produtos } \\
\text { originais, porém com restrições } \\
\text { para determinando usos. }\end{array}$ \\
\hline \multirow{2}{*}{$\begin{array}{l}\text { 9. Estrutura e } \\
\text { diversidade de } \\
\quad \text { partes } \\
\text { interessadas na } \\
\text { cadeia de valor } \\
\text { circular }\end{array}$} & a. Estrutura & Não disponível & Não disponível & Não disponível \\
\hline & $\begin{array}{c}\text { b. Partes } \\
\text { interessadas }\end{array}$ & $\begin{array}{c}\text { Desde } 2008 \text { conta com parceiros de fabricação } \\
\text { para construir uma cadeia de fornecimento de } \\
\text { ponta a ponta. }\end{array}$ & $\begin{array}{l}\text { Envolvimento para criação de } \\
\text { negócios associados ao } \\
\text { aproveitamento de resíduos } \\
\text { têxteis. }\end{array}$ & $\begin{array}{l}\text { Criação de uma rede de } \\
\text { empresas associadas a } \\
\text { reciclagem, a coleta, separação } \\
\text { e triagem de embalagens. }\end{array}$ \\
\hline
\end{tabular}




\begin{tabular}{|c|c|c|c|c|c|}
\hline \multirow[t]{5}{*}{$\mathrm{a}$} & \multirow{3}{*}{$\begin{array}{l}\text { 1. Resultados } \\
\text { financeiros }\end{array}$} & $\begin{array}{l}\text { a. Redução de } \\
\text { custo }\end{array}$ & $\begin{array}{l}\text { A resina plástica reciclada é de } 15 \% \text { a } 30 \% \\
\text { mais barata que a resina plástica virgem }\end{array}$ & $\begin{array}{l}\text { Lançamento de produtos com } \\
\text { foco em melhores práticas e } \\
\text { com baixo impacto ambiental } \\
\text { em desenvolvimento, tais } \\
\text { como jeans e malhas. }\end{array}$ & $\begin{array}{l}\text { Desenvolvimento constante de } \\
\text { novas aplicações para produtos } \\
\text { reciclados }\end{array}$ \\
\hline & & $\begin{array}{l}\text { b. Geração de } \\
\text { receita }\end{array}$ & Confidencial & $\begin{array}{l}\text { Produtos que primam pela } \\
\text { qualidade e durabilidade em } \\
\text { relação à média dos seus } \\
\text { concorrentes. }\end{array}$ & Confidencial \\
\hline & & c. Rentabilidade & Não disponível & Não disponível & Não disponível \\
\hline & $\begin{array}{l}\text { 2. Tributação ou } \\
\text { marcos } \\
\text { regulatórios }\end{array}$ & & $\begin{array}{l}\text { Mensalmente, a empresa é tributada em ISS } \\
2 \%+\text { PIS/COFINS } 9.65 \%+\text { eventual INSS } \\
\text { em contratos onde tenham pessoas alocadas. }\end{array}$ & $\begin{array}{l}\text { Regime tributário apontado } \\
\text { como limitador para adoção } \\
\text { de práticas e processos } \\
\text { circulares. (Ex.: bitributação } \\
\text { em resíduos) }\end{array}$ & $\begin{array}{l}\text { Política tributária e fiscal são } \\
\text { problema para negócios } \\
\text { circulares envolvendo a cadeia } \\
\text { de plásticos }\end{array}$ \\
\hline & $\begin{array}{l}\text { 3. Investimento } \\
\text { Circular }\end{array}$ & a. Inovação & Confidencial & $\begin{array}{c}\text { Inovações no uso da água } \\
\text { desde 2002, com otimização } \\
\text { do sistema de tratamento de } \\
\text { efluentes. Uso de novas fibras } \\
\text { naturais e insumos naturais } \\
\text { deste } 2011 \text {. Novos sistemas de } \\
\text { tratamento usando ozônio na } \\
\text { produção de jeans estonado. } \\
\text { Substituição de produtos } \\
\text { químicos nocivos. Uso de } \\
\text { poliamida biodegradável, }\end{array}$ & Confidencial \\
\hline
\end{tabular}




\begin{tabular}{|c|c|c|c|c|c|}
\hline & & & & $\begin{array}{l}\text { auxiliando no fim do ciclo de } \\
\text { vida do produto. }\end{array}$ & \\
\hline \multirow[t]{7}{*}{ III) Social } & $\begin{array}{l}\text { 1. Geração de } \\
\text { emprego }\end{array}$ & & Confidencial & Não disponível & Confidencial \\
\hline & $\begin{array}{l}\text { 2. Renda relativa } \\
\text { aos empregos } \\
\text { gerados }\end{array}$ & & Confidencial & Não disponível & Não disponível \\
\hline & $\begin{array}{l}\text { 3. Participação } \\
\text { dos funcionários } \\
\text { no modelo } \\
\text { circular }\end{array}$ & & Não disponível & Não disponível & Não disponível \\
\hline & & a. Cliente & Não disponível & Não disponível & Não disponível \\
\hline & & b. Valor & Não disponível & Não disponível & Não disponível \\
\hline & $\begin{array}{l}\text { 4. Caracterização } \\
\text { do mercado }\end{array}$ & c. Comunicação & Confidencial & $\begin{array}{l}\text { A empresa tem adotado } \\
\text { praticas associadas a modelos } \\
\text { mais duradouros de negócios. } \\
\text { O processo de transformação } \\
\text { interna já vem ocorrendo em } \\
\text { diversas áreas da empresa. } \\
\text { Tendo sido pioneira na gestão } \\
\text { da água, na redução de } \\
\text { impactos em processos de } \\
\text { tinturaria e estamparia, e na } \\
\text { utilização de Matérias-primas } \\
\text { com viés sustentável. }\end{array}$ & Confidencial \\
\hline & 5. Participação & & Não disponível & Não disponível & Não disponível \\
\hline
\end{tabular}




\begin{tabular}{|c|c|c|c|c|c|}
\hline & das partes & & & & \\
interessadas nos & & & & \\
processos de & & & & \\
decisão & & Não disponível & Não disponível & Não disponível \\
\hline & 6. Mudança do & & & \\
\hline
\end{tabular}

Fonte: traduzido de Rossi et al. (2019) 
Pode-se notar que o foco das empresas ainda predomina na ecoeficiência ao invés da ecoefetividade, pois a maioria dos impactos positivos, possivelmente encontrados na dimensão social não são medidos ou são confidenciais. Além disso, esses indicadores devem ser vistos em sua totalidade e não de maneira isolada.

A aplicação dos indicadores permitiu identificar que Empresa $\mathrm{C}$ pode aumentar o indicador de reuso para o produto (I5b) - área de Desenvolvimento do Produto. Além de negociar a bitributação (área Financeira) e aplicar os indicadores sociais não calculados, oportunidades para as áreas de Recursos Humanos, Responsabilidade Social, Marketing e Gestão da Mudança.

A Empresa D pode aumentar o uso de matérias primas recicladas (indicador I1a) que atualmente é de 7\%, além disso pode quantificar os indicadores econômicos (área Financeira) e aplicar os indicadores sociais oportunidades para desenvolvimento das áreas de Recursos Humanos, Responsabilidade Social, Marketing e Gestão da Mudança.

A Empresa E possui excelência nos indicadores materiais, pode melhorar nos indicadores econômicos (área Financeira) e aplicar os indicadores sociais, principalmente o de Mindset (III6), criando oportunidades de melhorias para as áreas de Recursos Humanos, Responsabilidade Social, Marketing e Gestão da Mudança.

\subsubsection{Empresa B}

O estudo de caso na Empresa B iniciou-se com entrevistas do estudo de caso exploratório e a consolidação de um convênio de pesquisa com a empresa em 2019. No dia 20/02/2020 foi feita uma visita técnica na planta, com o objetivo de visitar a produção, elencar os pontos principais da pesquisa e firmar a parceira.

Além disso, foram realizadas 12 entrevistas semiestruturadas descritas no Apêndice B com funcionários da Empresa $\mathrm{B}$. O resultado mostrou que a empresa possui diversos indicadores, presentes nos seus relatórios de sustentabilidade (Global Report Iniciative - GRI), além de possuir indicadores voltados para Avaliação do Ciclo de Vida e Pegada de Carbono, que estão aos poucos participando das tomadas de decisão da empresa. Entretanto a empresa ainda não mede diretamente as inovações da Economia Circular em sua totalidade, sendo que mostra a necessidade de criação de novas métricas.

Além da realização desse diagnóstico por meio das entrevistas semiestruturadas, foi enviado à empresa os arquivos em Excel das propostas dos índices presentes no item 5.3, cujo resultado está disposto a seguir. 
a) Índice de produto circular

O produto analisado pela empresa foi o vergalhão, utilizado na construção civil, e o resultado está disposto na Figura 21.

Figura 21 - Resultado para o vergalhão

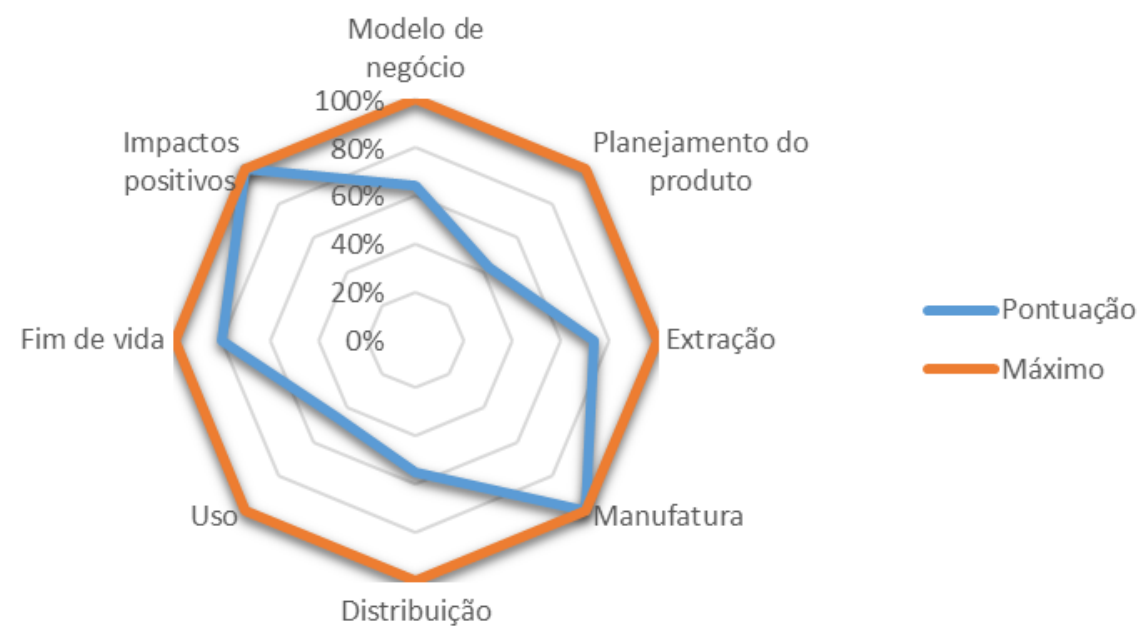

Fonte: Elaboração própria

Nota-se que a empresa recebeu pontuação máxima para manufatura e impactos positivos, mostrando sua otimização do processo e benefícios já mensurados, dessa forma encontrou-se um total de 76\%, conforme a Figura 22.

Figura 22 - Pontuação do índice de produto circular

\begin{tabular}{|c|c|c|c|c|}
\hline & Pontuação & Máximo & Pontuação & Máximo \\
\hline Modelo de negócio & 3,2 & 5 & $64 \%$ & $100 \%$ \\
\hline Planejamento do produto & 3 & 7 & $43 \%$ & $100 \%$ \\
\hline Extração & 3,7 & 5 & $74 \%$ & $100 \%$ \\
\hline Manufatura & 5 & 5 & $100 \%$ & $100 \%$ \\
\hline Distribuição & 2,2 & 4 & $55 \%$ & $100 \%$ \\
\hline Uso & 3,2 & 7 & $46 \%$ & $100 \%$ \\
\hline Fim de vida & 5,6 & 7 & $80 \%$ & $100 \%$ \\
\hline Impactos positivos & 5 & 5 & $100 \%$ & $100 \%$ \\
\hline & & & & \\
\hline & & & & \\
\hline & Pontuação & Máximo & & \\
\hline Resultado & $76 \%$ & $100 \%$ & & \\
\hline Muito boa & & & & \\
\hline
\end{tabular}

Fonte: Elaboração própria 
Entretanto, os resultados inferiores do índice foram os itens de planejamento do produto e uso. No item de modelo de negócio, a empresa apresentou baixa porcentagem no investimento com o modelo circular e dificuldades nos tributos que o envolvem. No item de planejamento do produto, algumas questões quanto à modularidade, desmonte, biomimética e design para reuso não foram atendidas, por ser um produto intermediário. No item de extração, a empresa não pontuou onde há a questão do reuso, pois $70 \%$ do produto é proveniente da reciclagem. No item de distribuição, não havia dados sobre o custo da distribuição e pontuou pouco onde se questionava sobre a garantia do produto. No item de uso, não houve pontuação nos quesitos de aluguel do produto, desmaterialização e menos gasto de energia no uso. No item de fim de vida, nota-se o não incentivo financeiro do take back e $80 \%$ dos produtos que retornam. Desses que retornam há possibilidade de reutilização de $80 \%$ do produto.

b) Índice para modelos de negócio circulares

O modelo de negócio estudado é aquele que providencia o vergalhão, ao qual é denotado pela BSI 8001 como Recuperação de matérias primas secundárias/subprodutos, pois há o fechamento de ciclos por meio de aproveitamento de sucata para a produção do vergalhão.

A aplicação do índice para modelos de negócio circulares permitiu que a empresa atingisse uma pontuação de 76,08 de 100, conforme Figura 23. Mostrando melhor desempenho no componente de Parcerias principais, evidenciando a colaboração para o fechamento de ciclos. Entretanto, como diagnosticado no índice de produtos circulares podese notar que o componente do modelo de negócio com pior desempenho foi o de proposta de valor.

Figura 23 - Resultados do índice para modelos de negócio circulares

\begin{tabular}{|c|c|}
\hline Circularidade (0 a 100) & 76,08 \\
\hline Proposta de valor (0 a 25) & 11,08 \\
\hline Parcerias principais (0 a 25) & 23,34 \\
\hline Recursos e atividades principais (0 a 25) & 21,66 \\
\hline Canais e Clientes (0 a 25) & 20,00 \\
\hline
\end{tabular}

Fonte: Elaboração própria 
Por ser um produto com vida útil longa, e convencionalmente utilizado na construção civil tradicional, há possibilidade de melhoria nesse aspecto por iniciativas de design, estratégia, como por exemplo o aluguel e a modularidade do produto, entre outros. Nota-se que o quesito de durabilidade é importante para a Economia Circular, entretanto, muitos aspectos do modelo de negócio podem ser repensados, como por exemplo a modularidade e a facilidade do desmonte.

No componente de proposta de valor, alguns quesitos, principalmente sobre o design (modularidade, desmontagem, atualização, reciclagem, livre de tóxicos, biomimética), não foram contemplados, evidenciando, propostas de melhorias. A parte do uso também pode ser melhorada, mostrando que o produto pode gerar economia de energia ou emissões no uso. No componente de recursos e atividades principais, pode-se ter melhorias nos processos de manufatura em ciclo fechado e no uso de energia renovável. No componente de canais e clientes pode-se melhorar no oferecimento de serviços de manufatura e incentivos financeiros para logística reversa.

De uma maneira geral, os indicadores foram bem compreendidos e a empresa pode observar vários aspectos importantes da Economia Circular, os pontos de melhorias encontrados podem ser elencados como:

1) Mudanças na proposta de valor do produto: modularidade, inspiração na natureza, projetado para desmonte, e demais aspectos do design.

2) Planejamento do produto: reuso e desmonte, incluindo propostas de take back para os clientes, podendo ser abatido no preço de venda.

3) Uso: aluguel do produto e inovações no seu modelo de negócio.

Por fim, foi feita uma apresentação para mostrar os resultados para a empresa e obter o feedback para avaliação dos índices. A empresa indicou que as perguntas eram diretas, bem estruturadas. Porém, por se tratar de um produto semiacabado, algumas perguntas não se encaixavam perfeitamente no modelo de negócio da empresa. Outro ponto é que algumas perguntas estavam repetidas.

\subsection{Proposta final dos índices para Economia Circular}

Por meio do estudo de caso realizado, foi possível reestruturar os índices para serem prontamente utilizáveis. Sendo assim, optou-se por fazer com que um índice alimente o outro, evitando sobreposição de perguntas. Ou seja, o índice de produtos circulares (variando de 0 a 
100), Quadro 10, participa do componente de Proposta de Valor do índice de modelos de negócio circulares. 
Quadro 10 - Índice para produtos circulares

\begin{tabular}{|c|c|c|c|}
\hline \multirow{13}{*}{$\begin{array}{l}\text { Planejamento do } \\
\text { produto }\end{array}$} & 1 & O produto foi projetado para ser modular? & Sim-1; Não-0 \\
\hline & 2 & O produto foi projetado para ser desmontável? & Sim-1; Não-0 \\
\hline & 3 & O produto foi projetado para ser atualizado/reconfigurado para um novo? & Sim-1; Não-0 \\
\hline & 4 & O produto é desenhado para reuso? & Sim-1; Não-0 \\
\hline & 5 & O produto foi projetado com inspiração na natureza? & Sim-1; Não-0 \\
\hline & 6 & O produto foi projetado para ser livre de substâncias tóxicas? & Sim-1; Não-0 \\
\hline & 7 & O produto é mais leve que sua versão anterior? & Sim-1; Não-0 \\
\hline & 8 & O produto pode ser reutilizado/biodegradado/compostado/reciclado? & Sim-1; Não-0 \\
\hline & 9 & O produto contém materiais reutilizados/reciclados/compostados? & Sim-1; Não-0 \\
\hline & 10 & O produto é desenhado para ser durável? & Sim-1; Não-0 \\
\hline & 11 & O produto é projetado para ser reciclado? & Sim-1; Não-0 \\
\hline & 12 & $\begin{array}{l}\text { Há incentivos financeiros para a produção/comercialização do produto visando a } \\
\text { circularidade? }\end{array}$ & Sim-1; Não-0 \\
\hline & 13 & Há rotulagem ambiental do produto? & Sim-1; Não-0 \\
\hline \multirow{6}{*}{ Extração } & 14 & Qual a porcentagem do produto é proveniente do reuso/remanufatura? & $0-100 \%$ ou seja, $0-1$ \\
\hline & 15 & Qual a porcentagem do produto é proveniente de reciclagem? & $0-100 \%$ ou seja, $0-1$ \\
\hline & 16 & Qual é a eficiência da reciclagem? & $0-100 \%$ ou seja, $0-1$ \\
\hline & 17 & Há redução no uso de matérias primas? & Sim-1; Não-0 \\
\hline & 18 & Há preferência no uso de matérias primas recicladas/renováveis? & Sim-1; Não-0 \\
\hline & 19 & $\begin{array}{l}\text { Há redução de substâncias tóxicas no produto (a RoHS (Restriction of Certain } \\
\text { Hazardous Substances))? }\end{array}$ & Sim-1; Não-0 \\
\hline \multirow[t]{2}{*}{ Manufatura } & 20 & Há redução no uso de água? & Sim-1; Não-0 \\
\hline & 21 & Há processos de manufatura em ciclo fechado (água, resíduos, etc)? & Sim-1; Não-0 \\
\hline
\end{tabular}




\begin{tabular}{|c|c|c|c|}
\hline & 22 & Há redução no uso de energia? & Sim-1; Não-0 \\
\hline & 23 & Há uso de energia renovável? & Sim-1; Não-0 \\
\hline & 24 & Há redução na emissão de poluentes? & Sim-1; Não-0 \\
\hline & 25 & Há redução na geração de resíduos? & Sim-1; Não-0 \\
\hline \multirow[t]{4}{*}{ Distribuição } & 26 & Como é a embalagem do produto? & $\begin{array}{l}\text { Embalagem não reciclável; } \\
0 ; \text { Embalagem feita de } \\
\text { múltiplos materiais e } \\
\text { reciclável; } 0,25 ; \\
\text { Embalagem feita apenas de } \\
\text { materiais reciclados; 0,5; } \\
\text { Embalagem desnecessária; } \\
1\end{array}$ \\
\hline & 27 & Há cálculo da pegada de carbono da distribuição? & Sim-1; Não-0 \\
\hline & 28 & Qual a porcentagem do custo do produto é voltada para a distribuição? & $0-100 \%$ ou seja, $1-0$ \\
\hline & 29 & Quantas vezes à mais é a garantia do produto em relação à média do mercado? & $\begin{array}{c}0 \text { vezes- } 0 ; 0,5 \text { vezes- } 0,1 ; 1 \\
\text { vezes- } 0,2 ; 1,5 \text { vezes- } 0,3 ; 2 \\
\text { vezes- } 0,4 ; 2,5 \text { vez- } 0,5 ; 3 \\
\text { vezes- } 0,6 ; 3,5 \text { vezes- } 0,7 ; 4 \\
\text { vezes- } 0,8 ; 4,5 \text { vezes- } 0,9 ; 5 \\
\quad \text { vezes- } 1\end{array}$ \\
\hline Uso & 30 & Quantas vezes à mais é a durabilidade do produto em relação à média do mercado? & $\begin{array}{l}0 \text { vezes- } 0 ; 0,5 \text { vezes- } 0,1 ; 1 \\
\text { vezes- } 0,2 ; 1,5 \text { vezes- } 0,3 ; 2 \\
\text { vezes- } 0,4 ; 2,5 \text { vez- } 0,5 ; 3 \\
\text { vezes- } 0,6 ; 3,5 \text { vezes- } 0,7 ; 4 \\
\text { vezes- } 0,8 ; 4,5 \text { vezes- } 0,9 ; 5\end{array}$ \\
\hline
\end{tabular}




\begin{tabular}{|c|c|c|c|}
\hline & & & vezes-1 \\
\hline & 31 & Há medição de circularidade do produto? & Sim-1; Não-0 \\
\hline & 32 & Há medição de longevidade do produto? & Sim-1; Não-0 \\
\hline & 33 & O produto economia energia ou combustível em seu funcionamento? & Sim-1; Não-0 \\
\hline & 34 & O produto reduz emissões ou resíduos em seu uso? & Sim-1; Não-0 \\
\hline & 35 & Há oferecimento de manutenção/reparo para o produto? & Sim-1; Não-0 \\
\hline & 36 & Há oferecimento de serviços de recondicionamento e remanufatura? & Sim-1; Não-0 \\
\hline \multirow{7}{*}{ Fim de vida } & 37 & Há oferecimento de logística reversa para o produto? & Sim-1; Não-0 \\
\hline & 38 & Qual é a porcentagem dos produtos que retornam? & $0-100 \%$ ou seja, $0-1$ \\
\hline & 39 & Há incentivos para a logística reversa? & Sim-1; Não-0 \\
\hline & 40 & Qual é a porcentagem do produto que pode ser reutilizável após seu uso? & $0-100 \%$ ou seja, $0-1$ \\
\hline & 41 & Qual é a porcentagem do produto que pode ser reciclável após seu uso? & $0-100 \%$ ou seja, $0-1$ \\
\hline & 42 & Qual é a eficiência da reciclagem? & $0-100 \%$ ou seja, $0-1$ \\
\hline & 43 & O produto pode ser remanufaturado? & Sim-1; Não-0 \\
\hline \multirow{5}{*}{ Impactos positivos } & 44 & Há geração de empregos com o modelo circular? & Sim-1; Não-0 \\
\hline & 45 & Há mapeamento das partes interessadas no modelo circular? & Sim-1; Não-0 \\
\hline & 46 & $\begin{array}{l}\text { Há melhoria ambiental com o modelo circular? (sequestro de carbono, melhoria da } \\
\text { qualidade da água, etc)? }\end{array}$ & Sim-1; Não-0 \\
\hline & 47 & Há mudança de mindset com o modelo circular? & Sim-1; Não-0 \\
\hline & 48 & Os clientes são comunicados quantos aos benefícios ambientais do produto? & Sim-1; Não-0 \\
\hline
\end{tabular}


A partir dessas respostas, por meio de uma média aritmética o resultado da porcentagem do produto é dado, variando em uma escala de 0-100\%. Esse valor é inserido no próximo índice, Quadro 11, na parte de "Proposta de Valor". 
Quadro 11 - Índice para modelos de negócio circulares

\begin{tabular}{|c|c|c|}
\hline \multirow{12}{*}{ Gerais } & $0)$ Geral & \\
\hline & a) O modelo de negócio enquadra-se na lista de modelos circulares da BSI 8001 ? & Sim - 1, Não - 0 \\
\hline & b) Há geração de receita com o modelo circular? & Sim - 1, Não - 0 \\
\hline & c) Há redução de custos com o modelo circular? & Sim - 1, Não - 0 \\
\hline & d) Qual é a porcentagem do investimento da empresa no modelo circular? & $0-100 \%$, ou seja, $0-1$ \\
\hline & e) Os tributos subsidiam de forma justa o modelo circular? & Sim - 1, Não - 0 \\
\hline & 1) estratégia & \\
\hline & a) Há a possibilidade de alugar o produto? & Sim - 1, Não - 0 \\
\hline & b) Pode haver o compartilhamento do uso do produto? & Sim - 1, Não - 0 \\
\hline & c) O produto pode ser desmaterializado/virtualizado? & Sim - 1, Não - 0 \\
\hline & d) Qual a durabilidade do produto em relação à média do mercado? & "1x" - 0; "2x" - 0,5 e "3x" - 1 \\
\hline & e) Qual é a duração da garantia do produto? & $\begin{array}{c}\text { "0,5 ano" - 0; "1 ano" - 0,25; "1,5 } \\
\text { ano" - 0,5; " } 2 \text { anos" - 0,75 e } \\
\text { "Mais de } 2 \text { anos" - } 1\end{array}$ \\
\hline Proposta de valor & & $\begin{array}{l}\text { Inserir valor da planilha de } \\
\text { produto }\end{array}$ \\
\hline Parcerias principais & 2) seleção de fornecedores & \\
\hline & a) Há critérios circulares para a seleção de fornecedores? & Sim - 1, Não - 0 \\
\hline & 3) diversidade nos stakeholders (social, cadeias reversas) & \\
\hline & a) Há interação entre os diversos stakeholders? & Sim - 1, Não - 0 \\
\hline & $\begin{array}{l}\text { b) Busca-se integrar stakeholders das cadeias reversas (coleta, reciclagem, logística } \\
\text { reversa, etc)? }\end{array}$ & Sim - 1, Não - 0 \\
\hline & 4) plataformas de compartilhamento/infraestrutura & \\
\hline & a) Há compartilhamento de banco de dados entre os parceiros principais? & Sim - 1, Não - 0 \\
\hline & b) Há compartilhamento de infraestrutura para a manufatura do produto? & Sim - 1, Não - 0 \\
\hline & 5) parcerias para fechamento de ciclos & \\
\hline & a) Como são firmadas as parcerias para o fechamento de ciclo? & $\begin{array}{l}\text { "Informalmente" - 0; } \\
\text { "Formalmente" - } 1\end{array}$ \\
\hline & 6) canais de comunicação & \\
\hline
\end{tabular}




\begin{tabular}{|c|c|c|}
\hline & a) Como são os canais de comunicação entre os stakeholders? & $\begin{array}{l}\text { "Nenhum" - 0; "Internet" - 0,33; } \\
\text { "Telefone" - 0,66; "Pessoal" - } 1\end{array}$ \\
\hline \multirow{3}{*}{$\begin{array}{l}\text { Recursos e atividades } \\
\text { principais }\end{array}$} & 7) quantificação de impactos (ACV, AFM, pegada ecológica) & \\
\hline & a) Há quantificação de impactos ambientais (ACV, AFM, pegada ecológica)? & Sim - 1, Não - 0 \\
\hline & b) Há metas para diminuição de impactos negativos? & Sim - 1, Não - 0 \\
\hline \multirow{8}{*}{ Canais e clientes } & 8) mindset dos clientes & \\
\hline & $\begin{array}{l}\text { b) Há evidências da preocupação ambiental, sustentável ou circular dos produtos } \\
\text { pelos clientes? }\end{array}$ & Sim - 1, Não - 0 \\
\hline & 9) relacionamento com clientes & \\
\hline & a) Como é o canal de comunicação com os clientes? & $\begin{array}{l}\text { "Nenhum" - 0; "Internet" - 0,33; } \\
\text { "Telefone" - 0,66; "Pessoal" - } 1\end{array}$ \\
\hline & $\begin{array}{l}\text { b) Há utilização do feedback dos clientes para melhoramento do produto ou } \\
\text { serviço? }\end{array}$ & Sim - 1, Não - 0 \\
\hline & 10) Mercado & \\
\hline & a) Há mercado para os produtos remanufaturados/recondicionados? & Sim - 1, Não - 0 \\
\hline & b) Há peças para reposição disponíveis para os clientes? & Sim - 1, Não - 0 \\
\hline
\end{tabular}


A partir dessas respostas, por meio de uma média aritmética o resultado da porcentagem do produto é dado, variando em uma escala de $0-100 \%$. 


\section{CONCLUSÕES}

O desenvolvimento de indicadores para a Economia Circular foi possível por meio da abordagem DRM, testando a teoria na prática, avançando a estruturação das métricas em seis estudos de caso. Inicialmente foi possível avaliar que na literatura haviam poucos indicadores voltados para todos os pilares da sustentabilidade e relativos a todos os componentes dos modelos de negócio.

Dessa maneira foram criadas três versões de índices que ao serem aplicados em diferentes modelos de negócio, proporcionaram o respaldo necessário para diagnosticar empresas ante os princípios da Economia Circular. Sendo assim, proporcionam base para elencar melhorias em seus produtos e modelo de negócios. Outro ponto importante foi a criação de indicadores que facilitam diagnosticar mpresas ante os três pilares da sustentabilidade. A aplicação destes mostrou que o pilar social encontrou maior dificuldade na obtenção de dados, e o econômico mostrou-se confidencial para diversas empresas. Como limitações do presente trabalho, vale ressaltar a aplicação em poucas empresas, sendo necessário uma amostra mais significativa. Além disso, as versões dos índices não foram aplicadas desde o início em uma mesma empresa.

A principal contribuição do presente trabalho está na criação de métricas para diferentes empresas ao qual relaciona modelo de negócios, sustentabilidade e princípios da Economia Circular. Os indicadores pautados na literatura e na aplicação em estudos de caso possibilitam de forma clara e direta diagnosticar e possibilitar diferentes empresas a melhorarem seu desempenho voltado para as inovações da Economia Circular. Outro ponto importante foi a realização de estudos de caso e entrevistas em diversas empresas da realidade brasileira.

Para futuros trabalhos pode-se buscar a aplicação efetiva dos indicadores da dimensão social, utilizar a versão final do índice em mais empresas e modelos de negócio, buscando melhorias para mais stakeholders, além de propor maneiras de interação entre os indicadores, por meio de sistemas complexos. 


\section{REFERÊNCIAS}

ABNT. ABNT NBR ISO 14040: Gestão ambiental - Avaliação do Ciclo de Vida Princípios e Estrutura. Rio de Janeiro: ABNT/NBR/ISO, 2009.

ABUKHADER, S. M. Eco-efficiency in the era of electronic commerce - should 'EcoEffectiveness' approach be adopted? Journal of Cleaner Production, v. 16, n. 7, p. 801-808, 2008.

ADVANCING SUSTAINABILITY LTD. Circular Benefits Tool (CBT), 2013. Disponível em: <https://www.advancingsustainability.com/resources-sustainability\#csi>

AGRAWAL, V. V.; ATASU, A.; VAN WASSENHOVEC, L. N. New Opportunities for Operations Management Research in Sustainability. M\&som-Manufacturing \& Service Operations Management, v. 21, n. 1, p. 1-12, WIN 2019.

AKANBI, L. A. et al. Salvaging building materials in a circular economy: A BIM-based whole-life performance estimator. Resources, Conservation and Recycling, v. 129, p. 175-186, 1 fev. 2018.

ALAMEREW, Y. A. et al. A Multi-Criteria Evaluation Method of Product-Level Circularity Strategies. Sustainability, v. 12, n. 12, p. 5129, jan. 2020.

ASIEDU, Y.; GU, P. Product life cycle cost analysis: State of the art review. International Journal of Production Research, v. 36, n. 4, p. 883-908, 1998.

AZEVEDO, S. G.; GODINA, R.; MATIAS, J. C. DE O. Proposal of a Sustainable Circular Index for Manufacturing Companies. Resources, v. 6, n. 4, p. 63, 10 nov. 2017.

BARBIROLI, G. Eco-efficiency or/and eco-effectiveness? Shifting to innovative paradigms for resource productivity. International Journal of Sustainable Development and World Ecology, v. 13, n. 5, p. 391-395, 2006.

BARGH, M. A Blue Economy for Aotearoa New Zealand? Environment, Development and Sustainability, v. 16, n. 3, p. 459-470, 2014.

BLESSING, L. T. M.; CHAKRABARTI, A. DRM: a Design Research Methodology. Londres: Springer, 2009.

BLOMSMA, F.; BRENNAN, G. The Emergence of Circular Economy: A New Framing Around Prolonging Resource Productivity. Journal of Industrial Ecology, v. 21, n. 3, p. 603-614, 2017.

BOBBA, S. et al. Life Cycle Assessment of repurposed electric vehicle batteries: an adapted method based on modelling energy flows. Journal of Energy Storage, v. 19, p. 213-225, 1 out. 2018.

BOCKEN, N. M. P. et al. Taking the Circularity to the Next Level: A Special Issue on the Circular Economy. Journal of Industrial Ecology, v. 21, n. 3, p. 476-482, 1 jun. 2017. 
BOCKEN, N. M. P.; RITALA, P.; HUOTARI, P. The Circular Economy: Exploring the Introduction of the Concept Among S\&P 500 Firms. Journal of Industrial Ecology, v. 21, n. 3, p. 487-490, 1 jun. 2017.

BRAUNGART, M.; MCDONOUGH, W.; BOLLINGER, A. Cradle-to-cradle design: creating healthy emissions - a strategy for eco-effective product and system design. Journal of Cleaner Production, v. 15, n. 13-14, p. 1337-1348, 2007.

BRUNNER, P. H. Substance Flow Analysis. Journal of Industrial Ecology, v. 16, n. 3, p. 293-295, 1 jun. 2012.

BSI. BS 8001:2017. Framework for Implementing the Principles of the Circular Economy in Organizations - Guide. London: The British Standards Institution, 2017.

C2C. Impact study: Technical report-Pilot study impact study of the cradle to cradle certified products program., 2014. Disponível em: <www.c2ccertified.org/impact-study>. Acesso em: 19 abr. 2018

CAYZER, S.; GRIFFITHS, P.; BEGHETTO, V. Design of indicators for measuring product performance in the circular economy. International Journal of Sustainable Engineering, $\mathrm{v}$. 10, n. 4-5, p. 289-298, 2017.

CIRCLE ECONOMY. Circle AssessmentCircle Economy, , 2014. Disponível em: $<$ https://www.circle-assessment.com/>

CIRCLE ECONOMY. Project portifolio: ACT modelCircle Economy, , 2015. Disponível em:

$<$ https://www.circle-economy.com/wpcontent/uploads/2015/02/CircleEconomy_ProjectPortfolio.pdf>

CIRCLE ECONOMY. The Circularity Gap ReportThe Plataform for Accelerating the Circular Economy (PACE), , 2019. Disponível em: < https://www.circularity-gap.world/>

CONFEDERAÇÃO NACIONAL DA INDÚSTRIA. Economia circular : oportunidades e desafios para a indústria brasileira. Brasília: CNI, 2018.

CORONA, B. et al. Towards sustainable development through the circular economy-A review and critical assessment on current circularity metrics. Resources, Conservation and Recycling, v. 151, 2019.

CULLEN, J. M. Circular Economy: Theoretical Benchmark or Perpetual Motion Machine? Journal of Industrial Ecology, v. 21, n. 3, p. 483-486, 1 jun. 2017.

DE LOS RIOS, I. C.; CHARNLEY, F. J. S. Skills and capabilities for a sustainable and circular economy: The changing role of design. Journal of Cleaner Production, v. 160, p. $109-122,2017$.

DESCHAMPS, J. et al. Is open-loop recycling the lowest preference in a circular economy? Answering through LCA of glass powder in concrete. Journal of Cleaner Production, v. 185, p. 14-22, 1 jun. 2018.

DESROCHERS, P. Natural capitalists' indictment of traditional capitalism: A reappraisal. Business Strategy and the Environment, v. 11, n. 4, p. 203-220, 2002. 
DI MAIO, F. et al. Measuring resource efficiency and circular economy: A market value approach. Resources, Conservation and Recycling, v. 122, p. 163-171, 1 jul. 2017.

DI MAIO, F.; REM, P. C. A Robust Indicator for Promoting Circular Economy through Recycling. Journal of Environmental Protection, v. 06, n. 10, p. 1095, 9 out. 2015.

EEA. Circular economy in Europe: developing the knowledge base. Luxemburgo: European Environment Agency, 2016.

ELIA, V.; GNONI, M. G.; TORNESE, F. Measuring circular economy strategies through index methods: A critical analysis. Journal of Cleaner Production, v. 142, p. 2741-2751, 2017.

ELLEN MACARTHUR FOUNDATION. DESIGNING FOR A CIRCULAR ECONOMY: The conceptual design of a circular mobile deviceFlora Poppelaars // Circular Economy Innovation Project // Schmidt-MacArthur Fellowship 2013-2014, , 2013a. Disponível em: $<$ https://www.ellenmacarthurfoundation.org/assets/downloads/Floras-CEIP-report-Designingfor-a-Circular-Economy.pdf>

ELLEN MACARTHUR FOUNDATION. Building Blocks: Circular economy design, business models, reverse cycles and enabling conditions are essential, 2013b. Disponível em: <https://www.ellenmacarthurfoundation.org/circular-economy/concept/building-blocks $>$. Acesso em: 23 out. 2018

ELLEN MACARTHUR FOUNDATION. Towards the circular economy, 2014. Disponível em: <https://www.ellenmacarthurfoundation.org/assets/downloads/publications/Towards-thecircular-economy-volume-3.pdf $>$

ELLEN MACARTHUR FOUNDATION. Schools Of Thought, 2017. Disponível em: $<$ https://www.ellenmacarthurfoundation.org/circular-economy/schools-ofthought/performance-economy>

ELLEN MACARTHUR FOUNDATION. Economia circular, 2018. Disponível em: $<$ https://www.ellenmacarthurfoundation.org/pt/economia-circular-1/conceito $>$

ELLEN MACARTHUR FOUNDATION. CirculyticsEllen MacArthur Foundation, , 2020. Disponível em: $<$ https://www.ellenmacarthurfoundation.org/resources/apply/circulyticsmeasuring-circularity/resources $>$. Acesso em: 28 fev. 2020

ELLEN MACARTHUR FOUNDATION; GRANTA. Circularity Indicators: An Approach to Measuring Circularity. Disponível em: $<$ https://www.ellenmacarthurfoundation.org/resources/apply/circularity-indicators $>$.

ELLEN MACARTHUR FOUNDATION; MCKINSEY \& COMPANY. Towards the Circular Economy: Accelerating the scale-up across global supply chainsWorld Economic Forum, 2014. Disponível em: $<\mathrm{http}$ ://www3.weforum.org/docs/WEF_ENV_TowardsCircularEconomy_Report_2014.pdf $>$

ESPOSITO, M.; TSE, T.; SOUFANI, K. Is the Circular Economy a New Fast-Expanding Market? Thunderbird International Business Review, v. 59, n. 1, p. 9-14, 2017. 
EVANS, J.; BOCKEN, N. Circular Economy Toolkit. Disponível em: $<$ http://www.circulareconomytoolkit. com>. Acesso em: 19 abr. 2018.

FIGGE, F. et al. Longevity and Circularity as Indicators of Eco-Efficient Resource Use in the Circular Economy. Ecological Economics, v. 150, p. 297-306, 2018.

FIKSEL, J. Designing Resilient, Sustainable Systems. Environmental Science \& Technology, v. 37, n. 23, p. 5330-5339, 1 dez. 2003.

FOGARASSY, C. et al. The development of a circular evaluation (CEV) tool: case study for the 2024 Budapest Olympics. HUNGARIAN AGRICULTURAL ENGINEERING, n. 31, p. 10-20, 2017.

FOLAN, P.; BROWNE, J. A review of performance measurement: Towards performance management. Computers in Industry, v. 56, n. 7, p. 663-680, 1 set. 2005.

FRANCO-SANTOS, M. et al. Towards a definition of a business performance measurement system. International Journal of Operations and Production Management, v. 27, n. 8, p. 784-801, 2007.

FRANKLIN-JOHNSON, E.; FIGGE, F.; CANNING, L. Resource duration as a managerial indicator for Circular Economy performance. Journal of Cleaner Production, v. 133, p. 589-598, 2016.

FREGONARA, E. et al. Economic-Environmental Indicators to Support Investment Decisions: A Focus on the Buildings' End-of-Life Stage. Buildings, v. 7, n. 3, p. 65, 21 jul. 2017.

FRISHAMMAR, J.; PARIDA, V. Circular Business Model Transformation: A Roadmap for Incumbent Firms. California Management Review, v. 61, n. 2, p. 5-29, 2019.

GEHIN, A.; ZWOLINSKI, P.; BRISSAUD, D. A tool to implement sustainable end-of-life strategies in the product development phase. Journal of Cleaner Production, v. 16, n. 5, p. $566-576,2008$.

GEISENDORF, S.; PIETRULLA, F. The circular economy and circular economic concepts - a literature analysis and redefinition. Thunderbird International Business Review, v. 60, n. 5, p. 771-782, 1 set. 2018.

GEISSDOERFER, M. et al. Business models and supply chains for the circular economy. Journal of Cleaner Production, v. 190, p. 712-721, 20 jul. 2018.

GENG, Y. et al. Assessment of the National Eco-Industrial Park Standard for Promoting Industrial Symbiosis in China. Journal of Industrial Ecology, v. 13, n. 1, p. 15-26, 1 fev. 2009.

GENG, Y. et al. Emergy analysis of an industrial park: The case of Dalian, China. Science of The Total Environment, v. 408, n. 22, p. 5273-5283, 15 out. 2010.

GENG, Y. et al. Towards a national circular economy indicator system in China: An evaluation and critical analysis. Journal of Cleaner Production, v. 23, n. 1, p. 216-224, 2012. 
GENG, Y. et al. Measuring China's circular economy. Science, v. 340, n. 6127, p. 1526-1527, 2013.

GENOVESE, A. et al. Sustainable supply chain management and the transition towards a circular economy: Evidence and some applications. Omega, New Research Frontiers in Sustainability. v. 66, p. 344-357, 1 jan. 2017.

GHISELLINI, P.; CIALANI, C.; ULGIATI, S. A review on circular economy: the expected transition to a balanced interplay of environmental and economic systems. Journal of Cleaner Production, v. 114, p. 11-32, 15 fev. 2016.

GIL, A. C. Métodos e técnicas de pesquisa social. São Paulo: Editora Atlas S.A., 1999.

GILL, J.; JOHNSON, P. Research methods for managers. 3. ed. London: SAGE Publications Ltd, 2002.

GIURCO, D. et al. Circular Economy: Questions for Responsible Minerals, Additive Manufacturing and Recycling of Metals. Resources, v. 3, n. 2, p. 432-453, 6 maio 2014.

GOLINSKA, P. et al. Grey Decision Making as a tool for the classification of the sustainability level of remanufacturing companies. Journal of Cleaner Production, Decision-support models and tools for helping to make real progress to more sustainable societies. v. 105 , p. $28-40,15$ out. 2015.

GRAEDEL, T. E. et al. What Do We Know About Metal Recycling Rates? Journal of Industrial Ecology, v. 15, n. 3, p. 355-366, 1 jun. 2011.

GRIFFITHS, P.; CAYZER, S. Design of indicators for measuring product performance in the circular economy. Smart Innovation, Systems and Technologies, v. 52, p. 307-321, 2016.

GULDMANN, E.; HUULGAARD, R. D. Barriers to circular business model innovation: A multiple-case study. Journal of Cleaner Production, v. 243, p. 118160, 10 jan. 2020.

HAAS, W. et al. How Circular is the Global Economy?: An Assessment of Material Flows, Waste Production, and Recycling in the European Union and the World in 2005. Journal of Industrial Ecology, v. 19, n. 5, p. 765-777, 2015.

HATFIELD-DODDS, S. et al. Assessing global resource use and greenhouse emissions to 2050, with ambitious resource efficiency and climate mitigation policies. Journal of Cleaner Production, v. 144, p. 403-414, 2017.

HAUPT, M.; VADENBO, C.; HELlWEG, S. Do We Have the Right Performance Indicators for the Circular Economy?: Insight into the Swiss Waste Management System. Journal of Industrial Ecology, v. 21, n. 3, p. 615-627, 1 jun. 2017.

HAWKEN, A.; MUNCK, G. L. Cross-National Indices with Gender-Differentiated Data: What Do They Measure? How Valid Are They? Social Indicators Research, v. 111, n. 3, p. 801-838, 1 maio 2013.

HENRY, M. et al. A typology of circular start-ups: An Analysis of 128 circular business models. Journal of Cleaner Production, v. 245, p. 118528, 1 fev. 2020. 
HU, Y. et al. Assessing resource productivity for industrial parks using adjusted raw material consumption (ARMC). Resources, Conservation and Recycling, v. 124, p. 42-49, 1 set. 2017.

HUYSMAN, S. et al. Performance indicators for a circular economy: A case study on postindustrial plastic waste. Resources, Conservation and Recycling, v. 120, p. 46-54, 1 maio 2017.

IANSITI, M.; LEVIEN, R. Keystones and Dominators: Framing Operating and Technology Strategy in a Business EcosystemHarvard Business School, , 2004. Disponível em: $\quad<$ https://www.semanticscholar.org/paper/Keystones-and-Dominators\%3A-FramingOperating-and-in-Iansiti-Levien/326eb6df46171210df8da2874b7121c5486cc2fd>

IRP. Domestic Extraction of World in 1970-2017, by material groupIRP, , 2019. Disponível em: <http://www.materialflows.net/>

JUN, H.; XIANG, H. Development of circular economy is a fundamental way to achieve agriculture sustainable development in China. . In: ENERGY PROCEDIA. 2011

JURGILEVICH, A. et al. Transition towards circular economy in the food system. Sustainability (Switzerland), v. 8, n. 1, p. 1-14, 2016.

KALMYKOVA, Y.; SADAGOPAN, M.; ROSADO, L. Circular economy - From review of theories and practices to development of implementation tools. Resources Conservation and Recycling, v. 135, p. 190-201, ago. 2018.

KARLSSON, C. Researching Operations Management. Nova Iorque: Routledge, 2009.

KAYAL, B. et al. An economic index for measuring firm's circularity: The case of water industry. Journal of Behavioral and Experimental Finance, v. 21, p. 123-129, 1 mar. 2019.

KINGFISHER. The business opportunity of closed loop innovation, 2014. Disponível em: $<$ https://www.kingfisher.com/sustainability/files/downloads/kingfisher_closed_loop_innovati on.pdf $>$

KIRCHHERR, J.; REIKE, D.; HEKKERT, M. Conceptualizing the circular economy: An analysis of 114 definitions. Resources, Conservation and Recycling, v. 127, n. Supplement C, p. 221-232, 1 dez. 2017.

KOEIJER, B.; WEVER, R.; HENSELER, J. Realizing Product Packaging Combinations in Circular Systems: Shaping the Research Agenda. Packaging Technology and Science, v. 30, n. $8,2016$.

KOK, L.; WURPEL, G.; TEN WOLDE, A. Unleashing the Power of the Circular Economy. Amsterdam: IMSA Amsterdam for Circle Economy, 2013.

KORHONEN, J.; HONKASALO, A.; SEPPÄLÄ, J. Circular Economy: The Concept and its Limitations. Ecological Economics, v. 143, p. 37-46, 1 jan. 2018.

KORHONEN, J.; SEAGER, T. P. Beyond eco-efficiency: A resilience perspective. Business Strategy and the Environment, v. 17, n. 7, p. 411-419, 2008. 
KRAVCHENKO, M.; PIGOSSO, D. C. A.; MCALOONE, T. C. A Procedure to Support Systematic Selection of Leading Indicators for Sustainability Performance Measurement of Circular Economy Initiatives. Sustainability, v. 12, n. 3, p. 951, jan. 2020.

KRISTENSEN, H. S.; MOSGAARD, M. A. A review of micro level indicators for a circular economy - moving away from the three dimensions of sustainability? Journal of Cleaner Production, v. 243, 2020.

LÈBRE, É.; CORDER, G.; GOLEV, A. The Role of the Mining Industry in a Circular Economy: A Framework for Resource Management at the Mine Site Level. Journal of Industrial Ecology, v. 21, n. 3, p. 662-672, 1 jun. 2017.

LI, R. H.; SU, C. H. Evaluation of the circular economy development level of Chinese chemical enterprises. Procedia Environmental Sciences, 18th Biennial ISEM Conference on Ecological Modelling for Global Change and Coupled Human and Natural System. v. 13, p. 1595-1601, 1 jan. 2012.

LINDER, M.; SARASINI, S.; VAN LOON, P. A Metric for Quantifying Product-Level Circularity. Journal of Industrial Ecology, v. 21, n. 3, p. 545-558, 2017.

LONCA, G. et al. Does material circularity rhyme with environmental efficiency? Case studies on used tires. Journal of Cleaner Production, v. 183, p. 424-435, 2018.

MARCOCAPELLINI. Measuring the products circularity. Disponível em: $<$ https://www.capcon.it/en/measuring-the-products-circularity-meeting-at-italian-councilpresidency/>.

MAYER, A. et al. Measuring Progress towards a Circular Economy: A Monitoring Framework for Economy-wide Material Loop Closing in the EU28. Journal of Industrial Ecology, v. 23, n. 1, p. 62-76, 2019.

MCDONOUGH, W.; BRAUNGART, M. Cradle to cradle: remaking the way we make things. Nova Iorque: North Point Press, 2002.

MENTIK, B. Circular Business Model Innovation: A process framework and a tool for business model innovation in a circular economy. Tese (Doutorado em Ecologia Industrial)-Holanda: Delft University of Technology \& Leiden University, 2014.

MERLI, R.; PREZIOSI, M.; ACAMPORA, A. How do scholars approach the circular economy? A systematic literature review. Journal of Cleaner Production, v. 178, p. 703-722, 20 mar. 2018.

MESA, J.; ESPARRAGOZA, I.; MAURY, H. Developing a set of sustainability indicators for product families based on the circular economy model. Journal of Cleaner Production, v. 196, p. 1429-1442, 2018.

MIGUEL, P. A. C. (ORG). Metodologia de pesquisa em engenharia de produção e gestão de operações. 2. ed. Rio de Janeiro: Elvesier/ABREPO, 2012.

MORAGA, G. et al. Circular economy indicators: What do they measure? Resources, Conservation and Recycling, v. 146, p. 452-461, 2019. 
MURRAY, A.; SKENE, K.; HAYNES, K. The Circular Economy: An Interdisciplinary Exploration of the Concept and Application in a Global Context. Journal of Business Ethics, v. 140, n. 3, p. 369-380, 1 fev. 2017.

NEELY, A. Measuring business performance. Londres: The Economist Books, 1998.

NEELY, A.; ADAMS, C.; KENNERLEY, M. The performance prims: the scorecard for measuring business success. Londres: Prentice Hall, 2002.

NEELY, A.; GREGORY, M.; PLATTS, K. Performance measurement system design: A literature review and research agenda. International Journal of Operations and Production Management, v. 25, n. 12, p. 1228-1263, 2005.

NELEN, D. et al. A multidimensional indicator set to assess the benefits of WEEE material recycling. Journal of Cleaner Production, v. 83, p. 305-316, 15 nov. 2014.

NIERO, M. et al. Combining Eco-Efficiency and Eco-Effectiveness for Continuous Loop Beverage Packaging Systems: Lessons from the Carlsberg Circular Community. Journal of Industrial Ecology, v. 21, n. 3, p. 742-753, 1 jun. 2017.

NIERO, M.; KALBAR, P. P. Coupling material circularity indicators and life cycle based indicators: A proposal to advance the assessment of circular economy strategies at the product level. Resources, Conservation and Recycling, v. 140, p. 305-312, 1 jan. 2019.

NUNES, B. T. et al. University Contributions to the Circular Economy: Professing the Hidden Curriculum. Sustainability, v. 10, n. 8, 2018.

NUNEZ-CACHO, P. et al. What Gets Measured, Gets Done: Development of a Circular Economy Measurement Scale for Building Industry. Sustainability, v. 10, n. 7, p. 2340, jul. 2018.

OSTERWALDER, A.; PIGNEUR, Y. Business Model Generation - Inovação em Modelos de Negócios: um manual para visionários, inovadores e revolucionários. Rio de Janeiro: Alta Books, 2011.

PARCHOMENKO, A. et al. Measuring the circular economy - A Multiple Correspondence Analysis of 63 metrics. Journal of Cleaner Production, v. 210, p. 200-216, 10 fev. 2019.

PARIDA, V. et al. Orchestrating industrial ecosystem in circular economy: A two-stage transformation model for large manufacturing companies. Journal of Business Research, v. 101, p. 715-725, 1 ago. 2019.

PARK, J. Y.; CHERTOW, M. R. Establishing and testing the "reuse potential" indicator for managing wastes as resources. v. 137, p. 45-53, 2014.

PAULIUK, S. et al. Regional distribution and losses of end-of-life steel throughout multiple product life cycles-Insights from the global multiregional MaTrace model. Resources, Conservation and Recycling, v. 116, p. 84-93, 1 jan. 2017.

PAULIUK, S. Critical appraisal of the circular economy standard BS 8001:2017 and a dashboard of quantitative system indicators for its implementation in organizations. Resources, Conservation and Recycling, v. 129, n. Supplement C, p. 81-92, 1 fev. 2018. 
PEARCE, D. W.; TURNER, R. K. Economics of natural resources and the environment. 3. ed. Inglaterra: The Johns Hopkins University Press, 1990.

PGGM. Circularity Assessment Tool, 2015. Disponível em: $<$ https://www.circleeconomy.com/actiam-launching-customer-for-circularity-assessment-tool/\#.W_fwlOhKhPZ>. Acesso em: 23 nov. 2018

PIERONI, M. P. P.; MCALOONE, T. C.; PIGOSSO, D. C. A. Business model innovation for circular economy and sustainability: A review of approaches. Journal of Cleaner Production, v. 215, p. 198-216, 2019.

PRIETO-SANDOVAL, V.; JACA, C.; ORMAZABAL, M. Towards a consensus on the circular economy. Journal of Cleaner Production, v. 179, p. 605-615, 1 abr. 2018.

PUTTERILL, M.; ROUSE, P. An integral framework for performance measurement. Management Decision, v. 41, n. 8, p. 791-805, 1 out. 2003.

REAP, J. et al. A survey of unresolved problems in life cycle assessment. Part 1: Goal and scope and inventory analysis. International Journal of Life Cycle Assessment, v. 13, n. 4, p. 290-300, 2008a.

REAP, J. et al. A survey of unresolved problems in life cycle assessment. Part 2: Impact assessment and interpretation. International Journal of Life Cycle Assessment, v. 13, n. 5, p. 374-388, 2008b.

REIKE, D.; VERMEULEN, W. J. V.; WITJES, S. The circular economy: New or Refurbished as CE 3.0? - Exploring Controversies in the Conceptualization of the Circular Economy through a Focus on History and Resource Value Retention Options. Resources, Conservation and Recycling, Sustainable Resource Management and the Circular Economy. v. 135, p. 246-264, 1 ago. 2018.

RESCOM. Circular Pathfinder. Disponível em: $<$ https://rescomd58.eurostep.com/idealco/pathfinder/>.

RESCOM. Circularity Calculator. Disponível em: <http://www.circularitycalculator.com/>.

RINCÓN-MORENO, J. et al. Advancing circular economy performance indicators and their application in Spanish companies. Journal of Cleaner Production, v. 279, p. 123605, 10 jan. 2021.

RISSE, M.; WEBER-BLASCHKE, G.; RICHTER, K. Eco-efficiency analysis of recycling recovered solid wood from construction into laminated timber products. Science of the Total Environment, v. 661, p. 107-119, 2019.

RODRIGUEZ-ANTON, J. M. et al. Analysis of the relations between circular economy and sustainable development goals. International Journal of Sustainable Development and World Ecology, v. 26, n. 8, p. 708-720, 2019.

ROMERO HERNÁNDEZ, O.; ROMERO, S. Maximizing the value of waste: From waste management to the circular economy. Thunderbird International Business Review, v. 60, n. 5, p. $757-764,1$ set. 2018. 
ROSSI, E. et al. Circular economy indicators for organizations considering sustainability and business models: Plastic, textile and electro-electronic cases. Journal of Cleaner Production, p. 119137, 4 nov. 2019.

SAIDANI, M. et al. Hybrid top-down and bottom-up framework to measure products' circularity performance. . In: PROCEEDINGS OF THE INTERNATIONAL CONFERENCE ON ENGINEERING DESIGN, ICED. 2017

SAIDANI, M. et al. A taxonomy of circular economy indicators. Journal of Cleaner Production, v. 207, p. 542-559, 10 jan. 2019.

SALA, S.; FARIOLI, F.; ZAMAGNI, A. Progress in sustainability science: lessons learnt from current methodologies for sustainability assessment: Part 1. The International Journal of Life Cycle Assessment, v. 18, n. 9, p. 1653-1672, 1 nov. 2013.

SASSANELLI, C. et al. Circular economy performance assessment methods: A systematic literature review. Journal of Cleaner Production, v. 229, p. 440-453, 20 ago. 2019.

SCHEEPENS, A. E.; VOGTLÄNDER, J. G.; BREZET, J. C. Two life cycle assessment (LCA) based methods to analyse and design complex (regional) circular economy systems. Case: Making water tourism more sustainable. Journal of Cleaner Production, v. 114, p. 257-268, 2016.

SKENE, K. R. Circles, spirals, pyramids and cubes: why the circular economy cannot work. Sustainability Science, v. 13, n. 2, p. 479-492, 1 mar. 2018.

STAHEL, W. R. The circular economy. Nature, v. 531, n. 7595, p. 435-438, 2016.

STAHEL, W. R.; CLIFT, R. Stocks and flows in the performance economy. In: Taking Stock of Industrial Ecology. [s.l: s.n.]. p. 137-158.

SUÁREZ-EIROA, B. et al. Operational principles of circular economy for sustainable development: Linking theory and practice. Journal of Cleaner Production, v. 214, p. 952-961, 20 mar. 2019.

TATE, W. L. et al. Seeing the forest and not the trees: Learning from nature's circular economy. Resources, Conservation and Recycling, v. 149, p. 115-129, 1 out. 2019.

TECCHIO, P. et al. In search of standards to support circularity in product policies: A systematic approach. Journal of Cleaner Production, v. 168, p. 1533-1546, 1 dez. 2017.

TUKKER, A. Product services for a resource-efficient and circular economy - a review. Journal of Cleaner Production, Special Volume: Why have 'Sustainable Product-Service Systems' not been widely implemented? v. 97, p. 76-91, 15 jun. 2015.

US CHAMBER OF COMMERCE FOUNDATION. Measuring Circular Economy: Circular Economy MetricsUS Chamber of Commerce Foundation, , 2017. Disponível em: $<$ https://www.uschamberfoundation.org/circular-economy-toolbox/aboutcircularity/measuring-circular-economy>. Acesso em: 23 nov. 2018 
VAN LOON, P.; VAN WASSENHOVE, L. N. Assessing the economic and environmental impact of remanufacturing: a decision support tool for OEM suppliers. International Journal of Production Research, v. 56, n. 4, p. 1662-1674, 16 fev. 2018.

VAN SCHAIK, A.; REUTER, M. A. Recycling Indices Visualizing the Performance of the Circular Economy. World of Metallurgy - ERZMETALL, v. 69, n. 4, p. 5-20, 2016.

VANEGAS, P. et al. Ease of disassembly of products to support circular economy strategies. Resources, Conservation and Recycling, v. 135, p. 323-334, 2018.

VBDO. Benchmark Circular Business Practices 2015VBDO, , 2015. Disponível em: $<$ https://corporate.arcelormittal.com/ /media/Files/A/ArcelorMittal/news-andmedia/news/VBDO\%20Benchmark\%20Circular\%20Business\%20Practices\%202015.pdf>

VERBERNE, J. J. H. Building circularity indicators an approach for measuring circularity of a building. Mestrado em Engenharia e Gestão da Construção-Netherlands: Eindhoven University of Technology, 2016.

VIKTORIA SWEDISH ICT. Measuring product circularity, 2015. Disponível em: $<$ https://www.viktoria.se/projects/measuring-product-circularity-resource $>$. Acesso em: 23 nov. 2018

VIRTANEN, M. et al. Regional material flow tools to promote circular economy. Journal of Cleaner Production, v. 235, p. 1020-1025, 20 out. 2019.

VOGTLÄNDER, J. G.; BREZET, H. C.; HENDRIKS, C. F. The virtual Eco-costs '99: A single LCA-based indicator for sustainability and the Eco-costs - Value ratio (EVR) model for economic allocation: A new LCA-based calculation model to determine the sustainability of products and services. International Journal of Life Cycle Assessment, v. 6, n. 3, p. 157-166, 2001.

VOSVIEWER. VOSviewer: visualizing scientific landscapesCentre for Science and Technology Studies, Leiden University, The Netherlands, , 2019. Disponível em: $<$ http://www.vosviewer.com/download $>$

WAAS, T. et al. Sustainability Assessment and Indicators: Tools in a Decision-Making Strategy for Sustainable Development. Sustainability, v. 6, n. 9, p. 5512-5534, set. 2014.

WALKER, S. et al. Evaluating the environmental dimension of material efficiency strategies relating to the circular economy. Sustainability, v. 10, n. 3, 2018.

WBCSD. Circular Metrics: landscape analysisClimate-KIC, , 2018. Disponível em: $<$ https://www.wbcsd.org/Programs/Circular-Economy/Factor-10/Metrics-

Measurement/Resources/Landscape-analysis>

WBCSD. Circular Transition Indicators v1.0: metrics for business, by businessWBCSD/KPMG, $\quad 2020.2$ Disponível em: $<$ https://docs.wbcsd.org/2020/01/WBCSD_Circular_Transition_Indicators_V1.0\%E2\%80\%9 3Metrics_for_business_by_business.pdf>. Acesso em: 28 fev. 2020 
WEN, Z.; MENG, X. Quantitative assessment of industrial symbiosis for the promotion of circular economy: a case study of the printed circuit boards industry in China's Suzhou New District. Journal of Cleaner Production, v. 90, p. 211-219, 1 mar. 2015.

WIEDMANN, T. A review of recent multi-region input-output models used for consumptionbased emission and resource accounting. Ecological Economics, Special Section: Analyzing the global human appropriation of net primary production - processes, trajectories, implications. v. 69, n. 2, p. 211-222, 15 dez. 2009.

YIN, R. K. Estudo de caso: planejamento e métodos. 3. ed. Porto Alegre: Bookman, 2005.

YUAN, Z.; BI, J.; MORIGUICHI, Y. The circular economy: A new development strategy in China. Journal of Industrial Ecology, v. 10, n. 1-2, p. 4-8, 2006.

ZHOU, Z.; CHEN, X.; XIAO, X. On Evaluation Model of Circular Economy for Iron and Steel Enterprise Based on Support Vector Machines with Heuristic Algorithm for Tuning Hyper-parameters. Applied Mathematics \& Information Sciences, n. 6, p. 2215-2223, 2013. 


\section{APÊNDICE A}

\section{$\underline{\text { Protocolo de estudo de caso exploratório }}$}

Público-alvo: empresas estabelecidas que estão em processo de transição ou que já transitaram para a Economia Circular.

\section{Pergunta que o estudo de caso busca responder:}

Como as empresas estão os medindo o seu desempenho baseado no contexto da Economia Circular?

\section{Bloco 1: Informações gerais e contexto da organização}

Informações sobre a empresa

\begin{tabular}{|l|l|}
\hline Setor & \\
\hline $\mathrm{N}^{\mathrm{o}}$ de funcionários & \\
\hline País (es) & \\
\hline Produtos & \\
\hline
\end{tabular}

Informações sobre o entrevistado e área de atuação

\begin{tabular}{|l|l|}
\hline Função/Cargo & \\
\hline Tempo no cargo & \\
$\begin{array}{l}\text { Tempo de experiência (em } \\
\text { outras empresas) }\end{array}$ & \\
\hline $\begin{array}{l}\text { Estrutura organizacional da área } \\
\text { de meio ambiente }\end{array}$ & \\
\hline
\end{tabular}

Bloco 2: Análise das melhorias no desempenho da organização advindas da implementação dos princípios da economia circular

A economia circular melhorou em quais aspectos o desempenho da organização?

Quais oportunidades e benefícios a implementação dos princípios da economia circular trouxe para a organização? 
Como a empresa mede os benefícios (valores) advindos da implementação dos princípios da EC? É adotado algum indicador para medir tais valores?

A mudança para o modelo de negócio circular traz resultados financeiros sustentáveis?

\section{Bloco 3: Levantamento de elementos a serem medidos na Economia Circular}

Tendo em vista a revisão de literatura, foi proposto um conjunto de elementos chaves a serem medidos, vide item 5.1 . 


\section{APÊNDICE B}

\section{$\underline{\text { Entrevistas semiestruturadas }}$}

Público-alvo: Empresa B.

\section{Pergunta que o estudo de caso busca responder:}

Como a empresa está medindo o seu desempenho baseado no contexto da Economia Circular?

\section{Entrevista 1 (02/06/2020): Gerente de Sustentabilidade}

1.1 Quais indicadores nos âmbitos econômicos, sociais e ambientais utilizam?

Utilizamos indicadores presentes no nosso GRI, nos quais constam indicadores ambientais, sociais e econômicos.

1.2 Fazem uso de Avaliação do Ciclo de Vida (ACV)? Análise de Fluxo de Materiais (AFM)? Pegada de Carbono?

Fazemos o uso de Pegada de Carbono e ACV. Trabalhamos de duas formas, fazendo o Sustainable Innovation Tool. Em termos mundiais, para pesquisa de desenvolvimento de novos produtos e processos, fazendo uma ACV simplificada. Isso ainda está em processo de validação, mas definimos como abordagem estratégica, fazendo em nossos processos uma análise sob a perspectiva do Ciclo de Vida. No nível Brasil estamos fazendo o roll out do modelo Stelligence, fazendo uma ACV social, econômica e ambiental simplificada para as construções. Além disso, usamos ACV aplicada como declaração ambiental para ter um diferencial competitivo. Ainda não analisamos uma ACV para avaliar os impactos ambientais, apesar de conhecermos quais são eles, trabalhamos muito com o $\mathrm{CO}_{2}$, temos os planos diretores $\mathrm{CO}_{2}$. Se pensarmos em impactos, esse seria o principal. Temos meta de até 2050 sermos carbono neutro.

1.3 Quais são os indicadores econômicos principais?

Aqueles presentes no GRI.

1.4 E quanto aos indicadores sociais?

Também presentes no GRI. 
1.5 Quais desses indicadores acredita ser a chave para medir as inovações que a Economia Circular traz?

Há o conceito de circularidade que passa por quatro grandes pilares, mas que passa também pelos dois ciclos: biológico e técnico. Esse é o grande ponto da dificuldade de materializar isso em um indicador. No ciclo técnico há uma facilidade de mensurar, diferentemente do que há no ciclo biológico. Um indicador de circularidade, por ser complexo deve abordar os dois lados. Os indicadores que temos hoje são apenas socioambientais, indicadores de sustentabilidade.

\section{Entrevista 2 (01/07/2020): Gerente de Meio Ambiente de Coprodutos}

2.1 Quais indicadores nos âmbitos ambientais, sociais e econômicos utilizam na empresa e considera como os principais?

Dentre os ambientais hoje são relacionados aos principais aspectos ambientais da nossa atividade. Então são os KPI's relacionados à água, resíduo, emissões de gás carbônico. Existem os chamados reativos, mas que também são importantes que são os de reclamações da comunidade, multas, advertências, também compõem os KPI's ambientais. Os sociais, relacionados às partes interessadas são os que controlamos mais hoje, mas por exemplo, o quanto somos solicitados em relação às partes interessadas, clientes por exemplo, ou sensibilidade dos mesmos em relação às declarações ambientais dos produtos, ainda não são medidos tão claramente. $\mathrm{O}$ econômico nós fazemos um controle muito mais interno, de controle dos próprios custos e oportunidades de melhorias para redução de custos. Mas em relação à estratégia é difícil relacionar os indicadores econômicos com os ambientais.

2.2 Como indicadores associados à ACV e Pegada de Carbono auxiliam na tomada de decisão?

Acredito que deveriam influenciar mais do que influenciam hoje. Isso também é relacionado ao modelo de negócio da empresa. Hoje a empresa faz o planejamento estratégico, sempre olha para os próximos cinco anos e tenta prever o que pode ocorrer nesse período. Então esses indicadores podem auxiliar muito, mas são relativamente novos dentro da empresa e estão se permeando cada vez mais. Ainda não é possível analisar esses resultados de como eles influenciam na tomada de decisão, mas eles podem agregar muito. Acredito que isso tem que ser discutido na estratégia, avaliando oportunidades e riscos. 
2.3 Dos indicadores que utilizam, quais acreditam serem chaves para medir as inovações que a Economia Circular traz?

Acredito que para a Economia Circular deve-se ter como ponto principal medir o valor, por exemplo, eu crio uma inovação e trago valor para alguém dentro da minha cadeia toda e o ponto chave é como medir isso. Não é uma única resposta, por exemplo, dentro de reuso, reaproveitamento de coprodutos, como eu ganho valor em um processo como esse? Eu tenho um ganho de valor para o meu fornecedor, que paga menos, provavelmente desse meu produto alternativo. Eu tenho um ganho associado à não extração de uma matéria prima, ou seja, meu produto é um substituto. Estou incentivando uma Economia nova, que pode estar atrelada à empregos, renda. Então acho muito difícil mensurar, pensando nesses processos, um único KPI que meça tudo isso. Talvez o desafio seja, pensar nesses processos e ter um índice. Vejo como um conjunto de KPI's.

\section{Entrevista 3 (13/07/2020): Gerentes de Meio Ambiente de Coprodutos de planos e longos}

3.1 Quais indicadores nos âmbitos ambientais, sociais e econômicos utilizam na empresa e considera como os principais?

\#entrevistado 1: Eu trabalho muito com a parte de resíduos e coprodutos, então os mais usuais para mim são os índices de reciclagem e de resíduos não recuperados, a nível mundial. Então a partir desses índices sabemos nossa meta para evitar mandar para aterro, ou reaproveitar internamente ou recolocar no mercado de uma forma mais sustentável. Mas no nosso GRI tem outros, voltados para emissões atmosféricas, qualidade de água, etc.

\#entrevistado 2: Pela minha área, o indicador que eu tenho mais contato é o de resíduos não recuperados, $\mathrm{kg}$ por tonelada de aço bruto, englobando tanto o que vai para estoque, quanto o que vai para disposição final. Temos áreas licenciadas para a gestão desses estoques, para avaliar com pesquisas uma forma de utilizar esses coprodutos. Temos por exemplo a escória granulada de alto forno que é vendida para a indústria do cimento, substituindo o clinquer. O indicador de resíduo não aproveitado vai para o estoque. Nesse sentido temos o indicador também de estoque interno, somos limitados pelo tamanho de nossas áreas, portanto demanda uma gestão, otimização desses pátios. Fora isso há o consumo de água, nível de recirculação, emissão de material particulado, etc.

3.2 Como indicadores associados à ACV e Pegada de Carbono auxiliam na tomada de decisão? 
\#entrevistado 1: Hoje ainda não chegamos nesse nível de detalhe, não é um item que verificamos.

\#entrevistado 2: A parte de ACV, circularidade e fechamento de ciclos, temos verificado. Porém a parte de Pegada de Carbono não se vê muito na tomada de decisão, mas não é nula. Pois a empresa tem investido em pesquisas, está tentando se certificar na 50.001 (gestão de energia), então esse tema vem sido discutido e entrado nos planos diretores. Mas como não é a minha área eu não tenho um exemplo específico.

3.3 Dos indicadores que utilizam, quais acreditam serem chaves para medir as inovações que a Economia Circular traz?

\#entrevistado 1: O indicador de reciclagem é óbvio que ele se relaciona com a Economia Circular, mas tem os outros indicadores presentes no GRI que são importantes. Talvez uma forma de direcionar seria a rotulagem ecológica da ABNT.

\#entrevistado 2: Eu não vejo hoje um indicador que mensure quão aderentes estamos com os conceitos de Economia Circular. Na minha visão isso hoje não existe, não temos isso sistematizado. A Economia Circular engloba não somente reaproveitar, mas utilizar um menor nível de energia, essa demanda já acontece hoje, talvez no passado não existia. Antigamente apenas se pensava na qualidade do produto e hoje pensa-se também na qualidade do coproduto, resíduos e sua destinação. Já é uma mudança de mentalidade.

\section{Entrevista 4 (20/07/2020): Área corporativa mundial}

4.1 Quais indicadores nos âmbitos ambientais, sociais e econômicos utilizam na empresa e considera como os principais?

Eu posso dizer que indicadores principais geralmente em empresas são os econômicos e financeiros. Nós também temos indicadores fortes da área ambiental que usamos por muito tempo. Agora, sobre os indicadores sociais, são mais difíceis de medir, mas tentamos superar isso com indicadores usáveis. Mas temos pessoas do time da empresa na França que trabalham com isso há um tempo e podem te dar o diagnóstico da empresa sobre essa área. São indicadores menos tangíveis, por isso são difíceis de se obter. Agora, sobre indicadores ambientais, a Pegada de Carbono, ou emissões de gases de efeito estufa são importantes principalmente por atraírem stakeholders como investidores. Mas além disso temos outras emissões ao ar, água e resíduos ou coprodutos que também são importantes. 
4.2 Como indicadores associados à ACV e Pegada de Carbono auxiliam na tomada de decisão?

A ACV afeta a tomada de decisão pois há muito clientes que se interessam por isso. Então os impactos da ACV são interesse do nosso time de vendas que passam para o time de desenvolvimento e após isso para a produção. Agora, a Pegada de Carbono é interesse de investidores e também de clientes, eles pressionam fortemente esse aspecto. Além disso, isso está relacionado com alguns relatórios nossos, a medida do carbono é chave para analisar o Aquecimento Global, o qual é interesse da sociedade.

4.3 Dos indicadores que utilizam, quais acreditam serem chaves para medir as inovações que a Economia Circular traz?

Muitos dos nossos clientes gostariam de usar indicadores sobre o conteúdo de material reciclado nos nossos produtos. Mas nós discutimos muito contra isso, pois o aço é altamente reciclável que se os clientes tiverem esse indicador, ele não seria útil para a reciclagem apenas informaria a quantidade de sucata obtida pelo mundo afora. Eu diria que indicadores sobre coprodutos são importantes pois eles ajudam a reduzir a Pegada de Carbono. Além disso, seria importante medir a reciclagem dos gases, para o reuso. Outro seria a conversão de monóxido de carbono. São todas tecnologias novas, ainda não sabemos como esses KPI's podem ser.

\section{Entrevista 5 (05/08/2020): Relações Institucionais}

5.1 Quais indicadores nos âmbitos ambientais, sociais e econômicos utilizam na empresa e considera como os principais?

No que diz respeito ao âmbito ambiental e econômico eu não tenho muito acesso pois não participo do estabelecimento desses KPI's. No âmbito social já está mais ligado à minha área, principalmente sobre a conscientização dos stakeholders a respeito da cadeia produtiva do nosso produto, da excelência do nosso produto, e da certificação do mesmo. A minha área de relacionamento institucional junto às comunidades, com os clientes, e os fornecedores, ajuda no cumprimento do KPI de mostrar a sustentabilidade e excelência dos nossos produtos. Com relação ao meio ambiente, nosso produto tem a função de obedecer a sustentabilidade e os ODS.

5.2 Como indicadores associados à ACV e Pegada de Carbono auxiliam na tomada de decisão? 
As grandes empresas mundiais estão muito ligadas à Pegada de Carbono, nós também não poderíamos ficar de fora. Mas essa discussão é mais técnica da área de meio ambiente e estratégia.

5.3 Dos indicadores que utilizam, quais acreditam serem chaves para medir as inovações que a Economia Circular traz?

Eu acredito que a chave é criar processos inteligentes, com redução de custos, na verdade otimizando custos, nos diversos produtos, não só o aço, o minério e as florestas, que fazem parte de nossa produção.

\section{Entrevista 6 (10/08/2020): Gerente de meio ambiente - Mineração}

6.1 Quais indicadores nos âmbitos ambientais, sociais e econômicos utilizam na empresa e considera como os principais?

Os indicadores são fundamentais para empresa, entretanto os indicadores econômicos e sociais não são da minha área de responsabilidade. A minha gerência está relacionada às questões ambientais. Com relação ao negócio, a mineração tem como característica o uso intensivo de recursos naturais, no nosso caso, nosso player de mineração de ferro é considerado pequeno, mas com destaque aos indicadores ambientais eu gostaria de colocar o uso racional dos recursos naturais. Então seria a otimização da utilização dos recursos. Então devemos assegurar a explotação de recursos de uma forma eficiente. Então há uma série de ações que implicam na pesquisa geológica, modelamento, análise do material, definição de prática operacionais, no dia a dia da empresa para buscar processos e rotas de processos que possam otimizar a utilização do recurso.

6.2 Como indicadores associados à ACV e Pegada de Carbono auxiliam na tomada de decisão?

Esse é um ponto importante, nos nossos relatórios de sustentabilidade anuais nós apresentamos esses dados, não só a visão interna desses indicadores, como o Carbono e o Ciclo de Vida, mas também comunicar aos outros stakeholders, como a comunidade, evidenciando nossa responsabilidade principalmente na mineração, o uso dos recursos. Hoje se fala muito da licença social, vemos que as empresas devem is além da legislação, para poder apresentar um diferencial.

6.3 Dos indicadores que utilizam, quais acreditam serem chaves para medir as inovações que a Economia Circular traz? 
Eu penso que podemos aprimorar os indicadores existentes, buscar estabelecer no contexto da organização como um todo, pensando no ciclo de vida, na questão da Economia Circular, buscando indicadores mais integrados. Uma vez que a mineração é um dos insumos mais importantes do negócio do aço. Buscar um indicador que abranja o negócio como um todo. Mas por um outro lado, vemos principalmente que a mineração atua com a natureza e dessa forma a geologia não se coloca de forma homogênea. Então a todo o momento buscamos novos processos, novas tecnologias, etc. Posso dar alguns exemplos de inovação, nossa mineração foi uma das primeiras a desenvolver uma tecnologia de disposição de rejeitos sem o uso de barragens. Voltando a minha primeira resposta acho que o ponto principal é a otimização de recursos, visto que temos um uso intensivo de recursos naturais. Então a inovação em adequação de rotas de processos pode ser importante para a otimização de recursos.

\section{Entrevista 7 (19/08/2020): Gerente de Cultura}

7.1 Quais indicadores nos âmbitos ambientais, sociais e econômicos utilizam na empresa e considera como os principais?

Olhando para o âmbito social eu trabalho na área de inovação, e temos indicadores de como a inovação impacta a empresa. Mas não temos nenhum indicador que mede como impactamos a sociedade. O que vai além da empresa, não por enquanto. Sabemos que isso é importante para medir, mas no nível de maturidade da empresa, entendemos que precisamos trabalhar primeiro os indicadores internos para depois conseguir olhar para o externo.

7.2 Como indicadores associados à ACV e Pegada de Carbono auxiliam na tomada de decisão?

Já foram itens bem acessórios no começo, mas agora estão sendo mais utilizados, principalmente a Pegada de Carbono, que tem um viés financeiro, que conversa melhor com as empresas. Hoje eles estão sendo mais considerados na tomada de decisão, mas acho ainda que isso ainda não acontece no nível necessário, podendo impactar a Economia Circular e o meio ambiente.

7.3 Dos indicadores que utilizam, quais acreditam serem chaves para medir as inovações que a Economia Circular traz?

Acredito que não temos essa preocupação, no meu contexto de trabalho, de medir o impacto das nossas ações na Economia Circular. Então fica a provocação de o quão coerente é 
dizer que nos importamos com o contexto da Economia Circular, mas não temos isso traduzido em indicadores em nosso trabalho? Então sendo muito transparente, não temos hoje essa preocupação traduzida através de indicadores.

\section{Entrevista 8 (26/08/2020): Gerente de Meio Ambiente}

8.1 Quais indicadores nos âmbitos ambientais, sociais e econômicos utilizam na empresa e considera como os principais?

Na parte ambiental, pelo nosso SGA acompanhamos indicadores hídricos, consumo de água, indicadores de lançamento de efluentes, indicador de reuso de água, etc. Da parte atmosférica temos indicadores de emissão de material particulado, e de gases como $\mathrm{NO}_{\mathrm{x}}, \mathrm{SO}_{2}$, etc. Há indicadores também de eficiência energética, pois em nossa planta fazemos reutilização de gases no processo para geração de energia elétrica através de termoelétricas. Além disso, verificamos pegada de $\mathrm{CO}_{2}$, ou seja, na parte de MDL verificamos os créditos de carbono, monitorando a emissão de gás carbônico. Há indicadores na parte de resíduos, como índice de reciclagem dos resíduos, indicadores de estoques de coprodutos. Por fim, há os indicadores de biodiversidade (fauna e flora), só que são mais estáticos pois dependem de campanhas. Na parte social temos indicadores que avaliam os programas sociais, educação ambiental, mídia positiva, capital social, programas voltados para a comunidade, onde trabalhamos em sinergia com a gerência de comunicação e relações institucionais.

8.2 Como indicadores associados à ACV e Pegada de Carbono auxiliam na tomada de decisão?

Eles são importantes, temos um procedimento empresarial que os investimentos que a empresa está estudando, é obrigatório envolver o departamento de meio ambiente, verificando o potencial do projeto para a redução de geração de carbono. Sempre que há algo atrelado à Pegada de Carbono, isso é observado, pois o projeto pode ser elegível para aprovação, para geração de crédito de carbono.

8.3 Dos indicadores que utilizam, quais acreditam serem chaves para medir as inovações que a Economia Circular traz?

Citei vários indicadores, mas eu sinto falta de um olhar mais abrangente desses indicadores, sendo possível avaliar o que eles estão mostrando em relação à Economia Circular. Como eu avalio tudo se conversa para avaliar a circularidade? Esses indicadores de autossuficiência energética, pegada de carbono, recirculação, reciclagem são fundamentais 
para Economia Circular, além de indicadores de outras esferas, como econômico, clientes, etc.

\section{Entrevista 9 (26/08/2020): Gerente de Saúde, Segurança e Meio Ambiente}

9.1 Quais indicadores nos âmbitos ambientais, sociais e econômicos utilizam na empresa e considera como os principais?

Nós temos os indicadores operacionais, de controle de fato, de performance ambiental. Além disso, nós fazemos uma avaliação junto à sociedade local, como pesquisa de favorabilidade, mostrando como nós somos percebidos pela comunidade. E do ponto de vista econômico, nós trabalhamos mais a correlação entre os indicadores ambientais e econômicos.

9.2 Como indicadores associados à ACV e Pegada de Carbono auxiliam na tomada de decisão?

Nós temos diretrizes estratégicas globais e trabalhamos também com indicadores mais voltados para projetos específicos. Então a Pegada de Carbono ainda não faz parte das Diretrizes estratégicas globais. No caso da ACV temos um bom caminho para aprender e usar isso em nosso sistema. Mas a Pegada de Carbono aqui no nosso site é um dos aspectos ambientais menos relevantes. Para nós o aspecto ambiental mais relevante é a água, pois é um recurso restrito aqui no município, cada vez se mostra mais restrito.

9.3 Dos indicadores que utilizam, quais acreditam serem chaves para medir as inovações que a Economia Circular traz?

Acredito que indicadores de recursos naturais são importantes e a sua redução, reutilização, temos trabalhado muito forte na redução de geração de resíduos, pensando nisso na extrapolação dos muros da empresa, visando a gestão dos stakeholders buscando a promoção da Economia Circular. Então seriam esses, recursos naturais e resíduos como uma estrada mais consolidada.

\section{Entrevista 10 (04/09/2020): Pesquisa e Desenvolvimento na área de Sustentabilidade}

10.1 Quais indicadores nos âmbitos ambientais, sociais e econômicos utilizam na empresa e considera como os principais?

Indicadores de consumo específico de água doce, recirculação, porcentagem de descarte, emissão de gás carbônico por tonelada, consumo específico de energia, emissão de chaminés. Basicamente água, energia e emissões. 
10.2 Como indicadores associados à ACV e Pegada de Carbono auxiliam na tomada de decisão?

Para aprovar um projeto, existe naturalmente uma análise econômica, mas existe uma avaliação de benefícios adicionais daquele projeto. Então quando falamos de projetos ambientais, a maioria das vezes não há um retorno econômico, mas os benefícios de redução de emissão, recuperação de recursos, ou uso inteligente de recursos, são itens considerados em tomadas de decisão de projetos.

10.3 Dos indicadores que utilizam, quais acreditam serem chaves para medir as inovações que a Economia Circular traz?

Dos que eu citei acredito que são importantes: a taxa de recirculação de água, consumo de água doce, potencial de recuperação de energia, e emissões. Para novos indicadores pode-se pensar em computar emissões difusas, e perdas de calor.

\section{Entrevista 11 (29/09/2020): Gerência de Governança, riscos e controles}

11.1 Quais indicadores nos âmbitos ambientais, sociais e econômicos utilizam na empresa e considera como os principais?

$\mathrm{Na}$ área que trabalho estou associada à Diretoria Financeira, trabalhando com Gestão de riscos, estratégias e oportunidades. Logo indicadores financeiros como Ebitda e fluxo de caixa são essenciais. Na parte social há o impacto da imagem da empresa, o que pode afetar a imagem da empresa perante a comunidade e clientes, sendo assim, há o monitoramento da mídia. Há também saúde e segurança como acidentes, mas é um indicador mais interno. $\mathrm{Na}$ parte ambiental há a gestão de riscos, como não conformidade, novas legislações, imagem da empresa, emissões e solo.

11.2 Como indicadores associados à ACV e Pegada de Carbono auxiliam na tomada de decisão?

A parte de Pegada de Carbono tem sido muito discutida, principalmente em como trazer a questão ao Brasil, também por exigência dos clientes. A questão é como absorver o incremento do custo e ser um diferencial de vendas.

11.3 Dos indicadores que utilizam, quais acreditam serem chaves para medir as inovações que a Economia Circular traz?

Acredito que são: market share, retorno econômico e inovação de processos. 


\section{Entrevista 12 (15/10/2020): Especialista na Gerência Geral de Inovação}

12.1 Quais indicadores nos âmbitos ambientais, sociais e econômicos utilizam na empresa e considera como os principais?

No meu escopo de trabalho, internamente, eu utilizo indicadores econômicos, que estão na criação de valor. Externamente, criamos indicadores para o cliente final.

12.2 Como indicadores associados à ACV e Pegada de Carbono auxiliam na tomada de decisão?

Na nossa rotina, temos mais interação com a parte comercial da empresa, utilizamos esses indicadores no processo de venda. Além disso, pensamos como fazer para comunicar isso melhor, como tornar isso mais claro para o cliente.

12.3 Dos indicadores que utilizam, quais acreditam serem chaves para medir as inovações que a Economia Circular traz?

Internamente, mensuramos mais a criação de valor, isso para a empresa, o valor econômico. Externamente, por mais que comunicamos para nossos clientes os benefícios da Economia Circular, acredito que há ainda dificuldade para mensurar, sendo um desafio constante. 